\title{
A influência das correntes no tempo de navegação na região da Bacia de Santos
}

Dissertação apresentada ao Instituto Oceanográfico da Universidade de São Paulo, como partes dos requisitos para obtenção do título de Mestre em Ciências pelo Programa de Pós-graduação em Oceanografia Física.

Orientador: Prof. Dr. Marcelo Dottori 


\title{
UNIVERSIDADE DE SÃO PAULO \\ INSTITUO OCEANOGRÁFICO
}

\section{A influência das correntes no tempo de navegação na região da Bacia de Santos}

\author{
GUILHERME YUKIO SEKI
}

Versão Corrigida

Dissertação apresentada ao Instituto Oceanográfico da Universidade de São Paulo, como partes dos requisitos para obtenção do título de Mestre em Ciências pelo Programa de Pósgraduação em Oceanografia Física.

Julgado em

Prof. Dr.

Conceito

Prof. Dr.

Conceito

Prof. Dr.

Conceito 


\section{Sumário}

1 Introdução.

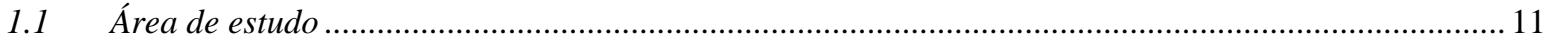

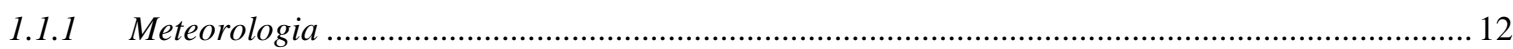

1.1.2 A hidrografia da plataforma continental na Bacia de Santos ................................................... 15

1.1.3 As correntes na Plataforma Continental Sudeste (PCSE) .......................................................... 17

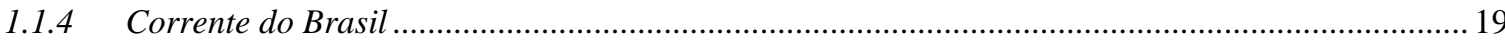

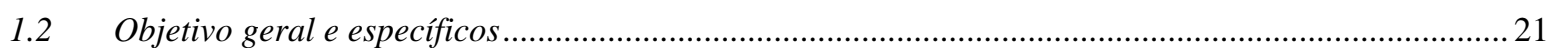

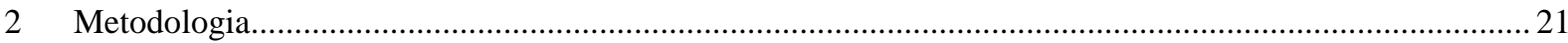

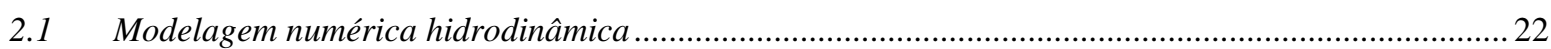

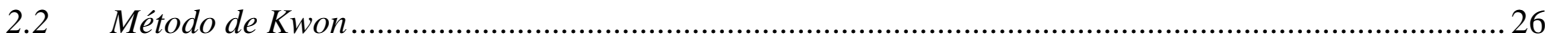

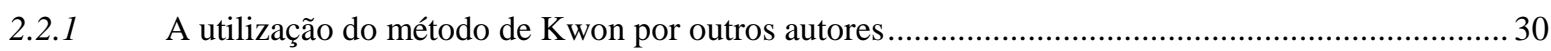

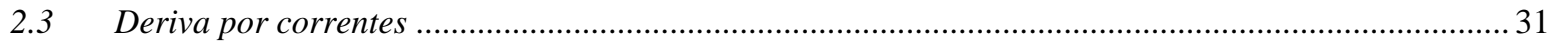

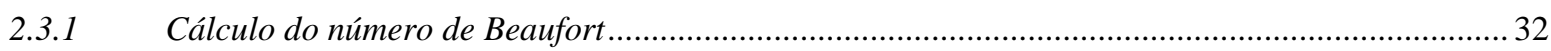

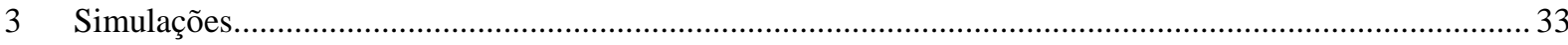

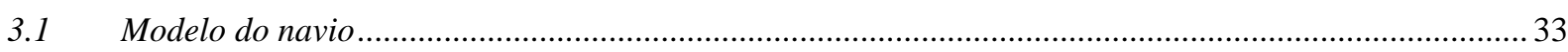

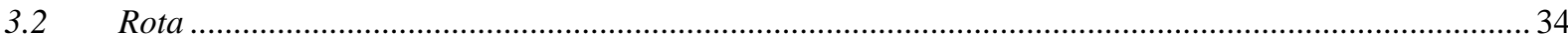

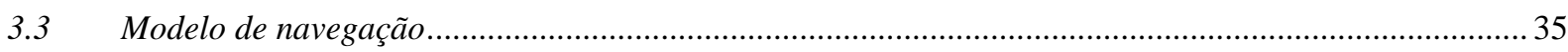

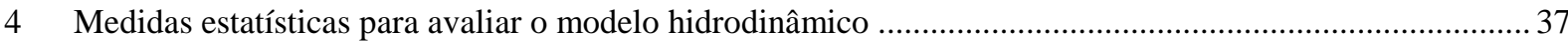

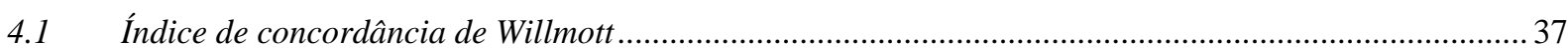

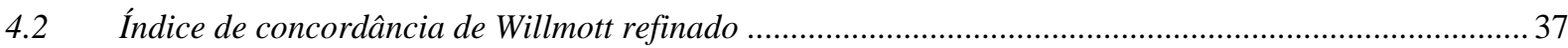

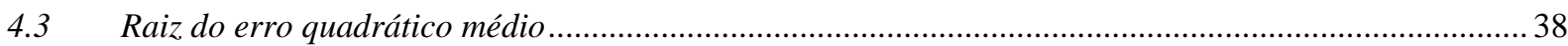

5 Medidas estatísticas para avaliar o modelo hidrodinâmico ....................................................................... 38

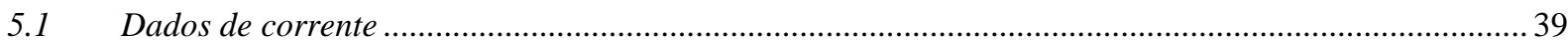

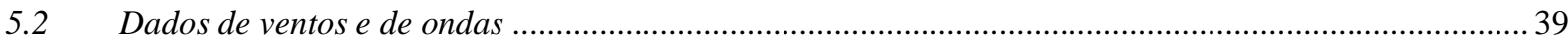

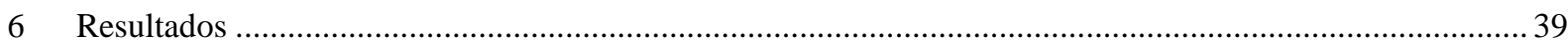

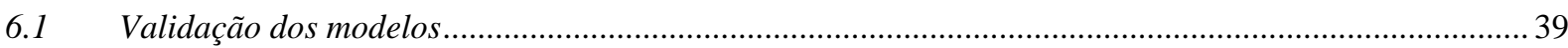

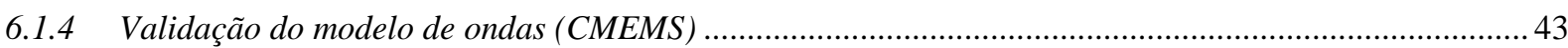

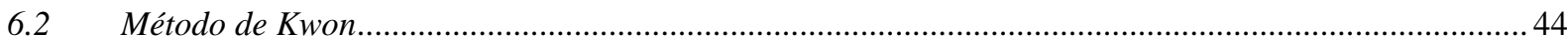

6.3 Variação do tempo de navegação devido as condições do meio .......................................................... 45

6.3.1 Variação da velocidade do navio devido somente à deriva por correntes ...............................................46

6.3.2 Variação do tempo de navegação devido à resistência adicionada por ondas e ventos ........................... 48

6.3.3 Variação do tempo de navegação do navio devido à resistência adicionada por ondas e ventos e deriva

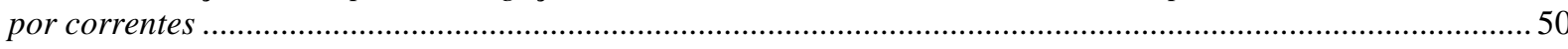

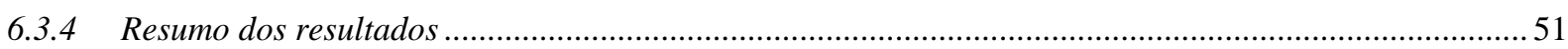

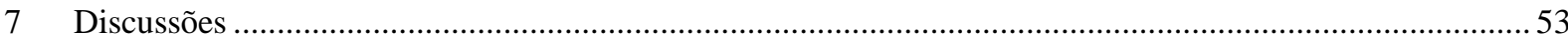

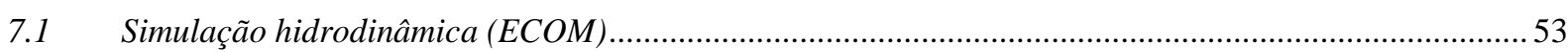

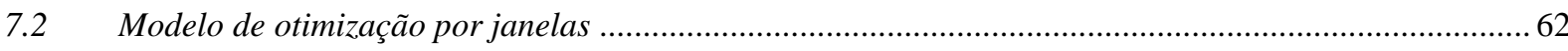

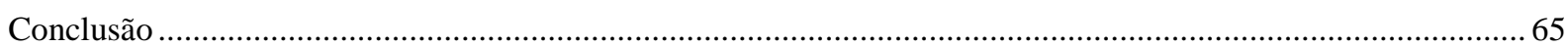




\section{Resumo}

Este trabalho analisou a influência da deriva por correntes e redução de velocidade adicionada pela resistência por ondas e ventos no tempo de navegação de um navio Aframax, na rota entre o Terminal de Angra dos Reis- FPSO Cidade de São Paulo. A análise foi através de resultados de modelagem numérica hidrodinâmico (ECOM), em paralelo com o método de Kwon (2008), que estima a redução de velocidade pela adição de resistência por ondas e ventos. O modelo numérico foi validado para a região da Corrente do Brasil, com dados observados do projeto SANSAO. Assim como os dados de vento do CFSv2 (NCEP), utilizados para forçar o modelo hidrodinâmico, e os dados de ondas do CMEMS, utilizado pelo método de Kwon (2008), foram validados com os dados observados do projeto PNBOIA. Com o navio lastreado, a média do tempo de navegação na rota Terminal de Angra dos Reis - FPSO Cidade de São Paulo (TF), teve um aumento de apenas 1,04\%, no qual, as correntes tiveram participação de 13,50\% dessa média, e as ondas e ventos, os restantes $86,50 \%$. Na navegação na rota oposta FPSO Cidade de São Paulo - FPSO Cidade de São Paulo (FT), com o navio totalmente carregado, ocorreu um aumento de $9,73 \%$ na média do tempo de navegação, deste valor, apenas $6 \%$ foi responsável pela deriva por correntes e $94 \%$ devido à redução da velocidade por ondas e ventos. Utilizando um modelo de otimização de janelas com base na escolha da melhor condição de navegação, com saídas de navio a cada 72 horas, foi possível reduzir o tempo de navegação em 2,55\% (66\% por influência das correntes) na rota TF e em 8,11\% (30\% por influência das correntes) na rota FT.

Palavras-chave: Modelagem numérica hidrodinâmica, resistência adicionada por ondas e vento, Método de Kwon, otimização do tempo de navegação. 


\begin{abstract}
This work analyzed the influence of drift by currents and waves and winds added resistence in the navigation time of an Aframax ship on the route between the Angra dos Reis Terminal FPSO City of São Paulo. The evaluation was based on numerical modeling results (ECOM), in parallel with the method of Kwon (2008), which estimates the speed reduction by wind and wave added resistance. The numerical model was validated for the Brazil Current region, with data from the SANSAO project. As well as the CFSv2 (NCEP) wind data, used to force the hydrodynamic model, and the CMEMS wave data, used by the Kwon method (2008), were validated with observed PNBOIA data. With ballast conditions, the average time of navigation on the Angra dos Reis - FPSO Cidade de São Paulo (TF) Terminal route increased by only $1.04 \%$, in which the currents had a $13.50 \%$ of this average, and the waves and winds, the remaining $86.50 \%$. In the navigation on the opposite route FPSO City of São Paulo Angra dos Reis Terminal (FT), with the ship fully loaded, there was an increase of $9.73 \%$ in the mean of navigation time, of this value, only $6 \%$ was responsible for drift by currents and 94\% due to the reduction of speed by waves and winds. Using a window optimization model based on the choice of the best navigation condition, with ship outputs every 72 hours, it was possible to reduce the navigation time by $2.55 \%$ ( $66 \%$ by currents) in the TF route and in $8.11 \%$ (30\% by influence of currents) on the FT route.
\end{abstract}

Key words: Hydrodynamic numerical modeling, wave and wind added resistance, Kwon method, navigation time optimization. 


\section{Lista de Figuras}

Figura 1 Região da Bacia de Santos (pontilhada), incluindo o Terminal de Angra dos Reis (triângulo), FPSO Cidade de São Paulo (asterisco) (Fonte de dados: IBAMA, 2018).

Figura 2 Campo de pressão $(\mathrm{hPa})$ ao nível médio do mar: valores médios para o período de 1989 a 2010 para (A) verão - Dez/Jan/Fev. Fonte: (Dereczynski et al, 2015)........ 13

Figura 3 Campo de pressão (hPa) ao nível médio do mar: valores médios para o período de 1989 a 2010 para inverno - Jun/Jul/Ago.Fonte: (Dereczynski et al, 2015). 14

Figura 4 Representação da Plataforma Continental Norte de São Paulo durante o verão (esquerda) e inverno (direita). Fonte: Moraes, 2016, adaptado de Castro (1996)... 16

Figura 5 Correntes na Plataforma Continental Sudeste. PCI: plataforma continental interna; PCM: plataforma continental média; PCE: plataforma continental externa; ACAS: Água Central do Atlântico Sul; AT: Água Tropical. Fonte: Prevelato(2014)......... 19

Figura 6 Representação esquemática do Giro Subtropical do Atlântico Sul. De acordo com Peterson e Stramma (1991) (Fonte: Silveira, 2000)

Figura 7 Fluxograma ilustrando o método ilustrado utilizado para estimar a velocidade de um navio

Figura 8 Grade ortogonal curvilínea e as posições do Terminal de Angra dos Reis e o FPSO Cidade de São Paulo.

Figura 9 Ângulo de incidência das ondas no navio 28

Figura 10 Dimensões do navio, sendo L o comprimento entre as perpendiculares, B a largura do navio no nível da água e d o calado.

Figura 11 Perda de velocidade do navio devido as ondas e ventos, resultados obtidos por Kim et al. (2017) ( $\mathrm{V}=23$ nós, $\left.\theta=0^{\circ}\right)$.

Figura 12 Ilustração das somas de vetores do navio, sendo $V c$ a velocidade da corrente, $V r$ a velocidade resultante e $V n$ a velocidade do navio. 
Figura 13 Ilustração do modelo de navegação, sendo $V_{\mathrm{r}}$ a velocidade resultante de navegação, t o passo de tempo do cálculo de $\mathrm{V}_{\mathrm{r}}$ e d a distância percorrida.

Figura 14 Localização do Terminal de Angra dos Reis, FPSO Cidade de São Paulo e dos fundeios PNBOIA e SANSAO. E região da seção vertical analisada do modelo, na data do dia 28 de outubro de 2016.

Figura 15 Dados modelo CFSV2 comparados aos medidos in situ pela boia metaoceanográfica do programa PBNBOIA localizada na latitude: $25^{\circ} 26^{\prime} 22.2^{\prime \prime} \mathrm{S}$ longitude: $45^{\circ} 2^{\prime} 9.96^{\prime \prime}$ $\mathrm{O}$

Figura 16 Dados modelo hidrodinâmico comparados aos medidos in situ pela boia metaoceanográfica do projeto SANSAO localizada na latitude: $26^{\circ} 10^{\prime} 59,4^{\prime \prime} \mathrm{S}$ longitude: $45^{\circ} 5$ 8.16" O para o período de 28/10/2016 a 10/01/2016

Figura 17 Massas de água na Bacia de Santos definidas pela temperatura (modelo ECOM, data:28/10 - 00:30)

Figura 18 Campos de velocidade da Corrente do Brasil (modelo ECOM, data:28/10 - 00:30).

Figura 19 Dados de ondas do CMEMS comparados aos medidos in situ pela boia metaoceanográfica do programa PNBOIA localizada na latitude: $26^{\circ} 10^{\prime} 59,4^{\prime \prime} \mathrm{S}$ longitude: $45^{\circ} 58.16^{\prime \prime} \mathrm{O}$.

Figura 20. Perda de velocidade do navio devido as condições do tempo e diferentes ângulos de incidência de ondas e ventos. 45

Figura 21 Variação do tempo de navegação na rota Terminal de Angra dos Reis - FPSO Cidade de São Paulo. A variação é determinada somente pela deriva por correntes. 46

Figura 22 Variação do tempo de navegação na rota FPSO Cidade de São Paulo - Terminal de Angra dos Reis. A variação é determinada somente pela deriva por correntes.......47

Figura 23 Variação do tempo de navegação na rota Terminal de Angra dos Reis- FPSO Cidade de São Paulo com o navio lastreado, e número de Beaufort. A variação é determinada somente pela resistência adicionada por ondas e ventos. 
Figura 24 Variação do tempo de navegação na rota FPSO Cidade de São Paulo - Terminal de Angra dos Reis- com o navio totalmente carregado, e número de Beaufort. A variação é determinada somente pela resistência adicionada por ondas e ventos.

Figura 25 Variação do tempo de navegação na rota FPSO Cidade de São Paulo - Terminal Angra dos Reis com o navio lastreado. A variação do tempo de navegação é determinada resistência adicionada por ondas e ventos e deriva por correntes.......50

Figura 26 Variação do tempo de navegação na rota Terminal Angra dos Reis - FPSO Cidade de São Paulo com o navio carregado. A variação é determinada pela resistência adicionada por ondas e ventos e deriva por correntes.

Figura 27 Cenário típico, com ventos de nordeste, na rota Terminal de Angra dos Reis - FPSO Cidade de São Paulo, mostrando os padrões distintos de circulação entre as Correntes da Plataforma Continental (CPlataforma), Corrente do Brasil (CB), e a circulação anticiclônica (AC). Os vetores representam a velocidade e a direção dos ventos (figura superior) e das correntes (figura inferior).

Figura 28 Representação de Mattos (2006) da separação parcial da CB para dar origem à CCST AS.

Figura 29 Cenário com ventos de alta intensidade de nordeste na rota Terminal de Angra dos Reis - FPSO Cidade de São Paulo, mostrando os padrões distintos de circulação entre as Correntes da Plataforma Continental (CPlataforma), Corrente do Brasil (CB), e a circulação anticiclônica (AC). Os vetores representam a velocidade e a direção dos ventos (figura superior) e das correntes (figura inferior).

Figura 30 Cenário durante uma passagem de frente fria na rota Terminal de Angra dos Reis FPSO Cidade de São Paulo, mostrando os padrões distintos de circulação entre as Correntes da Plataforma Continental (CPlataforma), Corrente do Brasil (CB), e a circulação anticiclônica (AC). Os vetores representam a velocidade e a direção dos ventos (figura superior) e das correntes (figura inferior).

Figura 31 Cenário pós passagem de frente fria na rota Terminal de Angra dos Reis - FPSO Cidade de São Paulo, mostrando os padrões distintos de circulação entre as Correntes da Plataforma Continental (CPlataforma), Corrente do Brasil (CB), e a circulação anticiclônica (AC). Os vetores representam a velocidade e a direção dos ventos (figura superior) e das correntes (figura inferior)

Figura 32 Cenário com ventos intensos de sudoeste na rota Terminal de Angra dos Reis - FPSO Cidade de São Paulo, mostrando os padrões distintos de circulação entre as Correntes da Plataforma Continental (CPlataforma), Corrente do Brasil (CB), e a circulação 
anticiclônica (AC). Os vetores representam a velocidade e a direção dos ventos (figura superior) e das correntes (figura inferior).

Figura 33 Correntes enfrentadas pelo navio na navegação na rota Terminal de Angra dos Reis - FPSO Cidade de São Paulo, mostrando os padrões distintos de circulação entre as Correntes da Plataforma Continental (CPlataforma), Corrente do Brasil (CB), e a circulação anticiclônica (AC). Os vetores representam a velocidade e a direção dos ventos (figura superior) e das correntes (figura inferior). 58

Figura 34 Correntes enfrentadas pelo navio na navegação na rota Terminal de Angra dos Reis - FPSO Cidade de São Paulo, mostrando os padrões distintos de circulação entre as Correntes da Plataforma Continental (CPlataforma), Corrente do Brasil (CB), e a circulação anticiclônica (AC). Os vetores representam a velocidade e a direção dos ventos (figura superior) e das correntes (figura inferior).

Figura 35 Correlação entre as componentes das correntes e ventos paralelo à costa e perpendiculares à costa. Sendo $\mathrm{PC}$ a região da plataforma continental, $\mathrm{CB}$ a regição da Corrente do Brasil e AC a regiões do anticiclone. 


\section{Lista de Tabelas}

Tabela 1 - Coeficiente de redução devido a direção das ondas irregulares e vento $\left(C_{\beta}\right) \ldots \ldots . . .28$

Tabela 2 - Coeficiente de redução de velocidade $\mathrm{C}_{\mathrm{u}}$

Tabela 3 - Coeficiente da forma do navio $\left(\mathrm{C}_{\text {form }}\right)$

Tabela 4 - Medidas do navio Aframax SCF Baltica....

Tabela 5 - Terminal Aquaviário de Angra dos Reis - RJ.

Tabela 6 - FPSO Cidade de São Paulo 34

Tabela 7 - Simulações de navegação

Tabela 8 - Validação do vento (NCEP) 40

Tabela 9 - Validação do modelo ECOM

Tabela 10 - Validação dos dados de ondas (CMEMS)

Tabela 11 - Rota: Terminal de Angra dos Reis - FPSO Cidade de São Paulo (lastreado)......52

Tabela 12 - Rota: FPSO Cidade de São Paulo - Terminal de Angra dos Reis (totalmente carregado)

Tabela 13 - Variação do tempo de navegação conforme o sentido do vento paralelo à costa. 61

Tabela 14 - Resultados do modelo de otimização para a rota: Terminal de Angra dos Reis FPSO Cidade de São Paulo (lastreado)

Tabela 15 - Resultados do modelo de otimização para a rota: FPSO Cidade de São Paulo

Terminal de Angra dos Reis - (carregado) 


\section{Introdução}

A precisão no cálculo da perda de velocidade de um navio permite uma previsão do consumo de combustível assim como a emissão de gases de um navio. A IMO (International Marine Organization), a qual trabalha com políticas e práticas relacionadas aos gases do efeito estufa emitidos por navios, tem estimado a emissão desses gases em navegações internacionais, calculando o correspondente valor de 2,2\% das emissões antropogênicas, e que as emissões podem aumentar entre 50\% e 250\% em 2050 (resolução MEPC.304(72)). Devido ao crescimento alarmante de emissões de gases do efeito estufa na navegação, medidas como o Energy Efficiency Design Index (EEDI), que promove o uso mais eficiente (menos poluidor) de navios, estão se tornando mandatórias para navios novos, sendo o primeiro tratado juridicamente vinculativo a ser adotado desde o Protocolo de Kyoto. O EEDI trabalha com aspectos técnicos, como a otimização na performance de navios baseadas em design do navio e medidas do uso de combustíveis alternativos. No entanto, o aumento da eficiência da energia na navegação também está ligado as condições ambientais, como a dinâmica de ondas, ventos e correntes.

O desempenho da navegação marinha é constantemente influenciado por fatores ambientais como ondas e ventos. As ondas podem colocar em risco uma embarcação assim como causar desconforto a tripulação. Navios de grande porte, como navios aliviadores de petróleo são tradicionalmente arquitetados e otimizados (seguindo as medidas do EEDI) para águas calmas, que seria um mar sem ondas e ventos, mas na maioria das vezes operam em condições moderadas que reduzem a velocidade do navio ou aumentam o consumo de energia do motor. A resistência adicionada pelos fatores ambientais como ondas e ventos a esses navios são consideras insensíveis por muitos autores como Soding e Shigunov (2015). Entretanto, Shigunov (2017) afirma que há uma margem de $15 \%$ de potência requerida a esses navios devido as condições ambientais.

Além das ondas e ventos, o efeito das correntes tem sido desprezado no planejamento das navegações em regiões como na costa brasileira, porém, em regiões como no Atlântico Norte, é comum o uso de informação de correntes para elaboração de rotas de navios. Utilizando modelos hidrodinâmicos na região da Corrente do Golfo, LO e McCord (1995) estimaram uma média relativa de redução de 7,5\% do consumo de combustíveis utilizando correntes favoráveis a navegação e 4,5\% de redução evitando correntes desfavoráveis, com a média de navegação de 16 nós. Chang (2013), realizou estudos na Corrente de Kuroshio, estimando a redução de apenas $1,8 \%$ do tempo de navegação utilizando correntes favoráveis, no entanto uma redução 
de 5,7\% evitando rotas desfavoráveis, com velocidade de navegação de 12 nós. Em ambos os trabalhos, foram estimados valores significantes de redução do consumo de combustível, o que motiva a realização de estudos de correntes relativos à navegação na costa brasileira. Ao longa da costa do Brasil, flui para sul a Corrente do Brasil, que assim como a Corrente do Golfo e a Corrente de Kuroshio, são correntes de contorno oeste, consideradas correntes fortes e persistentes.

A exploração do petróleo é uma das principais atividades econômicas no Brasil, com as previsões de escassez fizeram que o país buscasse alternativas de exploração deste recurso, sendo o Pré-sal uma destas alternativas. As reservas do Pré-sal estão estimadas em 12 bilhões de barris (IEA, 2013). Em 2018, o Pré-sal atingiu a marca de 1,2 milhão de barris por dia na Bacia de Santos (2018), destacando-se o Campo de Lula na Bacia de Santos, com a produção de 850 mil barris diários. Os campos de produção na Bacia de Santos estão localizados cerca de $300 \mathrm{~km}$ da costa, duas vezes a distância da Bacia de Campos, e seus poços são perfurados a mais de $7000 \mathrm{~m}$ metros de profundidade, sendo $3000 \mathrm{~m}$ de coluna d'água e $4000 \mathrm{~m}$ abaixo do leito oceânico. Diante destes cenários, há um grande desfio na logística do transporte não somente do óleo e gás, mas também de materiais necessários a toda cadeia de produção, assim como os trabalhadores. Considerando o transporte desde os primeiros processos de produção até a entrega ao cliente final, seus custos representam duas ou três vezes o lucro de uma companhia no setor de combustíveis (Terra et al.,2014).

Afim de analisar a influência das variáveis ambientais na operação de navios aliviadores na região do Pré-sal, este trabalho tem como foco realizar simulação com o modelo hidrodinâmico ECOM (GEORGAS; BLUMBER, 2010) na região da Bacia de Santos, e aplicar o método de Kwon (2008), que estima a redução de velocidade de um navio pela resistência adicionada por ondas e ventos. Como objeto de estudo, as simulações foram realizadas para um navio do tipo Aframax, entre o Terminal Aquaviário de Angra dos Reis e a Unidade Flutuante de Produção FPSO (Floating Production Storage and Offloading) Cidade de São Paulo, localizada no Campo Petrolífero de Sapinhoá, situado na porção central da Bacia de Santos.

\section{1 Área de estudo}

A bacia de Santos está localizada na região sudeste do Brasil e abrange os litorais dos estados do Rio de Janeiro, São Paulo, Paraná e Santa Catarina, sendo a maior bacia sedimentar offshore do país. Sua área, até a isóbata de $3.000 \mathrm{~m}$, é de aproximadamente $350.000 \mathrm{~km}^{2}$. Geologicamente, segundo Moreira et al. (2007), está limitada ao norte com a Bacia de Campos, 
pelo alto de Cabo Frio $\left(23^{\circ} \mathrm{S}\right)$, e a sul com a bacia de Pelotas, pelo alto de Florianópolis $\left(23,5^{\circ} \mathrm{S}\right)$ (Figura 1). A leste, estende-se até o Platô de São Paulo, e a oeste, se limita aos cinturões de Serras Costeiras.

Na região da Bacia de Santos está localizada a Plataforma Continental Sudeste (PCSE), também limitada ao norte na região de Cabo Frio e, ao sul, se estende até o Cabo de Santa Marta $\left(28,5^{\circ} \mathrm{S}\right)$, no limite sul do estado de Santa Catarina. A profundidade da quebra da plataforma varia entre 120 m e 180 m (Zembruski, 1979). A largura da PCSE é bastante variável, sendo mais estreia nas extremidades. Ao largo de Cabo Frio a largura é de 50 km, no centro, ao largo de Santos, a largura é de 230 km, e ao largo de Santa Marta, a largura é de 70 km (Castro e Miranda, 1998)

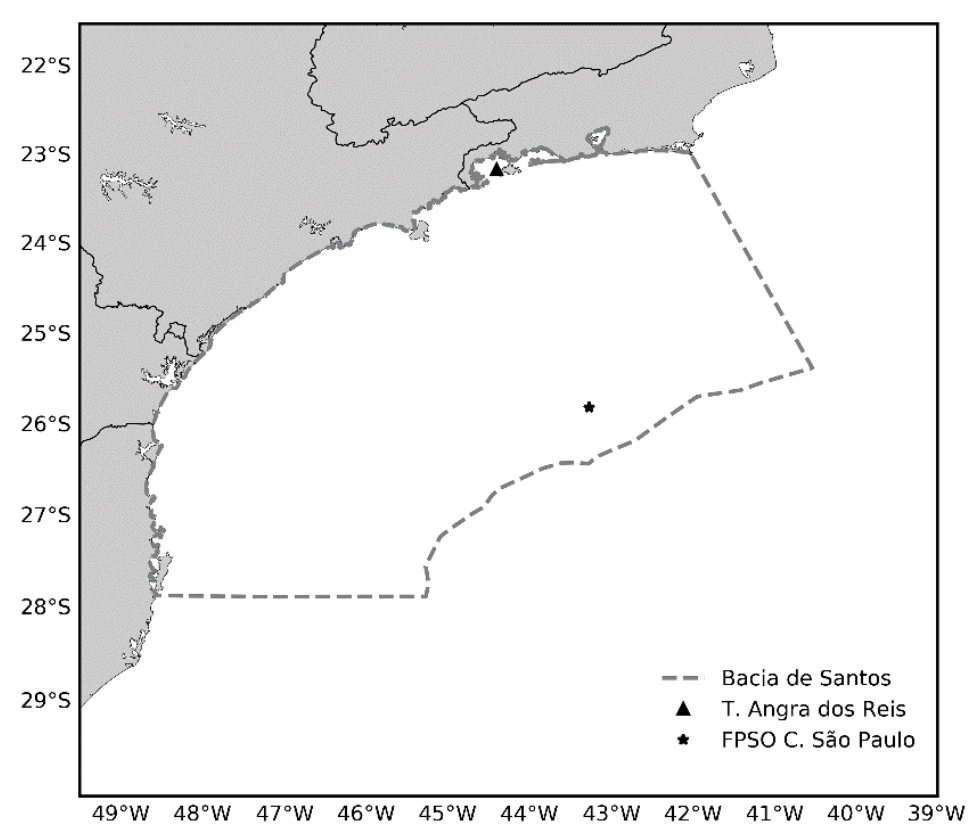

Figura 1 Região da Bacia de Santos (pontilhada), incluindo o Terminal de Angra dos Reis (triângulo), FPSO Cidade de São Paulo (asterisco) (Fonte de dados: IBAMA, 2018).

\subsubsection{Meteorologia}

O sistema atmosférico na área de estudo é influenciado principalmente por sistemas meteorológicos na escala sinótica. Os principais são a Alta Subtropical do Atlântico Sul (ASAS) e os sistemas frontais. A ASAS está situada no Atlântico Sul, influenciando o clima em quase toda américa do Sul. A ASAS, por ser de um sistema de alta pressão, gira no sentido antihorário (anticiclônico) nos níveis de baixa atmosfera. Desse modo, como a ASAS situa-se a Sudoeste da Bacia de Santos, atinge a região com direções predominantes de quadrante NE, 
deslocando-se, principalmente, no sentido leste/oeste (Dereczynski et al, 2015). No inverno (julho), a ASAS possui uma pressão mais elevada $(1.024 \mathrm{hPa})$, e desloca-se para oeste $\left(8^{\circ} \mathrm{O}\right) \mathrm{e}$ ligeiramente para o norte, invadindo o continente na latitude de $27^{\circ} \mathrm{S}$ (Figura 2). Já no verão, o centro do anticiclone encontra-se mais afastado do continente $\left(32^{\circ} \mathrm{S} / 5^{\circ} \mathrm{O}\right)$ e com menor pressão $(1.020 \mathrm{hPa})$ (Figura 3).

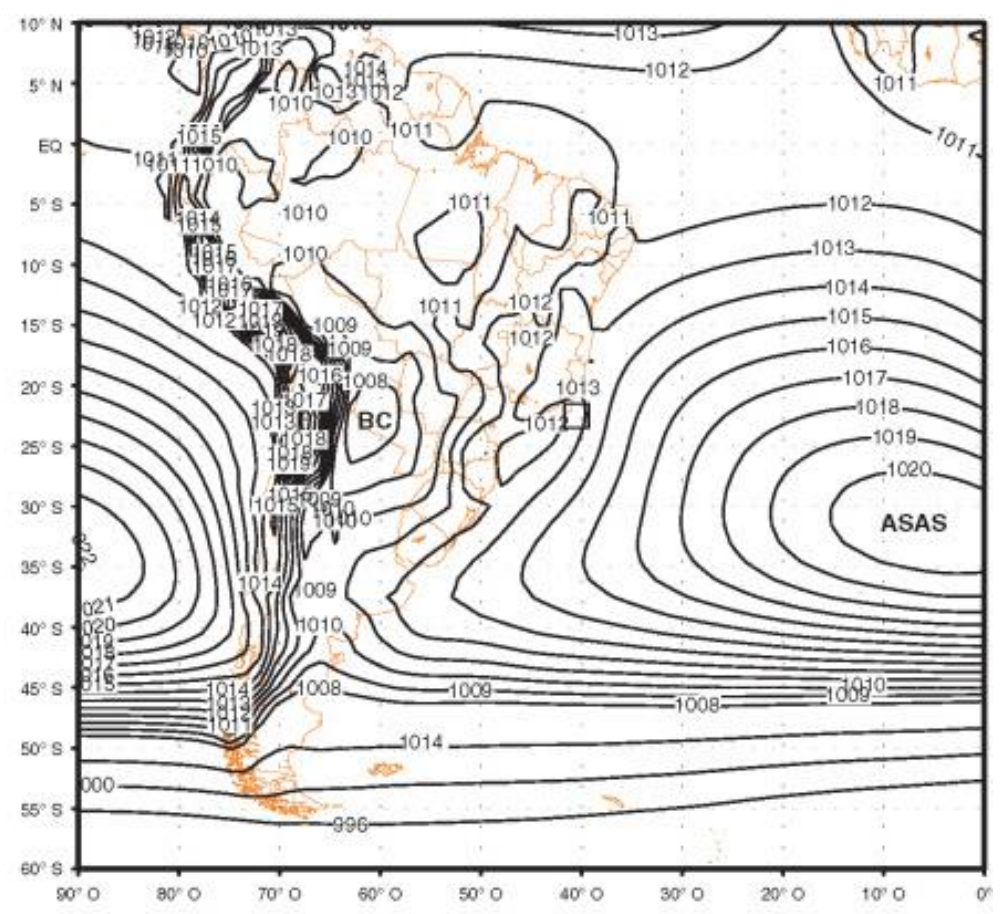

Figura 2 Campo de pressão (hPa) ao nível médio do mar: valores médios para o período de 1989 a 2010 para (A) verão Dez/Jan/Fev. Fonte: (Dereczynski et al, 2015). 


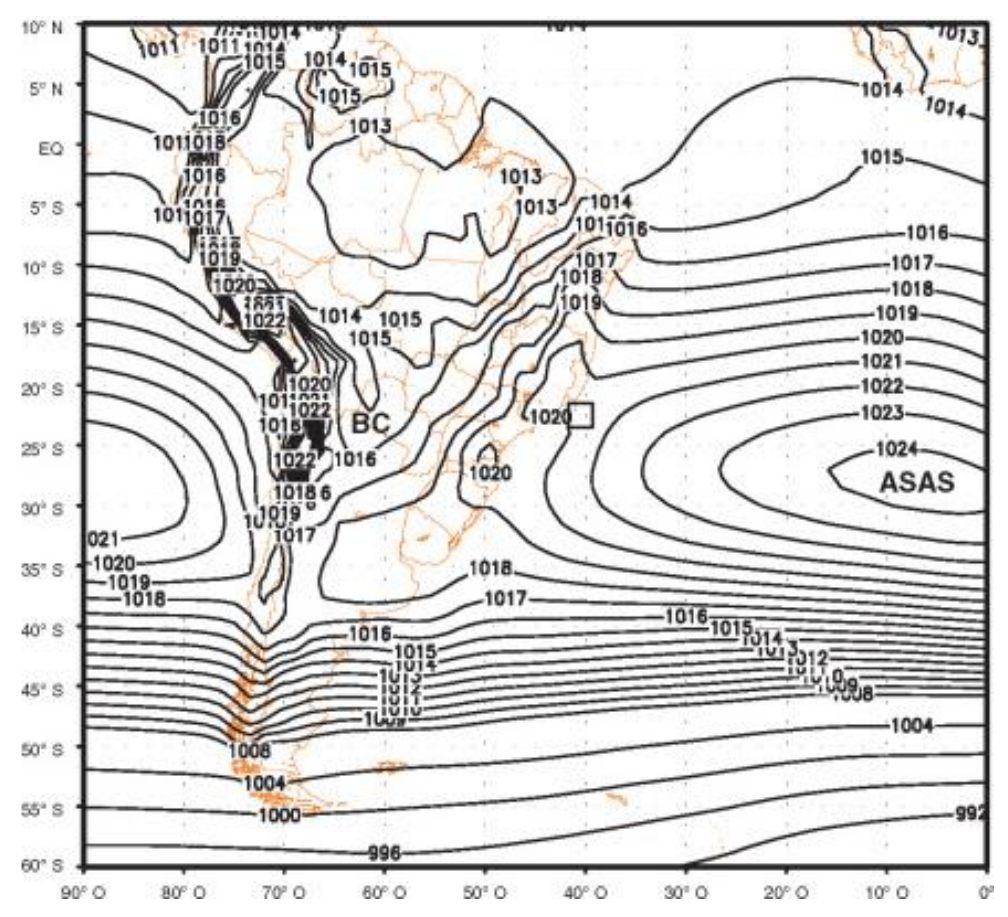

Figura 3 Campo de pressão (hPa) ao nível médio do mar: valores médios para o período de 1989 a 2010 para inverno Jun/Jul/Ago.Fonte: (Dereczynski et al, 2015).

No verão, devido ao deslocamento do ASAS para o sul, os ventos que sopram na Região Sudeste do Brasil são mais intensos, entre 4,5 e 5 m/s, e sopram de norte-nordeste. Já no inverno, sopram do quadrante NE, com intensidade entre 3,0 e 3,5 m/s (Dereczynski et al, 2015).

O deslocamento de sistemas frontais ocorre com o transporte de massa de ar polares em direção aos trópicos. A região Sudeste do Brasil possui características frontogenéticas, ou seja, a interação atmosférica sobre o continente nessa região favorece a formação e intensificação de frentes frias (Satyamurty e Mattos, 1989). Com a chegada de sistema frontais, ocorre a instabilidade termodinâmica da ASAS. Esses sistemas promovem a precipitação e intensificação dos ventos (Dereczynski et al, 2015). Segundo Stech e Lorenzzetti (1992), baseando-se em cartas meteorológicas sinóticas e imagens termais de satélite GOES, o deslocamento comum da frente fria é de sudoeste para nordeste, sendo a velocidade do sistema frontal de aproximadamente $500 \mathrm{~km} / \mathrm{dia}$. Um estudo mais recente foi realizado por Coelho (2007), encontrando uma velocidade média de $(787,2 \mathrm{~km} /$ dia), em uma análise de 12 frentes frias. Originalmente, os ventos de nordeste giram em sentido anti-horário, mudando sua direção e em cerca de 24 horas passa a ser de sudeste após a sua passagem. Em casos mais intensos, as 
velocidades podem passar de $20 \mathrm{~m} / \mathrm{s}$ (Dereczynski et al, 2015). O tempo consecutivo entre duas frentes frias é tipicamente entre 3-4 a 12-15 dias, sendo menor na primavera e inverno (Dottori e Castro, 2009).

\subsubsection{A hidrografia da plataforma continental na Bacia de Santos}

Castro (1996) definiu critérios para compartimentar a Plataforma Continental Norte de São Paulo e Rezende (2003) sugere que esse critério possa ser aplicado para toda a Plataforma Continental Sudeste (PCSE). Os compartimentos estão divididos em (Figura 4):

- Plataforma Continental Interna (PCI): localizada entre a costa e a Frente Térmica Profunda (FTP), formada pela interface das massas de água Água Continental (AC) e a Água Central do Atlântico Sul (ACAS). No verão, com o avanço da FTP em direção a costa, a PCI é mais curta, entre 10-30 km. Já no inverno, estende-se a 40$80 \mathrm{~km}$.

- Plataforma Continental Média (PCM): localizada entre a FTP e a Frente Halina Superficial (FHS), formada pela interface das massas de água AC e Água Tropical (AT). Durante o verão, pode variar entre $10-30 \mathrm{~km}$ até $60-80 \mathrm{~km}$ da costa, enquanto no inverno é mais estreita, entre 40-60 km e 60-80 km. Apresenta alta estratificação durante o verão devido a entrada da ACAS.

- Plataforma Continental Externa (PCE): Está localizada entre à FHS e a quebra da plataforma. A sua estrutura pouco varia sazonalmente. 


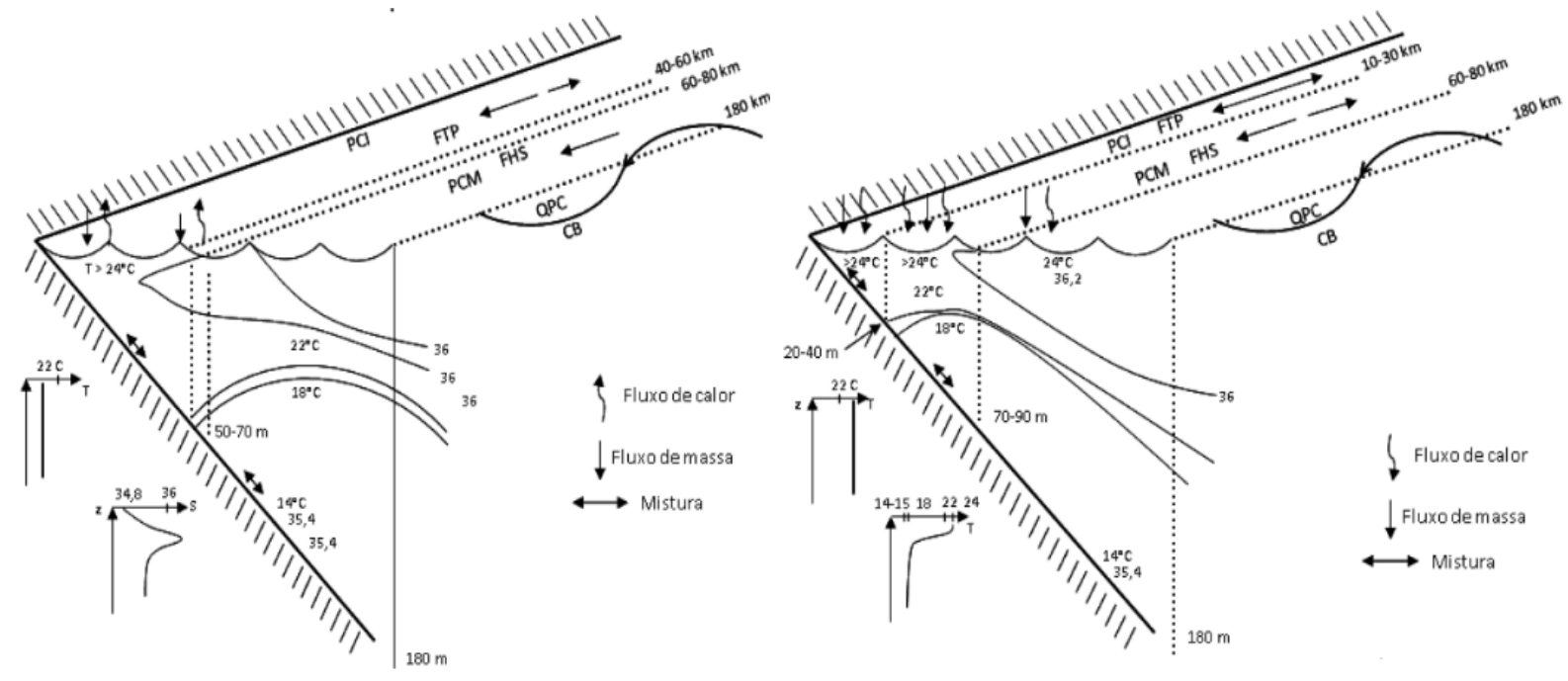

Figura 4 Representação da Plataforma Continental Norte de São Paulo durante o verão (esquerda) e inverno (direita). Fonte: Moraes, 2016, adaptado de Castro (1996).

Na região da Bacia de Santos estão presentes 5 tipos de massas de água: Água Costeira (AC), Água Tropical (AT), Água Central do Atlântico Sul (ACAS), Água Intermediária Antártica (AIA) e Água Profunda do Atlântico Norte (APAN). Cada uma caracterizada com um índice termohalino, constituído pelas condições de formação e por processos de mistura com outras massas.

Água Costeira (AC): É identificada pelo seu alto valor de temperatura e baixo valor de salinidade, como resultado do aporte de água doce proveniente de estuários. É caracterizada por temperaturas maiores que $26^{\circ} \mathrm{C}$ e salinidades menores ou igual a 34 ups

Água Tropical (AT): Formada em baixas latitudes por processos de intensa radiação solar e alto índice de evaporação em relação a precipitação. Normalmente é transportada pela Corrente do Brasil CB na região do talude, conforme é transportada para o sul é misturada com águas mais frias e menos salinas. Segunda Silveira et al. (2000) é caracterizada por temperaturas maiores que $20^{\circ} \mathrm{C}$ e salinidades acima de 36 ups ao largo do Sudeste brasileiro.

Água Central do Atlântico Sul (ACAS): É formada por afundamento na região da Convergência Subtropical (Sverdrup et al.,1942), pela mistura da AT e Água Subantártica (ASA). É encontrada na região da picnoclina com temperaturas entre $6^{\circ}$ e $20^{\circ} \mathrm{C}$ e salinidades entre 34,6 e 36 ups (Silveira et al.,2000), logo abaixo da AT. 
Água Intermediária Antártica (AIA): Segundo Wüst (1975) e Defant (1941), é formada na Convergência Subantártica do afundamento da Àgua Superficial Antártica, misturando-se e espalhando-se em níveis intermediários para o norte. Gordon e Greengrove (1986) sugerem que a maior parte da AIA flui para leste em aproximadamente $38^{\circ} \mathrm{S}$ na Confluência Brasil-Malvinas, como parte da Recirculação Interna do Giro Subtropical. A temperatura da AIA é definida entre $3^{\circ}$ e $6^{\circ} \mathrm{C}$ e a salinidade entre, 34,2 e 34,6 (Sverdrup et al.,1942) sendo localizada abaixo da ACAS.

Água Profunda do Atlântico Norte (APAN): É formada no Mar de Labrador em altas latitudes, fluindo para o sul até aproximadamente $32^{\circ} \mathrm{S}$, onde parte da corrente retorna para o Equador (Weatherly, 1993). Localiza-se abaixo da AIA, sendo a sua temperatura definida entre $3^{\circ}$ e $4^{\circ} \mathrm{C}$ e salinidade, entre 34,6 e 45 . Está situada entre 1500 e $3000 \mathrm{~m}$ ao largo do Sudeste brasileiro (Silveira et al.,2000).

\subsubsection{As correntes na Plataforma Continental Sudeste (PCSE)}

As forçantes que geram as correntes sobre a PCSE e variações no nível do mar podem atuar diretamente, como o gradiente de pressão baroclínico, ou indiretamente, como as correntes geradas por maré (Castro, 1996). O vento pode atuar na região localmente, ou remotamente através da geração de ondas segundo Dottori e Castro (2018). Esses autores, usando dados de correntógrafos, estimaram correlações entre 0,4-0,7 entre as correntes subinerciais (período menor que 29 horas para a região) locais paralelas à costa forçadas pelo vento local. A inclusão dos ventos remotos foi responsável por um aumento entre 10-20\% na correlação.

- Plataforma Continental Interna (PCI)

As principais forçantes em quase toda PCI são os gradientes de densidade, tensão de cisalhamento do vento e marés. No estado de São Paulo, no verão, devido ao clima de chuvas mais intenso, aumentando a vazão dos estuários de Santos e Cananéia, ocorre a presença de pluma de água menos salina, principalmente na região entre Cananéia e São Sebastião, gerando 
gradientes horizontais de densidade (baroclínicos) capazes de gerar correntes geostróficas deixando à costa a esquerda do fluxo.

$\mathrm{Na}$ ausência dos sistemas meteorológicos frontais, são predominantes os ventos de leste-nordeste forçados pelo ASAS, que geram divergência unilateral do transporte de deriva de Ekman fazendo com que as águas próximas à costa se afastem desta, ocorrendo então o abaixamento da superfície livre do mar, gerando gradientes de pressão barotrópicos perpendiculares à costa induzindo a formação de jato costeiro que deixam a costa à direita (Prevelato, 2014).

Com a passagem de frentes frias, como descrito na Seção 1.1.1, é comum a inversão das correntes na escala subinercial, forçando os jatos costeiras a deixarem a costa à esquerda.

Na região entre São Sebastião e Rio de Janeiro, Dottori e Castro (2009), através de análises de EOF (Emprirical Orthogonal Equations), encontraram que 93\% da variabilidade das correntes subinerciais é explicada pelo modo barotrópico.

\section{- Plataforma Continental Média (PCM)}

Em quase toda a região da PCM as correntes subinerciais são forçadas principalmente pela tensão de cisalhamento do vento, pelo gradiente de densidade gerado pela intrusão da ACAS, sendo mais intenso no verão (Coelho, 2007) e pela CB nas regiões mais estreitas da PCSE.

Na média, as correntes na PCM estão associadas à ASAS e fluem para sul (Coelho, 2007). Na região entre Santos e Rio de Janeiro, Coelho (2007) encontrou correntes opostas entre a PCI (fluindo para norte) e PCM (fluindo para sul). Os ventos oriundos das frentes frias também são bem influentes na região, gerando correntes mais intensas ao sul, entre o Cabo de Santa Marta e Ubatuba (Coelho, 2007), supostamente relacionadas a maior intensidade do vento paralelo à costa na região.

Segundo Dottori (2009), na região da PC, entre São Sebastião e Rio de Janeiro, em torno de $90 \%$ da variabilidade das correntes subinerciais na superfície é explicada pelo modo barotrópico. 
- Plataforma Continental Externa (PCE)

Souza (2000) concluiu que as correntes subinerciais são principalmente geradas pelos ventos locais ao largo de Santos e que no período de inverno as correntes para nordeste podem ser mais intensas e frequentes que aquelas para sudoeste. A autora encontrou o fluxo da CB no limite interno da PCE apenas esporadicamente, o que contradiz com o trabalho de Prevelato (2014), que afirma a CB ser a forçante dominante das correntes subinerciais na PCE.

A Figura 5 ilustra as divisões da circulação da PCSE, mostrando as massas de água em cada compartimente e as principais forçantes.

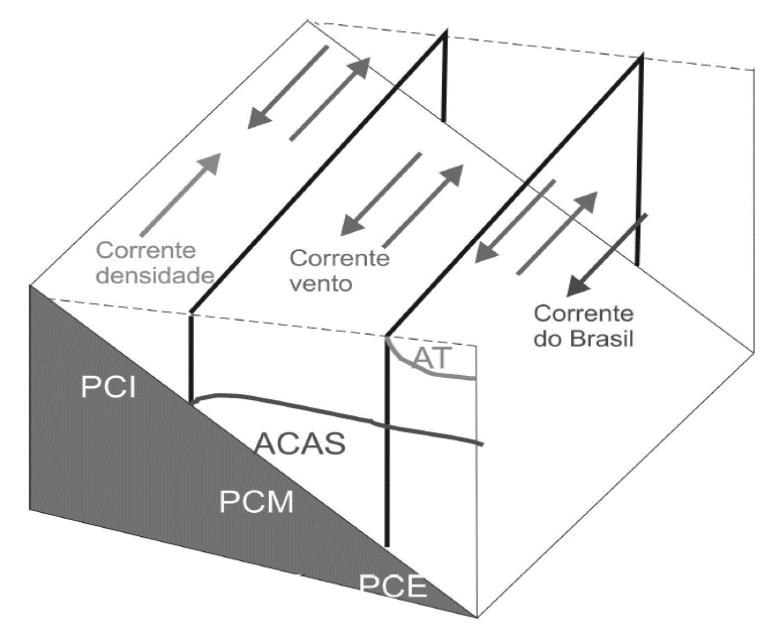

Figura 5 Correntes na Plataforma Continental Sudeste. PCI: plataforma continental interna; PCM: plataforma continental média; PCE: plataforma continental externa; ACAS: Água Central do Atlântico Sul; AT: Água Tropical. Fonte: Prevelato(2014).

\subsubsection{Corrente do Brasil}

A Corrente do Brasil (CB) é uma corrente subtropical de contorno oeste associada ao Giro Subtropical do Atlântico Sul. Origina-se próximo a latitude de $10^{\circ} \mathrm{S}$, na bifurcação da Corrente do ramo sul da Corrente Sul Equatorial (CSE), que ao norte dá origem a Corrente Norte do Brasil (CNB) e ao sul a CB (Silveira etr al., 2000). O fluxo da CB flui para sul ao longo da quebra da plataforma e do talude continental, entre $20^{\circ}-26^{\circ} \mathrm{S}$, e sua estrutura vai da superfície até profundidades de 400-500 m, Belo e Silveira (2013) descrevem que a base do jato da CB está entre 500 e 700 m no Campo de Lula. Na latitude entre $33^{\circ}$ - 38 $\mathrm{S}$, a CB conflui com a Corrente das Malvinas na região da Convergência Subtropical se afastando da costa, 
entre $40^{\circ}-46^{\circ} \mathrm{S}$ quando reverte a sua direção e dá origem a Corrente do Atlântico Sul (Figura 6)

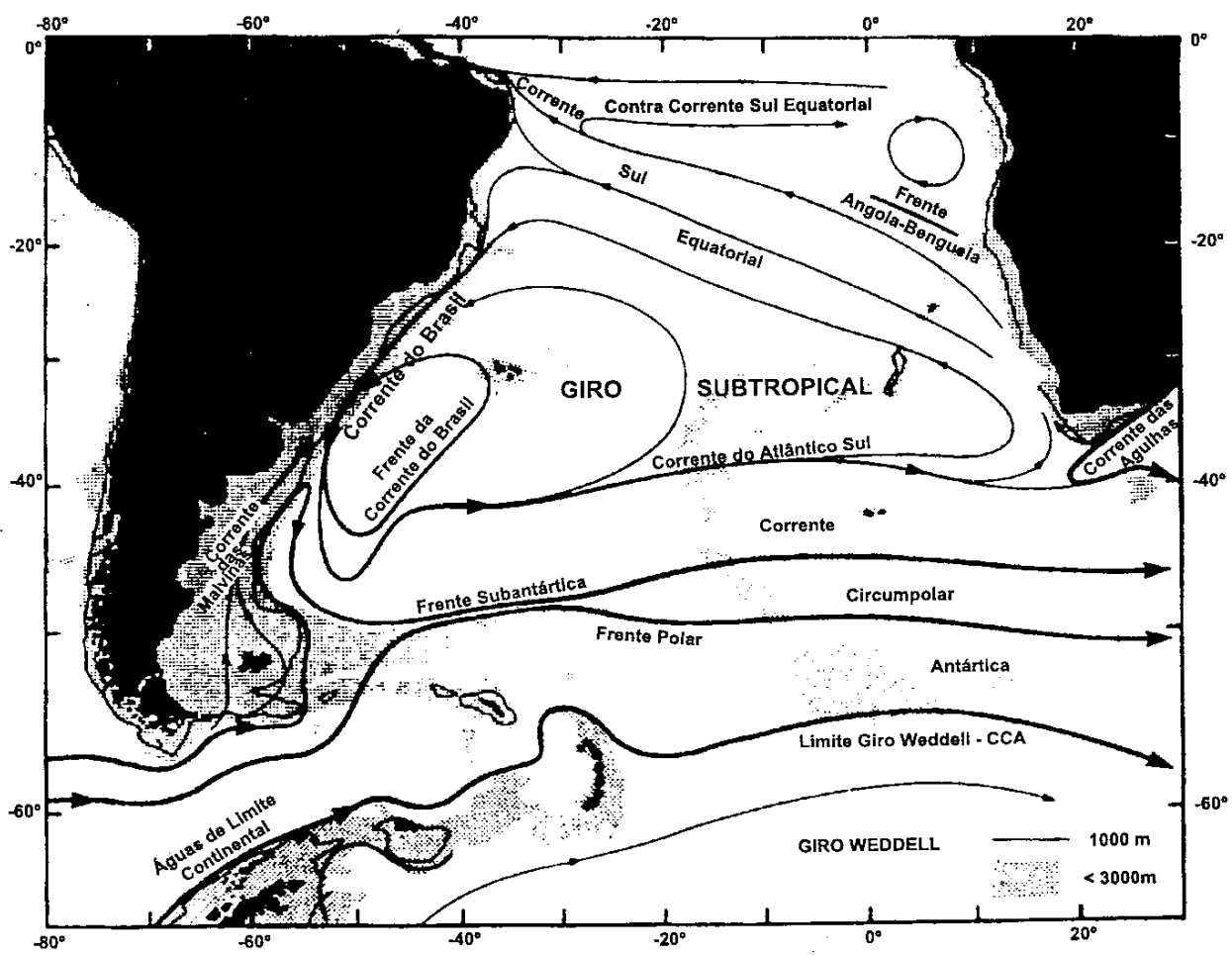

Figura 6 Representação esquemática do Giro Subtropical do Atlântico Sul. De acordo com Peterson e Stramma (1991)(Fonte: Silveira et al., 2000)

Segundo Silveira et. al (2000), entre as latitudes $20^{\circ} \mathrm{S}$ e $25^{\circ} \mathrm{S}$, a corrente superficial da CB atinge velocidades máximas entre 0,4 e $0,7 \mathrm{~m} / \mathrm{s}$ e possui uma largura entre 100 e $120 \mathrm{~km}$. A Corrente do Brasil transporta três massas de água: na superfície, até aproximadamente 100 m é encontrada a Água Tropical (AT); a partir de $20^{\circ} \mathrm{S}$, em direção sul, é encontrada na profundidade entre 100 e 500 m a Água Central do Atlântico Sul (ACAS) (Silveira et al., 2000); entre 500-1000 m, é encontrada a Água Intermediária Antártica nas latitudes entre $25-28^{\circ} \mathrm{S}$, fluindo na mesma direção das massas de água acima desta, para sul.

Entre 20-38 S, a CB apresenta-se instável, formando meandros e vórtices (Belo, 2013). Mascarenhas et al. (1971) e Signorini (1978) descreveram vórtices com $100 \mathrm{~km}$ de raio e profundidades próximas de $500 \mathrm{~m}$. Na região de Cabo Frio $\left(23^{\circ} \mathrm{S}\right)$ ocorre o estreitamento e a mudança da orientação da plataforma continental de NE-SO para L-O. Assim, a CB que vinha acompanhando a quebra da plataforma na direção NE-SO continua com seu fluxo na mesma direção devido a inércia, deslocando-se em direção às águas mais profundas. Com o aumento da profundidade, ocorre o espessamento da $\mathrm{CB}$, fazendo com que gire ciclonicamente para 
oeste, como consequência da conservação da vorticidade potencial. A CB entra na plataforma continental cruzando as isóbatas quase perpendicularmente e, ao percorrer regiões mais rasas, ocorre o efeito reverso, girando então anticiclonicamente para leste. Desse modo a CB segue para SO sob o comportamento de uma onda de Rossby topográfica (Campos, 1995)

\subsection{Objetivo geral e específicos}

Com o intuito de contribuir para redução de custos e emissão de gases do efeito na estufa oriundos da navegação, este trabalho tem como propósito avaliar o efeito da circulação e das ondas e ventos na velocidade de navegação de um navio Aframax em uma rota do Pré-sal na região da Bacia de Santos, aplicando simulações hidrodinâmicas utilizando o modelo numérico ECOM em paralelo com o método de Kwon (2008), o qual emprega equações semi-empíricas, para calcular a velocidade reduzida pela resistência adicionada por ondas irregulares e ventos. Para atingir o propósito deste trabalho, seguem os seguintes objetivos específicos:

- Validar os dados de vento (NCEP) utilizados para forçar o modelo ECOM, assim como as correntes gerada pelo modelo.

- Validar os dados de ondas (CMEMS) utilizados no método de Kwon (2008)

- Avaliar a influência da redução de velocidade pela adição de resistência por ondas e ventos e deriva por correntes na rota de navegação entre o Terminal de Angra dos Reis e o FPSO Cidade de São Paulo

- Otimizar o tempo de navegação na rota entre o Terminal de Angra dos Reis e o FPSO Cidade de São Paulo.

\section{Metodologia}

As simulações hidrodinâmicas foram geradas com o modelo Hidrodinâmico ECOM (Estuarine and Coastal Ocean Model) (GEORGAS; BLUMBER, 2010), originado do modelo POM (Princeton Ocean Model) (Blumberg e Mellor, 1987) em paralelo com o método semiempírico de Kwon, que prevê a perda de velocidade devido à resistência adicionada por ondas irregulares e ventos. O fluxograma da Figura 7 ilustra o procedimento da metodologia desenvolvida para estimar a velocidade do navio. 
- Campos iniciais de temperatura

e salinidade (CMEMS)

- Vento (NCEP)

- Contorno alimentado por

temperatura, salinidade e

velocidade (CMEMS)
Velocidade de

navegação $\left(\mathrm{V}_{1}\right)$
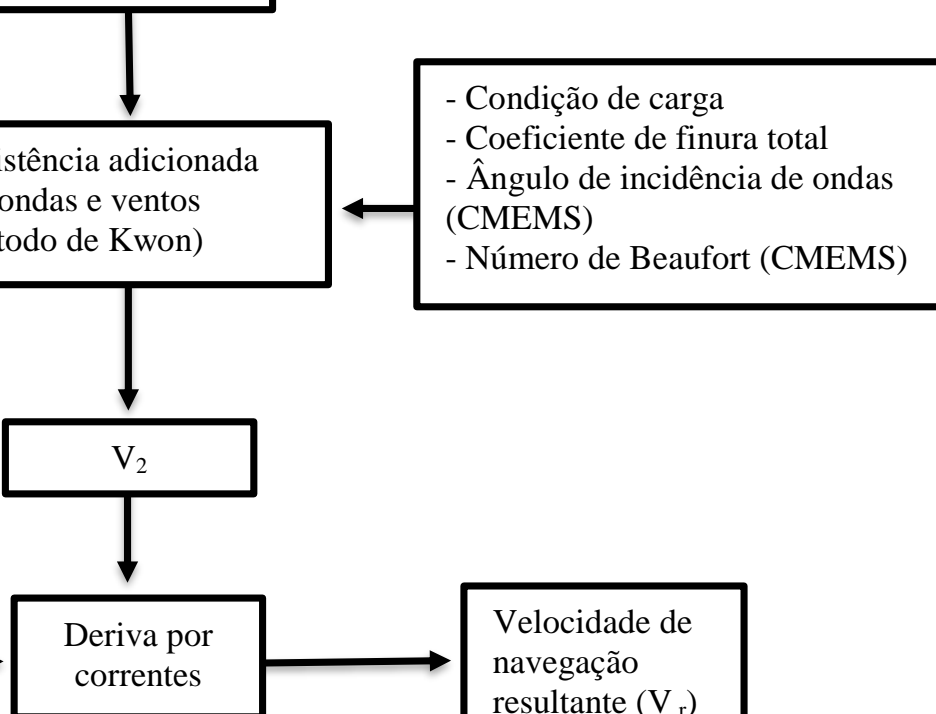

Velocidade de navegação resultante $\left(\mathrm{V}_{\mathrm{r}}\right)$

Figura 7 Fluxograma ilustrando o método ilustrado utilizado para estimar a velocidade de um navio

\subsection{Modelagem numérica hidrodinâmica}

As equações que formam a base da circulação do modelo ECOM descrevem os campos de velocidade e elevação da superfície, e os campos de temperatura e salinidade. Duas aproximações são usada pelos modelo (Bryan, 1969) , a aproximação de um fluído hidrostático, ou seja, o gradiente vertical de pressão é balanceado apenas pelo peso do fluído, e a aproximação de Boussinesq, a qual assume que a variação de densidade não tem efeito no campo de fluxo, exceto quando é originária da força gravitacional. Temos assim, $\rho \equiv \rho_{0}$, sendo $\rho_{0}$ a densidade de referência, que corresponde uma aproximação do valor médio esperado da densidade.

Considerando um sistema Cartesiano ortogonal com o eixo x crescente para leste, o eixo y crescente para norte, e o eixo z verticalmente para cima. Temos como condição de contorno material na superfície com perturbação na superfície livre

$$
z=\eta(\mathrm{x}, \mathrm{y}, \mathrm{t})
$$


e, no fundo,

$$
z=-H(x, y)
$$

sendo $H(x, y)$ a topografia do fundo. Se $\vec{V}$ é o vetor horizontal de velocidade com as componentes $(U, V)$ e $\nabla$ o operador gradiente horizontal, a equação da continuidade é resumida a:

$$
\nabla \cdot \vec{V}+\frac{\partial W}{\partial Z}=0
$$

As equações de conservação do momento discretizadas pelo modelo são, nas direções zonal, meridional e vertical:

$$
\begin{aligned}
\frac{\partial U}{\partial t}+\vec{V} \cdot \nabla U+W \frac{\partial U}{\partial z}-f V & =-\frac{1}{\rho_{0}} \frac{\partial P}{\partial x}+\frac{\partial}{\partial z}\left(K_{M} \frac{\partial U}{\partial z}\right)+F_{x} \\
\frac{\partial V}{\partial t}+\vec{V} \cdot \nabla V+W \frac{\partial V}{\partial z}+f U & =-\frac{1}{\rho_{0}} \frac{\partial P}{\partial y}+\frac{\partial}{\partial z}\left(K_{M} \frac{\partial V}{\partial z}\right)+F_{y} \\
\rho g & =-\frac{\partial \mathrm{P}}{\partial \mathrm{z}}
\end{aligned}
$$

no qual, $P$ corresponde a pressão, $K_{M}$ o coeficiente de difusão vertical de mistura turbulenta, $f$ o parâmetro de Coriolis no plano beta $(\beta)$ e $\rho$ a densidade in situ. Integrando a equação 2.1.6 da profundidade $z$ até a superfície $\eta$, obtemos a equação da pressão na profundidade $z$ :

$$
P(x, y, z, t)=P_{a t m}+g \rho_{0} \eta+g \int_{z}^{0} \rho\left(x, y, z^{\prime}, t\right) d z^{\prime}
$$

O qual a pressão atmosférica $\left(P_{a t m}\right)$ é considerada constante.

As equações da conservação da temperatura e salinidade podem ser escritas como:

$$
\begin{aligned}
& \frac{\partial \theta}{\partial t}+\vec{V} \cdot \nabla \theta+W \frac{\partial \theta}{\partial z}=\frac{\partial}{\partial z}\left[K_{H} \frac{\partial \theta}{\partial z}\right]+F_{\theta} \\
& \frac{\partial S}{\partial t}+\vec{V} \cdot \nabla S+W \frac{\partial S}{\partial z}=\frac{\partial}{\partial z}\left[K_{H} \frac{\partial S}{\partial z}\right]+F_{S}
\end{aligned}
$$


sendo $\theta$ a temperatura potencial e $S$ a salinidade. A temperatura potencial é a temperatura a qual uma parcela de água teria se fosse deslocada adiabaticamente para uma pressão de referência. $K_{H}$ é o coeficiente de difusão vertical de mistura turbulenta do calor e sal. Utilizando a temperatura potencial e a salinidade, a densidade potencial é calculada pela equação empírica do estado da forma

$$
\rho=\rho(\theta, S)
$$

dada por Fofonoff (1962). A densidade potencial $\rho$ fornece informação para calcular o gradiente horizontal baroclínico que entra nos termos de gradiente de pressão e na estabilidade vertical da coluna d'água.

Este modelo assume uma superfície livre e, portanto, em $z=\eta$ temos:

$$
\rho_{0} K_{M}\left(\frac{\partial U}{\partial z}, \frac{\partial U}{\partial z}\right)=\left(\tau_{b x}, \tau_{b y}\right)
$$

e

$$
W=U \frac{\partial \eta}{\partial x}+\frac{\partial \eta}{\partial y}+\frac{\partial \eta}{\partial t}
$$

sendo $\left(\tau_{o x}, \tau_{o y}\right)$ a tensão de cisalhamento do vento na superfície nas direções zonal e meridional, respectivamente.

Em $z=-H(x, y)$, as condições de contorno são dadas por:

$$
\begin{gathered}
\rho_{0} K_{M}\left(\frac{\partial U}{\partial z}, \frac{\partial U}{\partial z}\right)=\left(\tau_{b x}, \tau_{b y}\right) \\
W_{b}=-U_{b} \frac{\partial \mathrm{H}}{\partial x}-V_{b} \frac{\partial \mathrm{H}}{\partial y}
\end{gathered}
$$

no qual, $\left(\tau_{b x}, \tau_{b y}\right)$ é dada pela tensão de cisalhamento no fundo nas direções zonal e meridional, respectivamente.

Nos contornos laterais abertos, os valores atribuídos são prescritos para o domínio do modelo. Neste trabalho, os valores atribuídos no contorno foram fornecidos pelo modelo operacional global Mercator (Mason et al.,2019). 
A grade utilizada possui formação curvilínea ortogonal com resolução entre $0.2 \mathrm{~km}$ e 5 $\mathrm{km}$ na plataforma continental, e espaçamentos de até $35 \mathrm{~km}$ em locais de profundidade próximas de $2.000 \mathrm{~m}$ (Figura 8). Com 110 pontos na direção quase perpendicular a orientação da costa e 137 pontos na direção quase paralela à costa, esta grade foi anteriormente utilizada nos trabalhos de Pereira et al. (2007), Morais (2016) e Birocchi (2017).

Na vertical, a grade é dividida em 37 níveis sigma, variando de 0 , na superfície, a -1, no fundo, com distribuição $\sigma=(-1,-0,9,-0,75,-0,6-0,5-0,4-0,35,-0,324,-0,3,-0,275,-0,25,-$ $0,224,-0,2,-0,175,-0,15,-0,125,-0,1,-0,095,-0,09-0,085,-0,08,-0,075,-0,07,-0,065,-0,06$, $-0,055,-0,05,-0,045,-0,04,-0,035,-0,03,-0,025,-0,02,-0,015,-0,01,-0,005,0)$.

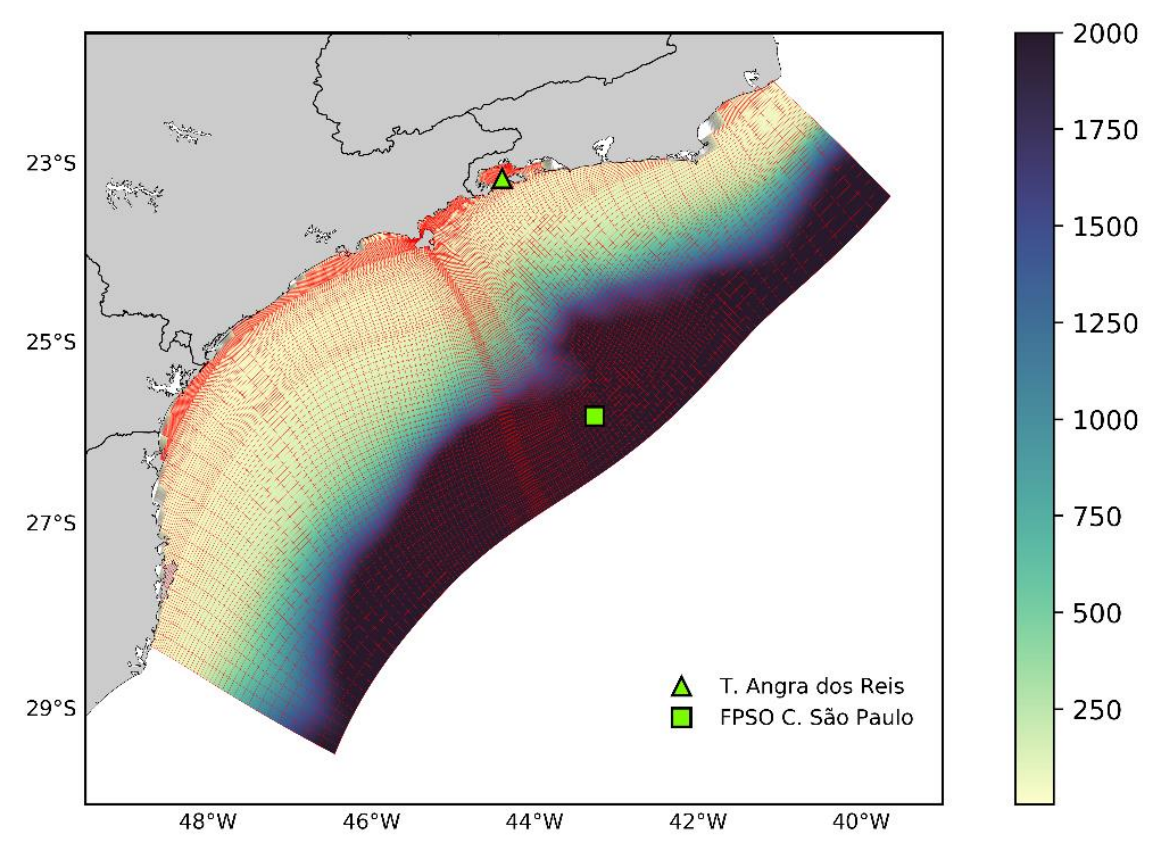

Figura 8 Grade ortogonal curvilínea e as posições do Terminal de Angra dos Reis e o FPSO Cidade de São Paulo.

Os dados de ventos utilizados para forçar o modelo foram fornecidos pelo Climate Forecast System Version 2 (CFSv2), desenvolvidos pelo Environmental Modelling Center (NCEP). O CFSv2 é um modelo global operacional totalmente acoplado que representa a interação entre a atmosfera, oceano, terra, e gelo oceânico (Saha et al., 2012). Este modelo disponibiliza dados horários com resolução horizontal de $0.5^{\circ}$ de latitude (aproximadamente 56 km). O CFSv2 assimila dados observados da superfície, de balões meteorológicos, de observações aéreas de aviões, e de observações de satélite.

Para as condições iniciais do modelo, foram utilizados os dados fornecidos pelo COPERNICUS MARINE ENVIRONMENT MONITORING SERVICE (CMEMS), programa Europeu de observação da Terra, gerenciado pela companhia Mercator Ocean. Os dados utilizados neste trabalho foram obtidos do PSY4V3R1 versão 3.1 do modelo oceânico NEMO 
(Madec et al., 2008). O modela utiliza a grade tripolar ORCA baseada em método semianalítico (Madec and Imbard, 1996) com resolução horizontal de $9 \mathrm{~km}$ no equador, $7 \mathrm{~km}$ em latitudes médias e $2 \mathrm{~km}$ na região do mar de Ross e Wedell. O modelo trabalha com 50 níveis verticais com 1 metro de resolução na superfície descrescendo até 450m no fundo, sendo 22 níveis nos primeiros $100 \mathrm{~m}$. A batimetria utilizada pelo sistema é uma combinação de interpolação do banco de dados do ETOPO1 (Amandte and Eaking, 2009) e GEBCO8 (Beckerl et al., 2009). Nas regiões com profundidade de até $200 \mathrm{~m}$ é utilizado o GEBCO8 e em profundidades maiores que $300 \mathrm{~m}$ é utilizado o ETOPO1. As forçantes atmosféricas são fornecidas pelo sistema integrado de previsão ECMWF (European Center for Medium-Range Weather Forecasts).

Para a inicialização do modelo ECOM foram gerados os campos de temperatura e salinidade interpolados do CMEMS para a grade do modelo utilizando o método do inverso do quadrado da distância, utilizando 10 pontos vizinhos (Maneewongvatana and Mount, 1999).

O tempo de aquecimento do modelo foi de 10 dias, sem a ação do vento. Este período foi determinado através de testes realizados no laboratório LHiCo (Laboratório de Hidrodinâmica Costeira) do Instituto Oceanográfico da Universidade de São Paulo, levando em consideração a formação e estabilização da Corrente do Brasil.

\subsection{Método de Kwon}

Kwon (1981) analisou diversos métodos para prever numericamente o aumento da resistência de um navio em ondas regulares. Espeficamente, foram analisados os resultados de em Nakamura et al. (1981), Fuji-Takahashi (1975), Nakamura-Fujii (1977), TakahashiTsukamoto (1977), ITTC (1978), Lindemann - Robertson (1980), Faltinsen et. al. (1981).

$\mathrm{O}$ autor revisou, também, os métodos para prever numericamente o aumento da resistência de um navio em ondas irregulares em Maruo (1957b, 1957d, 1960b), Pershin et. al. (1957), Kawashima et. al. (1959), Gerritsma et. al. (1961), Vassilopou. los (1967), Sibul (1969), Strom-Tejsen et. al. (1973), and Dalzell (1972a, 1972b, 1974,1975,1976a, 1976b, 1979)).

Finalmente, Kwon (1981) revisou os método para estimar a resistência adicionada por vento em Isherwood (1972), van Berlekom (1978,1981), Aage (1971), Wilson et al. (1970), Tsuji et al. (1970), Wagner (1967), Gould (1967), and Shearer et al. (1960).

Kwon (1981) levou em consideração em suas revisões literárias os seguintes tópicos:

- Resistência adicionada por ondas regulares; 
- Difração de onda;

- Força de arrasto por onda;

- Resistência adicionada por ondas irregulares;

- Resistência adicionada pelo vento;

- Condições de vento e onda no mar;

- Perda involuntária de velocidade e potência dada uma resistência adicionada;

- Efeito de um mar agitado na performance de velocidade de um navio;

Kwon (1981) não encontrou, entretanto, um método teórico convincentemente preciso para determinar a resistência adicionada por ondas curtas em relação ao comprimento do navio, o que perdura até os dias de hoje, apesar do avanço computacional. Sendo assim Kwon elaborou um método semi-empírico a partir de experimentos usando modelos de navio da Série 60 com oscilações em 6 graus de liberdade, dando ênfase em ondas curtas nas quais o efeito da reflexão é dominante comparado com os efeitos do movimento do navio, ou seja, utilizando a relação comprimento de onda/comprimento do navio $(\lambda / \mathrm{L})$ entre 0,23 e 1,18. O trabalho foi realizado através da análise de resultados obtidos de cinco navios tanques e containers, abrangendo o Número de Froude entre 0,10 e 0,25, que na arquitetura naval é utilizado para determinar de maneira prática a resistência principalmente por ondas de um objeto se movendo parcialmente submerso na água.

Apesar dos modelos avançados, o método de Froude ainda é utilizado para a construção de modernos navios. Desse modo, Kwon elaborou uma fórmula aproximada para calcular a resistência causada por ondas e ventos utilizando a Escala de Beaufort (Frost, 1966), uma estimativa que define a força do vento pelos seus efeitos sobre a superfície do oceano. A Escala de Beaufort foi desenvolvida em 1903 para ajudar os navegadores a estimar o vento por uma observação visual em mar aberto. No entanto, esta escala é utilizada até os dias de hoje, e começa em 0 para um mar calmo e com aparência espelhada, terminando em 12 em, uma passagem de furacão. A Escala de Beaufort é estritamente aplicada para um mar completamente desenvolvido, isto é, quando as ondas atingem o máximo valor para um vento particular com a pista e duração de vento necessários (Met Office, 2015).

A fórmula de Kwon é dada por:

$$
\frac{\Delta V}{V_{1}} 100 \%=C_{\beta} C_{v} C_{\text {form }}
$$




$$
V_{2}=V_{1}-\left(C_{\beta} C_{v} C_{\text {form }}\right) \frac{1}{100 \%} V_{1}
$$

sendo $V_{1}$ a velocidade nominal em águas calmas (sem vento e ondas), $V_{2}$ a velocidade dada as determinadas condições de tempo, $C_{\beta}$ o coeficiente de redução por direção, $C_{v}$ o coeficiente de redução de velocidade e $C_{\text {form }} \mathrm{o}$ coeficiente da forma do navio.

O Coeficiente de redução por direção $\left(C_{\beta}\right)$ é calculado pelo ângulo de incidência de ondas e ventos (Figura 9) e o Número de Beaufort (Tabela 1). O método de Kwon (2008) considera o ângulo de incidência do vento e ondas iguais, o que nem sempre ocorre, pois muitas vezes as ondas locais são geradas por ventos remotos.

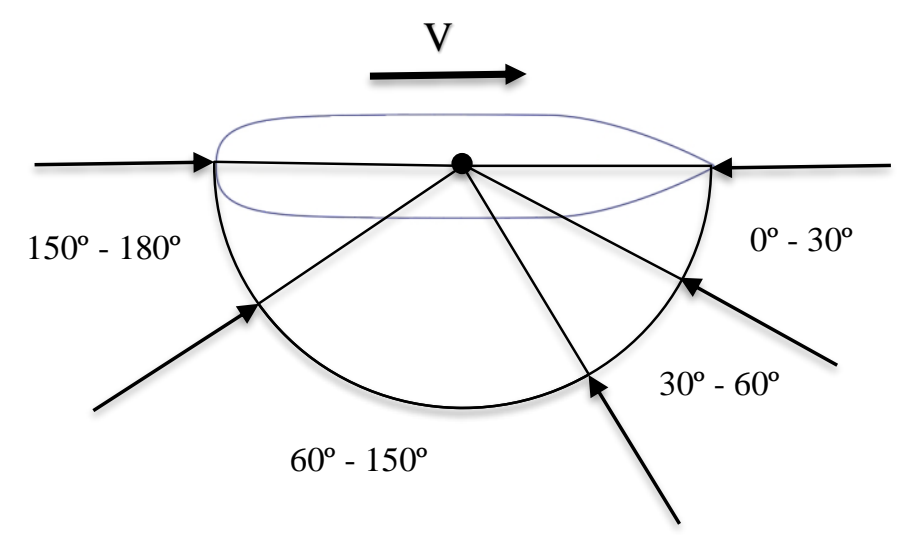

Figura 9 Ângulo de incidência das ondas no navio

Tabela 1 - Coeficiente de redução devido a direção das ondas irregulares e vento $\left(\mathrm{C}_{\beta}\right)$

\begin{tabular}{lll}
\hline Direção & Ângulo de incidência $(\theta)$ & Coeficiente de redução por direção $\left(\mathrm{C}_{\beta}\right)$ \\
\hline Frontal & $0-30$ & $2 \mathrm{C}_{\beta}=2$ \\
Proa & $30-60$ & $2 \mathrm{C}_{\beta}=1,7-0,03\left((\mathrm{BN}-4)^{2}\right)$ \\
Transversal & $60-150$ & $2 \mathrm{C}_{\beta}=0,9-0,06\left((\mathrm{BN}-6)^{2}\right)$ \\
Poupa & $150-180$ & $2 \mathrm{C}_{\beta}=0,4-0,03\left((\mathrm{BN}-8)^{2}\right)$
\end{tabular}

E dado pelo ângulo de incidência (considerando os ventos e as ondas na mesma direção) e o Número de Beaufort $(\mathrm{BN})$.

Coeficiente de redução de velocidade $\left(C_{u}\right)$ é calculado para cada coeficiente de finura total $\left(C_{b}\right)$, condição de carga e número de Froude $\left(F_{n}\right)$ do navio (Tabela 2). O coeficiente $C_{b}$ corresponde a razão entre o volume submerso do navio pelo volume de um bloco retangular com as dimensões de calado, largura e comprimento no nível da água (Figura 10), conforme a equação 2.5.3: 


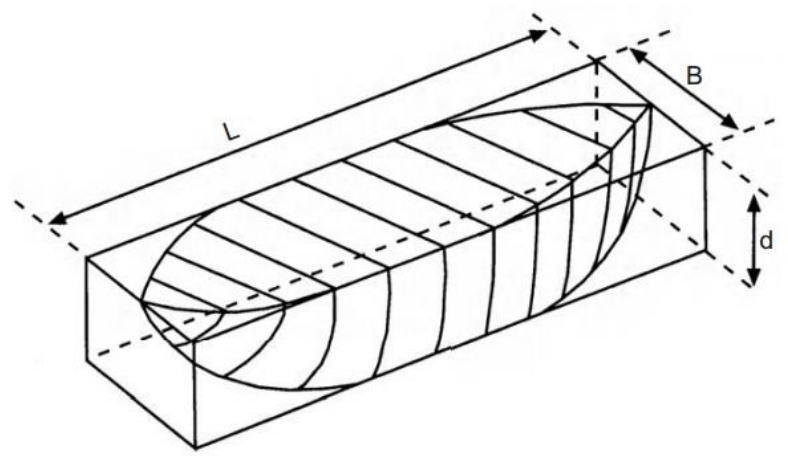

Figura 10 Dimensões do navio, sendo L o comprimento entre as perpendiculares, B a largura do navio no nível da água e d o calado.

$$
C b=\Delta /(\operatorname{L} x \quad B \quad x d)
$$

Tabela 2 - Coeficiente de redução de velocidade $\mathrm{C}_{\mathrm{u}}$

\begin{tabular}{lll}
\hline $\begin{array}{l}\text { Coeficiente de finura total } \\
C_{b}\end{array}$ & $\begin{array}{l}\text { Condição de carga do } \\
\text { navio }\end{array}$ & $\begin{array}{l}\text { Coeficiente de redução de velocidade } \\
C_{u}\end{array}$ \\
\hline 0,55 & padrão & $1,7-1,4 F_{n}-7,4 F_{n}{ }^{2}$ \\
0,6 & padrão & $2,2-2,5 F_{n}-9,7 F_{n}{ }^{2}$ \\
0,65 & padrão & $2,6-3,7 F_{n}-11,6 F_{n}{ }^{2}$ \\
0,7 & padrão & $3,1-5,3 F_{n}-12,4 F_{n}{ }^{2}$ \\
0,75 & carregado ou padrão & $2,4-10,6 F_{n}-9,5 F_{n}{ }^{2}$ \\
0,8 & carregado ou padrão & $2,6-13,1 F_{n}-15,1 F_{n}{ }^{2}$ \\
0,85 & carregado ou padrão & $3,1-18,7 F_{n}+28,0 F_{n}{ }^{2}$ \\
0,75 & lastreado & $2,6-12,5 F_{n}-13,5 F_{n}{ }^{2}$ \\
0,8 & lastreado & $3,0-16,3 F_{n}-21,6 F_{n}{ }^{2}$ \\
0,85 & lastreado & $3,4-20,9 F_{n}+31,8 F_{n}{ }^{2}$
\end{tabular}

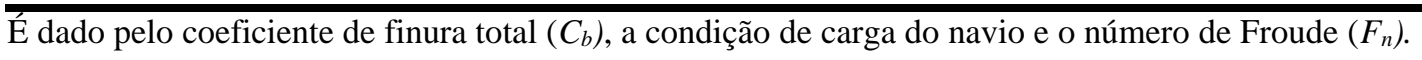

O Número de Froude é dado pela seguinte equação:

$$
F n=\frac{V}{\sqrt{g \cdot L}}
$$

sendo $V$ correspondente a velocidade do navio, $g$ a gravidade e $L$ o comprimento do navio no nível da água.

O Coeficiente da forma do navio $\left(C_{\text {form }}\right)$ é o coeficiente que leva em consideração o tipo de navio e sua condição de carga. Este coeficiente é dado pelo número de Beaufort e o deslocamento volumétrico de água devido ao peso do navio $\mathrm{em}^{3}(\Delta)$ (Tabela 3 ). 
Tabela 3 - Coeficiente da forma do navio $\left(\mathrm{C}_{\text {form }}\right)$

Tipo de navio por deslocamento

Coeficiente de redução por direção $\left(\mathrm{C}_{\beta}\right)$

Navios (exceto containers) carregados

$0,5 \mathrm{BN}+\mathrm{BN} 6,5 /\left(2.7 \times \Delta^{2 / 3}\right)$

Navios (exceto containers) lastreados

$0,7 \mathrm{BN}+\mathrm{BN} 6,5 /\left(2.7 \times \Delta^{2 / 3}\right)$

Containers em condição padrão de carga

$0,7 \mathrm{BN}+\mathrm{BN} 6,5 /\left(27 \times \Delta^{2 / 3}\right)$

É dado pelo tipo de navio e sua condição de carga e o Número de Beaufort (BN) e o volume deslocado de água pelo navio em $\mathrm{m}^{3}(\Delta)$.

\subsubsection{A utilização do método de Kwon por outros autores}

O método de Kwon foi comparado com outros métodos em trabalhos com o de Kim et al. (2017), que realizou simulações numéricas baseadas no IMO (2012) e ITTC (2014) para estimar a perda de velocidade de um container S175 devido a ondas e ventos. O autor utilizou métodos 2-D e 3-D de fluxo potencial e um CFD (Computational Fluid Dynamics) com um enfoque em URANS (Unsteady Reynolds-Averaged Navier-Stokes). Em uma de suas validações, comparou os resultados de suas simulações com os métodos de Kwon e o método de Prpic-Orsic e Faltisen (2012), como mostra a Fig. 7, obtendo uma boa aproximação colinear entre seus resultados e o método de Kwon.

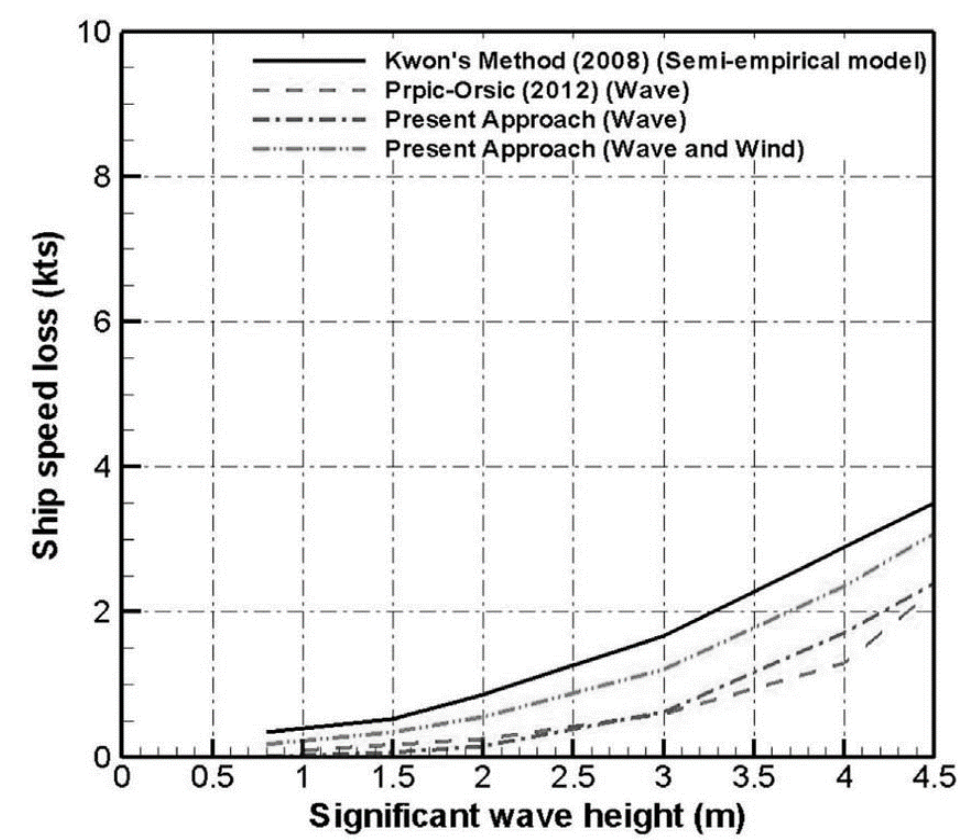

Figura 11 Perda de velocidade do navio devido as ondas e ventos, resultados obtidos por Kim et al. (2017) (V=23 nós, $\theta=$ $\left.0^{\circ}\right)$. 
O método de Kwon também foi utilizado por Lu et al. (2015) em um estudo de otimizações de rotas para operadores de navios em busca da melhorar eficiência energética, utilizando a equação:

$$
E E O=\frac{F C}{m_{\text {carga }} \times D}
$$

sendo $F C$ o consumo do motor principal, $m_{\text {carga }}$ a carga carregada e $D$ a distância navegada. O autor estima a resistência do navio em água calmas, o que corresponde a um mar sem vento e ondas, utilizando o método de Holtrop and Mennens (1982) para obter uma relação entre a velocidade de navegação, resistência total em águas calmas e potência efetiva. Sabendo a velocidade perdida devida as condições de mar calculada pelo método de Kwon, o autor estima o gasto de combustível devido ao aumento voluntário da potência do motor para que o navio atinja a velocidade registrada. Lu et al. (2015) pesquisaram a performance operacional dos navios tanques Suezmax e Aframax. Para o navio Suezmax, a diferença entre o Energy Efficiency of Operation (EEO) estimado e o real foi de apenas 5,12\%, e para o navio Aframax foi de 7,15\%. O autor acusa que o erro provavelmente está associado ao efeito da incrustação no casco e na hélice, e a degradação do motor. $\mathrm{O}$ autor registra um aumento gradual dos erros em intervalos de manutenção. Para o navio Aframax foi registrado um erro de aproximadamente $2 \%$ logo após a docagem seca. Este valor aumentou gradualmente até aproximadamente 10\% em 16 meses sem manutenção.

\subsection{Deriva por correntes}

A deriva por correntes pode ser estimada pela soma dos vetores velocidade de corrente com o vetor velocidade do navio como está ilustrado na Figura 12.

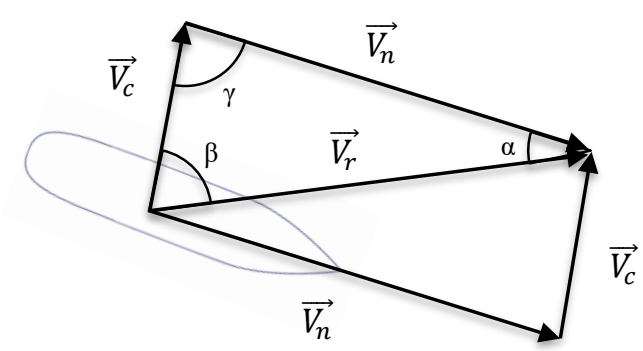

Figura 12 Ilustração das somas de vetores do navio, sendo $\overrightarrow{V_{c}}$ a velocidade da corrente, $\overrightarrow{V_{r}}$ a velocidade resultante e $\overrightarrow{V_{n}}$ a velocidade do navio. 
Sendo $\overrightarrow{V_{c}}$ a velocidade da corrente, $\overrightarrow{V_{r}}$ a velocidade resultante e $\overrightarrow{V_{n}}$ a velocidade do navio. A velocidade do navio $\left(\overrightarrow{V_{n}}\right)$ é considerada constante durante o curso e a sua direção é relativa à variação de $\overrightarrow{V_{c}}$, sendo que a resultante $\overrightarrow{V_{r}}$ permanece na direção de navegação.

Com os resultados do modelo ECOM pode ser obtido o ângulo $\beta$ em relação ao curso de navegação. Aplicando a lei dos senos, o ângulo $\gamma$ pode ser obtido por:

$$
\gamma=\operatorname{arcsen}\left(\frac{\left|V_{r}\right| \operatorname{sen} \beta}{\left|V_{n}\right|}\right)
$$

Aplicando a lei dos cossenos, o valor da velocidade da resultante é dado por:

$$
V_{r}=\sqrt{V_{n}{ }^{2}+V_{c}{ }^{2}-2\left|V_{n} V_{c}\right| \cos \gamma}
$$

Na prática o valor da corrente é em torno de uma ordem de grandeza menor que a velocidade do navio. Assim, o valor entre $\overrightarrow{V_{r}}$ e $\overrightarrow{V_{n}}$ são muito próximos, como também o ângulo entre eles. Desta forma, a direção da deriva por correntes é muito próxima ao curso de navegação, podendo então ser desprezado o efeito do arrasto lateral.

\subsubsection{Cálculo do número de Beaufort}

Para calcular o número de Beaufort foi a utilizado a relação de Frost (1966)

$$
H_{\text {médio }}=4,5 \times 10^{-2} B^{7 / 3}
$$

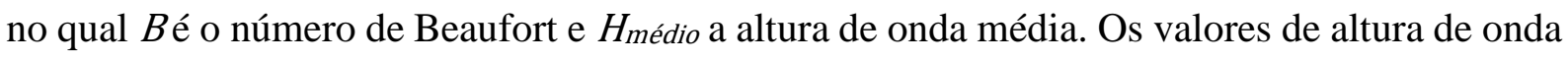
médio, assim como as direções de onda, foram obtidos do CMEMS, que são fornecidos pelo sistema global operacional de previsão e análise de ondas de superfície Météo-France com resolução de 1/12 graus, 5 dias de previsão e dados a cada 3 horas. O sistema Météo-France, é baseado no modelo de onda MFWAM (modelo de onda regional Europa-Atlântico). O modelo MFWAM usa o código do ECWAM-IFS38R2 com os termos de dissipação desenvolvido por Ardhuin et al. (2010). 


\section{Simulações}

\subsection{Modelo do navio}

Os dados de navio tanque Aframax SCF Baltica (Tabela 4) foram utilizados para as simulações devido a semelhança com o navio Aframax Castro Alves, o primeiro da série de 5 Aframax a serem construídos pela companhia do Atlântico Sul (EAS) a integrar a frota da Transpetro, com capacidade de transportar aproximadamente 800 mil barris de petróleo (portal Transpetro, 2019), o equivalente a 120 mil toneladas de porte bruto (TPB). O nome Aframax é baseado na terminologia Average Freight Rate Assessment (AFRA). Esses navios normalmente transportam óleo cru e possuem a capacidade de carregamento na faixa de 80 a 120 TPB. Na frota da Transpetro, os navios Aframax, além do Castro Alves, são o Fortaleza Knutsen, Navion Bergen e Recife Knutsen. A frota de transporte de óleo cru da Transpetro é constituída, também, por navios do tipo Suezmax, com capacidade de carregamento na faixa de 140 a 175 TPB, e navios Panamax, com capacidade de carregamento na faixa de 65 a 80 TPB.

Tabela 4 - Medidas do navio Aframax SCF Baltica

\section{Descrição do navio}

Nome

SCF Baltica

Número IMO

9305568

Tipo

Navio tanque

Comprimento total

$250 \mathrm{~m}$

Comprimento entre as perpendiculares

$240 \mathrm{~m}$

Largura

$44 \mathrm{~m}$

\section{Linha de carga}

\begin{tabular}{llll}
\hline & Calado (m) & Porte bruto (MT) & Deslocamento (MT) \\
Carga total & 15,743 & 120.312 & 140.251 \\
Lastreado & 8,25 & $48.293,7$ & $68.697,7$ \\
\hline
\end{tabular}

(MT = mil toneladas) 


\subsection{Rota}

Neste trabalho, foram simuladas navegações na rota ligando o Terminal Aquaviário de Angra dos Reis - RJ (TAR) (Tabela 5), latitude 23,15'S e longitude 44,50' O, ao FPSO Cidade de São Paulo (FPSO SP)(

Tabela 6) - Campo de Sapinhoá, localizado na latitude 25,80’ S, longitude 43,26' O, sendo a distância do trajeto de $319 \mathrm{~km}$. O TAR possui uma infraestrutura para a atracação de navios de grande porte cerca de duas vezes maior que um navio Suezmax.

Tabela 5 - Terminal Aquaviário de Angra dos Reis - RJ

\section{Tanque}

\begin{tabular}{lll}
\hline Produto & Petróleo & Derivados, álcool e biodiesel \\
Quantidade & 10 & 5 \\
Capacidade Nominal $\left(\mathrm{m}^{3}\right)$ & 845.557 & 132.489
\end{tabular}

\section{Pontos de atracação}

\begin{tabular}{lll}
\hline Píer & Píer 1 & Píer 2 \\
Calado $(\mathrm{m})$ & 25 & 25 \\
Comprimento máximo $(\mathrm{m})$ & 516 & 516 \\
Porte Bruto (t) & 500.000 & 500.000 \\
\hline
\end{tabular}

Fonte: Transpetro (2019)

Tabela 6 - FPSO Cidade de São Paulo

\section{Capacidade de processamento}

\begin{tabular}{ll}
\hline Petróleo $(\mathrm{bbl} / \mathrm{d})$ & Gás natural $\left(\mathrm{Mm}^{3} / \mathrm{d}\right)$ \\
120.000 & 5.000
\end{tabular}

\section{Produção em fevereiro de 2019}

Petróleo $(\mathrm{bbl} / \mathrm{d}) \quad$ Gás natural $\left(\mathrm{Mm}^{3} / \mathrm{d}\right) \quad \mathrm{N}^{\mathrm{o}}$ poços produtores
117.768
4.735 
Fonte: Anp (2019). A unidade bbl/d corresponde a barris por dia e a unidade $\mathrm{Mm}^{3} / \mathrm{d}$ corresponde a milhões de metros cúbicos por dia.

A velocidade de navegação foi estabelecida em 13,5 nós, a qual corresponde a velocidade média mais econômica da frota da PETROBRAS (Diz et al., 2014), sendo a sua variação dada pela redução involuntária, ou seja, a potência do motor é mantida constante e a velocidade de navegação é o resultado da potência eficiente (potência bruta menos as perdas por fatores como propulsão, transmissão e resistência em águas calmas) menos a resistência adicionada por ondas e ventos.

A condição de carga do navio Aframax na rota TF foi considerada de lastreamento e na rota inversa FT, foi considerada a condição da carga total. Para avaliar a influência do ambiente na velocidade do navio, foram realizadas simulações considerando individualmente cada um dos fatores ambientais, de acordo com a Tabela 7.

Tabela 7 - Simulações de navegação

\begin{tabular}{lllll}
\hline Rota & Partida & Chegada & $\begin{array}{l}\text { Condição de } \\
\text { carga }\end{array}$ & Redução de velocidade \\
\hline \multirow{2}{*}{ TF } & TAR & FPSO SP & Lastreado & $\begin{array}{l}1-\text { Correntes } \\
2-\text { Ondas e ventos } \\
3-\text { Correntes, ondas e ventos }\end{array}$ \\
\hline \multirow{2}{*}{ FT } & & & $1-$ Correntes \\
& FPSO SP & TAR & Carga total & $2-$ Ondas e ventos \\
& & & $3-$ Correntes, ondas e ventos \\
\hline TF, rota Terminal de Angra dos Reis (TAR) - FPSO Cidade de São Paulo (FPSO SP).
\end{tabular}

TF, rota Terminal de Angra dos Reis (TAR) - FPSO Cidade de São Paulo (FPSO SP).

\subsection{Modelo de navegação}

Para estimar as variações da velocidade de navegação, foi elaborado um modelo para calcular a velocidade resultante do navio dada a posição e o tempo conforme os fatores de redução selecionados. $\mathrm{O}$ seu deslocamento é determinado por:

$$
\text { distância }=t \times V_{r}
$$

sendo $V_{r}$ a velocidade resultante relativa a um ponto fixo, ou seja, a deriva por correntes afeta o valor de $V_{r}$, e t o passo de tempo. O curso da navegação é mantido sempre para a direção de 
destino e, assim, a cada passo de tempo (t), que no caso foi selecionado em 400 segundos, a velocidade resultante é recalculada (Figura 13).

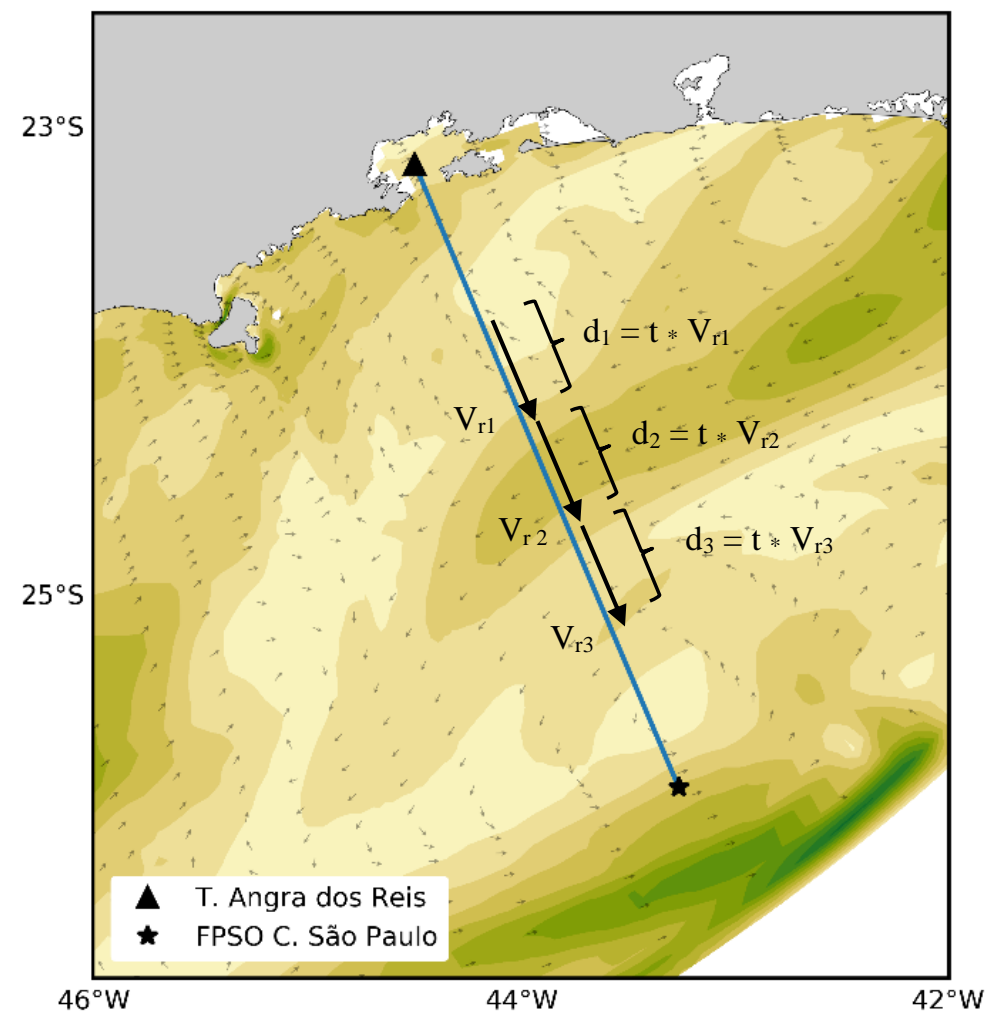

Figura 13 Ilustração do modelo de navegação, sendo $V_{r}$ a velocidade resultante de navegação, to passo de tempo do cálculo de $V_{r}$ e d a distância percorrida.

Para melhor precisão dos cálculos de Vr no modelo, os dados de onda, vento e corrente foram interpolados bilinearmente para a rota do navio obtendo então um valor a cada $600 \mathrm{~m}$. Utilizando a velocidade de navegação de 13,5 nós, aproximadamente $7 \mathrm{~m} / \mathrm{s}$, o cálculo de Vr é realizado aproximadamente a cada 280 m navegados. 


\section{Medidas estatísticas para avaliar o modelo hidrodinâmico}

Para avaliar a performance do modelo foram utilizados o índice de concordância de Willmott (2008) e refinado (Willmott, 2012) e a raiz do erro quadrático médio (RMSE em inglês).

\section{1 Índice de concordância de Willmott}

O índice de concordância de Willmott (1981) é calculado pela equação:

$$
d=1-\frac{\sum_{i=1}^{n}\left(P_{i}-O_{i}\right)^{2}}{\sum_{i=1}^{n}\left(\left|P_{i}-\bar{O}\right|+\left|O_{i}-\bar{O}\right|\right)^{2}}
$$

Este índice é utilizado comumente para comparar estimativas e previsões de modelo meteorológicos e oceanográficos $\left(\mathrm{P}_{\mathrm{i}} ; \mathrm{i}=1,2, \ldots, \mathrm{n}\right)$ com o seu correspondente observado $\left(\mathrm{O}_{\mathrm{i}} ; \mathrm{i}=\right.$ $1,2, \ldots, n)$ que se considera confiável. Sendo $d=1$ quando ocorre a concordância total entre o modelo e observado e d $=0$, quando a concordância é nula. Sendo um valor adimensional, pode ser utilizado para comparar parâmetros variáveis de diferentes unidades.

\section{2 Índice de concordância de Willmott refinado}

O índice de Willmott refinado está entre o limite inferior de -1 e o limite superior de 1, tendo um range dobrado em relação ao índice original (Willmott, 1982) e modificado (Willmott, 1985) de range entre 0 e 1 . O novo índice permite a comparação de modelos com baixa performance em suas simulações. $O$ índice é expresso pela equação:

$$
d_{r}=\left\{\begin{array}{l}
1-\frac{\sum_{i=1}^{n}\left|P_{i}-O_{i}\right|}{c \sum_{i=1}^{n}\left|O_{i}-\bar{O}\right|}, \text { se } \sum_{i=1}^{n}\left|P_{i}-O_{i}\right| \leq c \sum_{i=1}^{n}\left|O_{i}-\bar{O}\right| \\
\frac{c \sum_{i=1}^{n}\left|O_{i}-\bar{O}\right|}{\sum_{i=1}^{n}\left|P_{i}-O_{i}\right|}-1, \text { se } \\
\sum_{i=1}^{n}\left|P_{i}-O_{i}\right| \geq c \sum_{i=1}^{n}\left|O_{i}-\bar{O}\right|
\end{array}\right.
$$


O valor $d_{r}$ pode ser interpretado em termos da relação entre o erro médio absoluto (EMA) $\left(\sum_{i=1}^{n}\left|P_{i}-O_{i}\right|\right)$ e o desvio absoluto medido (DAM) $\left(\sum_{i=1}^{n}\left|O_{i}-\bar{O}\right|\right)$. Willmott (2012) afirma que a magnitude do erro relacionado ao EMA representa a diferença entre dois desvios, um do previsto pelo modelo $(P)$ e um do observado $(O)$, enquanto o denominador DAM representa apenas um desvio, então multiplicando o denominador por $2(\mathrm{c}=2)$ coloca o numerador e o denominador em balanço conceitual.

\subsection{Raiz do erro quadrático médio}

A Raiz do erro quadrático médio (RMSE em inglês) é o desvio padrão dos erros previstos, expressando a acurácia dos resultados numéricos com valores do erro nas mesmas dimensões da variável analisada dado pela equação:

$$
R M S E=\left[\frac{1}{n} \sum_{n}^{n}\left(P_{i}-O_{i}\right)^{2}\right]^{1 / 2}
$$

\section{Medidas estatísticas para avaliar o modelo hidrodinâmico}

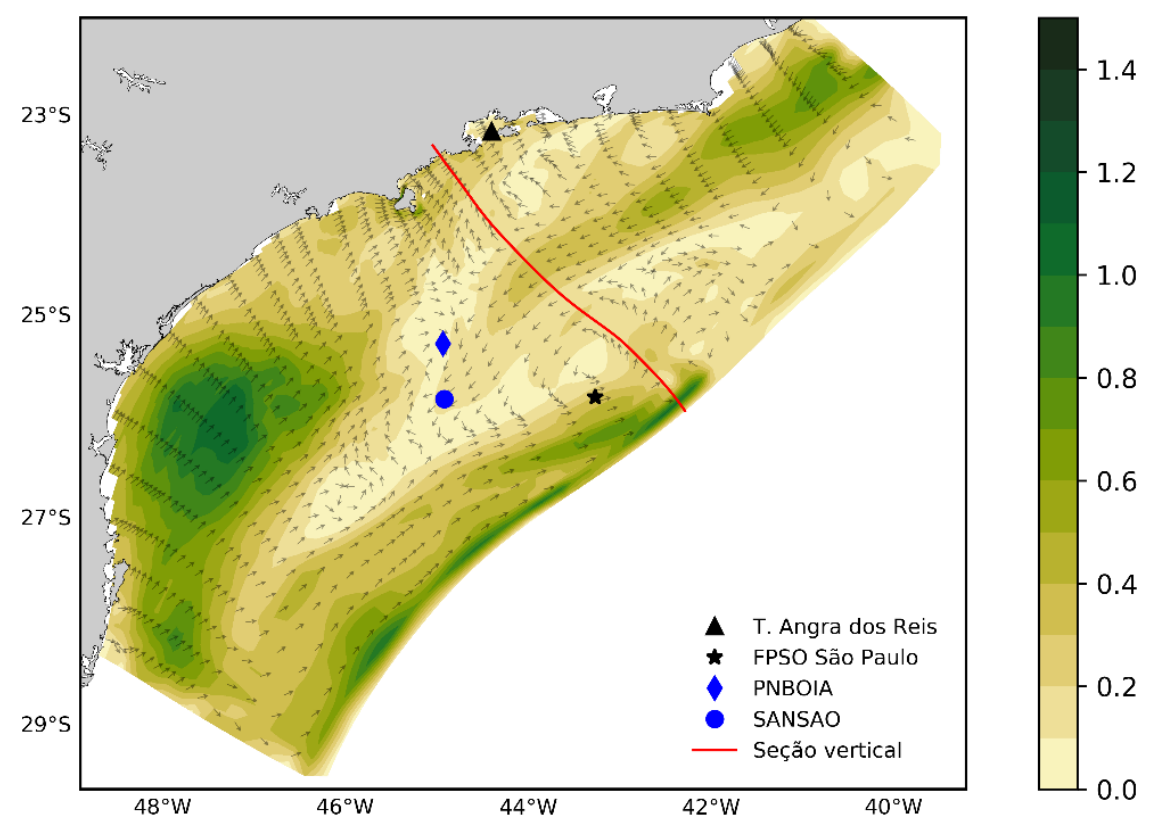

Figura 14 Localização do Terminal de Angra dos Reis, FPSO Cidade de São Paulo e dos fundeios PNBOIA e SANSAO. E região da seção vertical analisada do modelo, na data do dia 28 de outubro de 2016. 


\subsection{Dados de corrente}

Os dados observados de corrente foram medidos com um equipamento ADP (Acoustic Doppler Profiler) fundeado pelo projeto SANSAO (Impacts of the Southwestern Atlantic on the South American climate - The Oceanic importance) na latitude 26 10',9995 S e longitude $45^{\circ} 5^{\prime}, 136$ O. A série de velocidade foi coletada no período de 28/10/2016 a 10/01/2016. Os dados utilizados para a validação do modelo hidrodinâmico foram os dados de superfície.

A Figura 14 mostra a localização dos fundeios dos projetos PNBOIA e SANSAO.

\subsection{Dados de ventos e de ondas}

Tanto os dados de ventos como nos de ondas, observados, utilizados para avaliar os dados de vento do CFSV2 e os dados de ondas do CMEMS, respectivamente, foram fornecidos pelo Programa Nacional de Boias (PNBOIA) (DHN, 2013). Os dados foram coletados pela boia localizada em Santos, latitude $25^{\circ} 26,37^{\prime} \mathrm{S}$ e longitude $45^{\circ} 02,17^{\prime} \mathrm{O}$, do fabricante Axys Technologies Inc. modelo 3-Meters (3M). A boia possui dois anemômetros localizados a 3,7 e 4,7 metros da superfície do mar, sendo os dados medidos corrigidos para a altura de 10 metros utilizando o método de Liu et al. (1979).

Para medir ondas, a boia conta com um sensor direcional da Triaxys, equipado com três acelerômetros e três sensores angulares, podendo então medir oscilações nos três eixos ortogonais $\mathrm{x}, \mathrm{y}$ e $\mathrm{z}$, assim como os movimento de pitch, heave e roll. Os dados são préprocessados no módulo interno da boia e então enviados por telemetria (satélite) apenas os dados estatísticos resultante com médias a cada 3 horas (DHN, 2018).

\section{Resultados}

\subsection{Validação dos modelos}

Os vetores de velocidade de corrente e vento, dos dados observados e do modelo, foram rotacionados em $39^{\circ}$, no sentido anti-horário, a partir do norte geográfico para obter as componentes paralelas e perpendiculares à costa. 


\subsubsection{Validação do vento (NCEP)}

Os dados de previsão do vento do NCEP(CFSv2) se mostraram bem similares aos dados observados (PNBOIA)(Figura 15), principalmente na componente paralela à costa com o RMSE de $1,32 \mathrm{~m} / \mathrm{s}$ (Tabela 8). Na componente paralela à costa o RMSE foi $1,75 \mathrm{~m} / \mathrm{s}$.
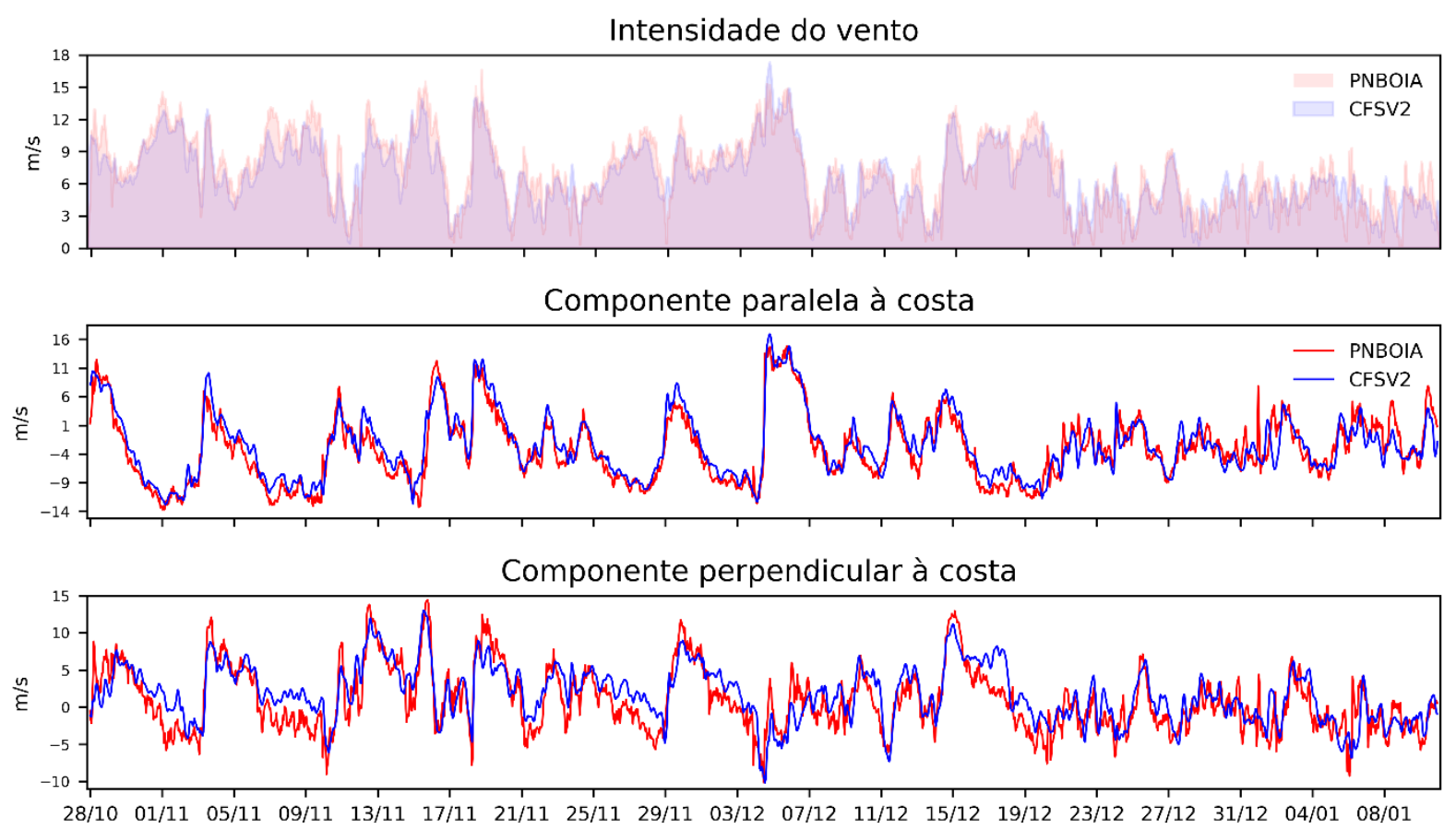

Figura 15 Dados modelo CFSV2 comparados aos medidos in situ pela boia metaoceanográfica do programa PBNBOIA localizada na latitude: $25^{\circ} 26^{\prime} 22.2^{\prime \prime} \mathrm{S}$ longitude: $45^{\circ} 2^{\prime} 9.96^{\prime \prime} \mathrm{O}$

Tabela 8 - Validação do vento do NCEP (CFSv2).

\begin{tabular}{llll}
\hline $\mathrm{n}=1798$ & RMSE $(\mathrm{m} / \mathrm{s})$ & Skill Refinado & Skill \\
\hline $\begin{array}{l}\text { Componente } \\
\text { paralela }\end{array}$ & 1,32 & 0,86 & 0,98 \\
$\begin{array}{l}\text { Componente } \\
\text { perpendicular }\end{array}$ & 1,75 & 0,92 & 0,92 \\
\hline Van & & & \\
\hline
\end{tabular}

Validação do modelo (NCEP) com os dados do projeto PNBOIA para o período de 28/10/2016 a 10/01/2016, com um número (n) amostral de 1798.

Com valores de skill próximos a 1 e baixos RMSE, e com resolução horizontal próxima de $56 \mathrm{~km}$, o CFSv2 apresenta-se como uma fonte confiável de dados para forçar modelos na região da Bacia de Santos. 


\subsubsection{Validação do modelo hidrodinâmico (ECOM)}

O modelo foi validado para a região da Corrente do Brasil com os dados do projeto SANSAO (Figura 16)(Tabela 9). Os dados do SANSAO foram filtrados com a aplicação do filtro de Lanczos (Duchon, 1979) com frequência de corte de 45 horas, para atenuar os ruídos de baixa frequência, como sinais de maré. Na validação, a componente paralela apresentou mais precisa, com skill refinado de 0,58 e RMSE de $0,22 \mathrm{~m} / \mathrm{s}$. Na componente perpendicular o valor de skill refinada foi de 0,53 e RMSE de 0,22 m/s (Tabela 9).

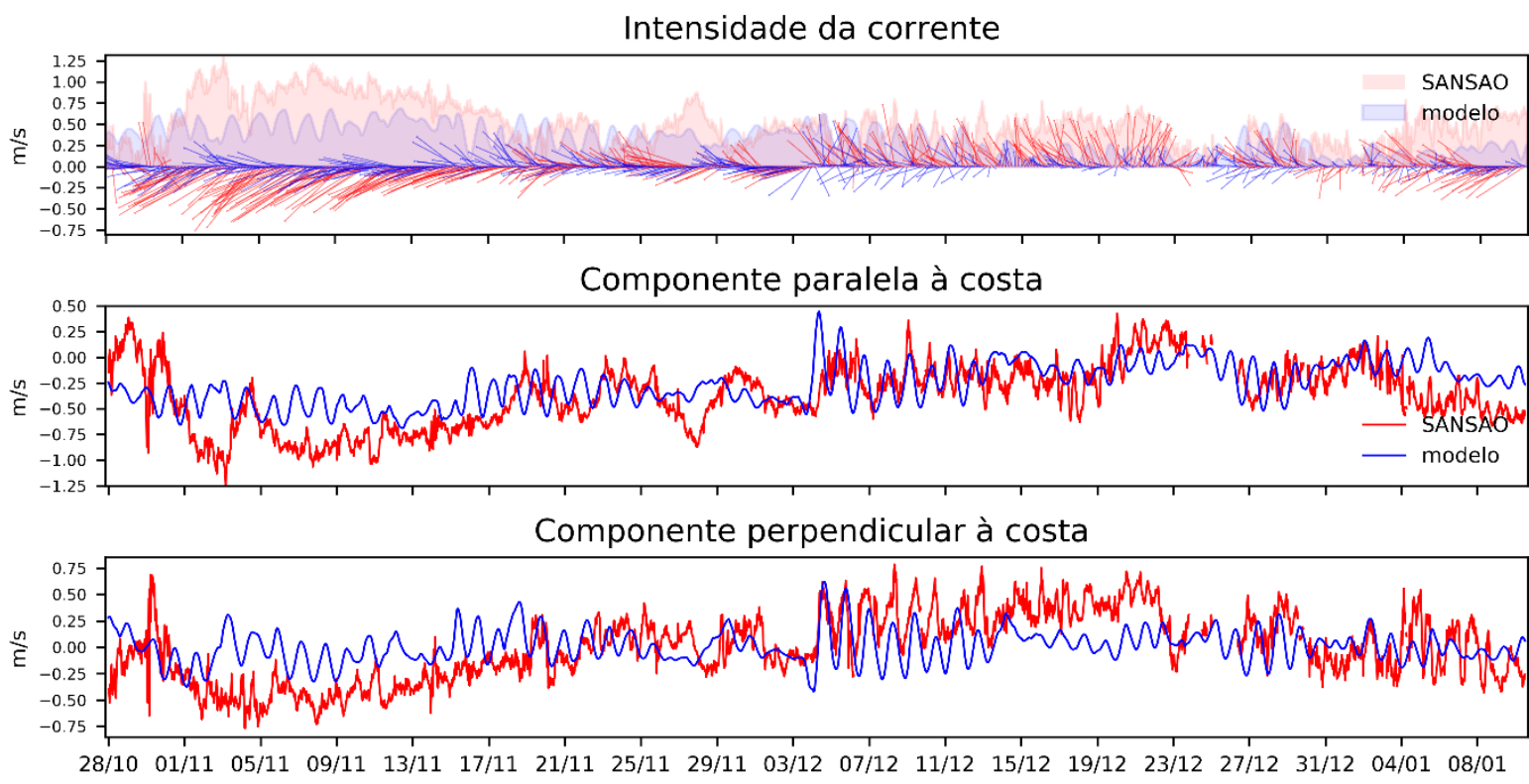

Figura 16 Dados modelo hidrodinâmico comparados aos medidos in situ pela boia metaoceanográfica do projeto SANSAO localizada na latitude: $26^{\circ} 10^{\prime}$ 59,4" S longitude: $45^{\circ} 5$ 8.16" O para o período de 28/10/2016 a 10/01/2016

Tabela 9 - Validação do modelo ECOM

\begin{tabular}{llll}
\hline $\mathrm{n}=1800$ & $\mathrm{RMSE}(\mathrm{m} / \mathrm{s})$ & Skill Refinado & Skill \\
\hline $\begin{array}{l}\text { Componente } \\
\text { paralela }\end{array}$ & 0,22 & 0,58 & 0,70 \\
$\begin{array}{l}\text { Componente } \\
\text { perpendicular }\end{array}$ & 0,24 & 0,53 & 0,47 \\
$\begin{array}{l}\text { Validação do modelo ECOM com os dados do projeto SANSAO para o período de 28/10/2016 a } \\
\text { 10/01/2016, com um número (n) amostral de 1800. }\end{array}$
\end{tabular}

Moraes (2016) validou o modelo ECOM na plataforma continental utilizando a mesma grade deste trabalho com dados dos projetos ECOSAN e DEPROAS. O autor validou o modelo 
na região entre Santos e São Sebastião, no inverno, no período de 28 de junho de 2005 a 28 de julho de 2005, na isóbata de 20 m (ECOSAN), obtendo o valor de skill (Willmott, 1981) de 0,74 para componente paralela e 0,25 para a componente perpendicular. Na região ao largo de Ubatuba, durante o verão, no período de 11 de dezembro de 2001 a 10 de janeiro de 2002, na isóbata de $50 \mathrm{~m}$ (DEPROAS) o autor encontrou valores de skill de 0,56 e 0,45 para as componentes paralelas e perpendiculares, respectivamente. Na região ao largo de Santos, no verão, para o período de 06 de janeiro de 2006 a 05 de fevereiro de 2007, na isóbata de 100m (ECOSAN), Moraes (2016) encontrou os valores de skill de 0,70 e 0,36 para as componentes paralelas e perpendiculares.

\subsubsection{Massas de água e Corrente do Brasil}

Para mostrar as massas de água e a estrutura vertical da CB, foi realizada uma seção vertical no transecto representada pela Figura 16, na mesma data da figura. A Figura 17 mostra a seção vertical de temperatura com a devida classificação das massas de água descrita no item 1.1.5. Conforme a descrição de Silveira (2006), a AT situa-se até aproximadamente $100 \mathrm{~m}$, e a ACAS abaixo da AT até aproximadamente $500 \mathrm{~m}$.

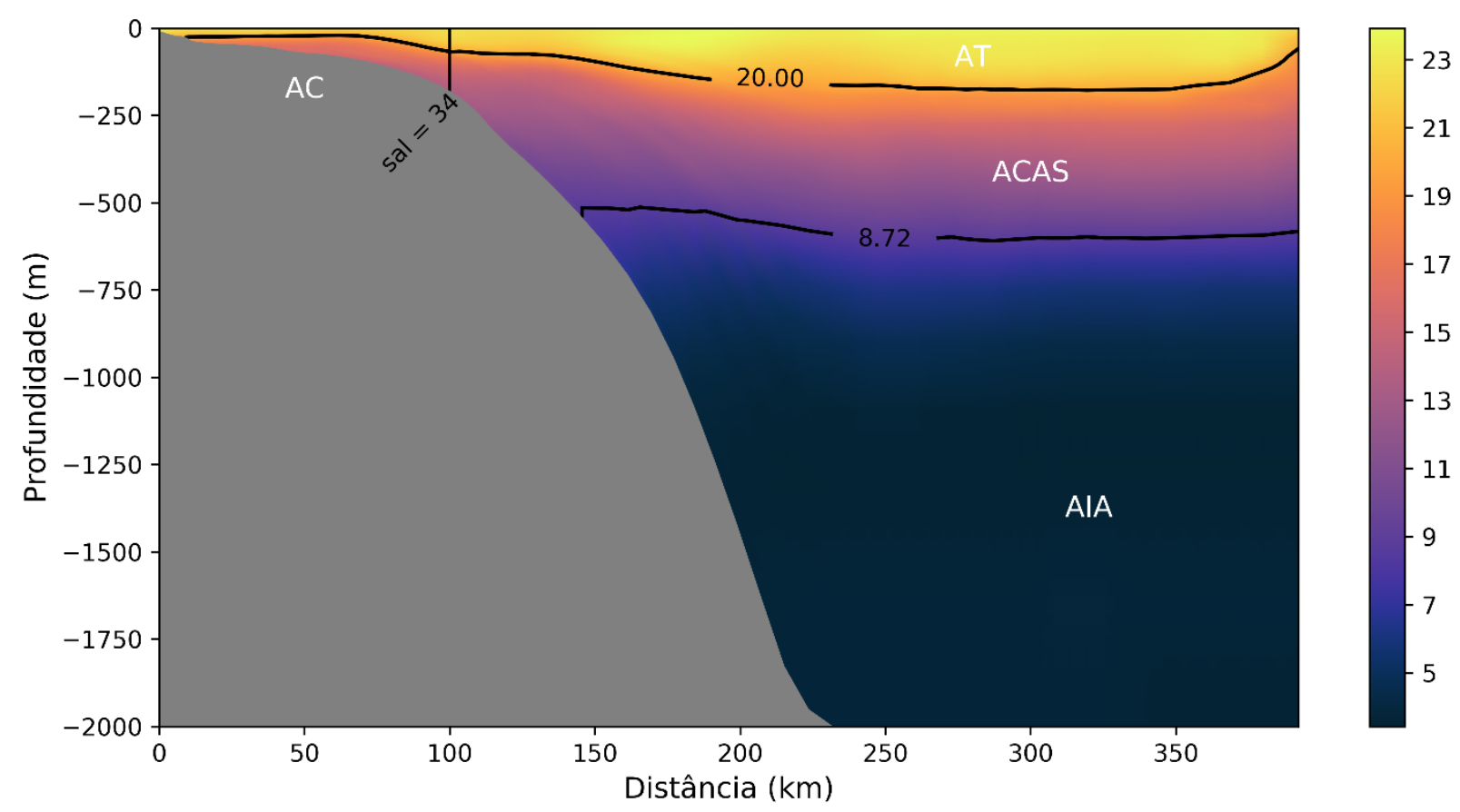

Figura 17 Massas de água na Bacia de Santos definidas pela temperatura (modelo ECOM, data:28/10 - 00:30) 
O campo de velocidade no núcleo da $\mathrm{CB}$ apresentou velocidades de 0,45 m/s (Figura 18), conforme descrito por Silveira (2006). A profundidade limite da CB corrobora com o trabalho de Souza (2000) que encontrou indícios da Corrente do Brasil ao largo de Santos até a profundidade de $700 \mathrm{~m}$.

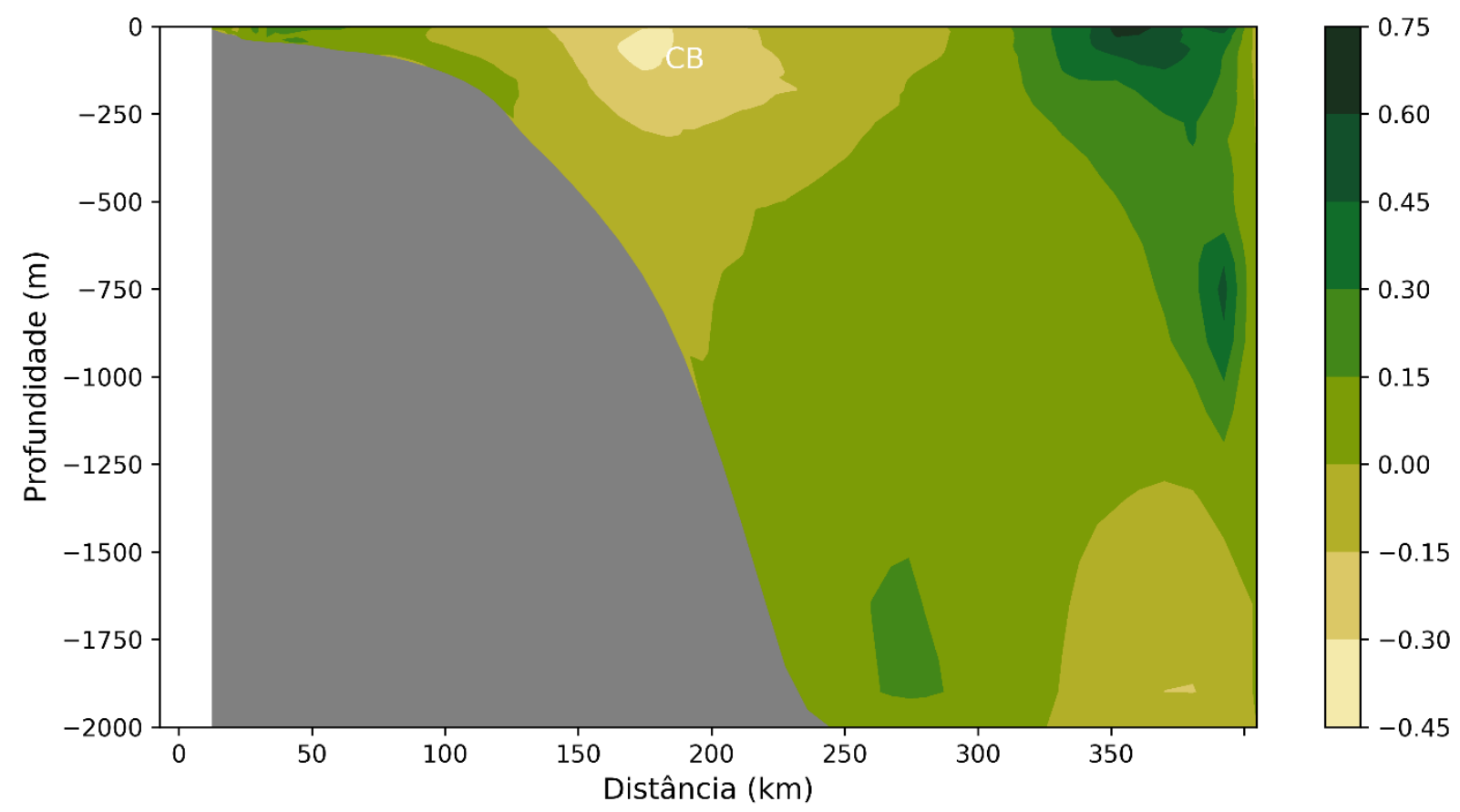

Figura 18 Campos de velocidade da Corrente do Brasil (modelo ECOM, data:28/10 - 00:30).

\subsubsection{Validação do modelo de ondas (CMEMS)}

Os dados do modelo de ondas fornecido pelo CMEMS mostraram-se bastante precisos (Figura 19) tanto na altura de onda média como na direção de onda, com valores de RMSE de $0,28 \mathrm{~m} \mathrm{e} 22,86^{\circ}$, respectivamente (Tabela 10 ). 

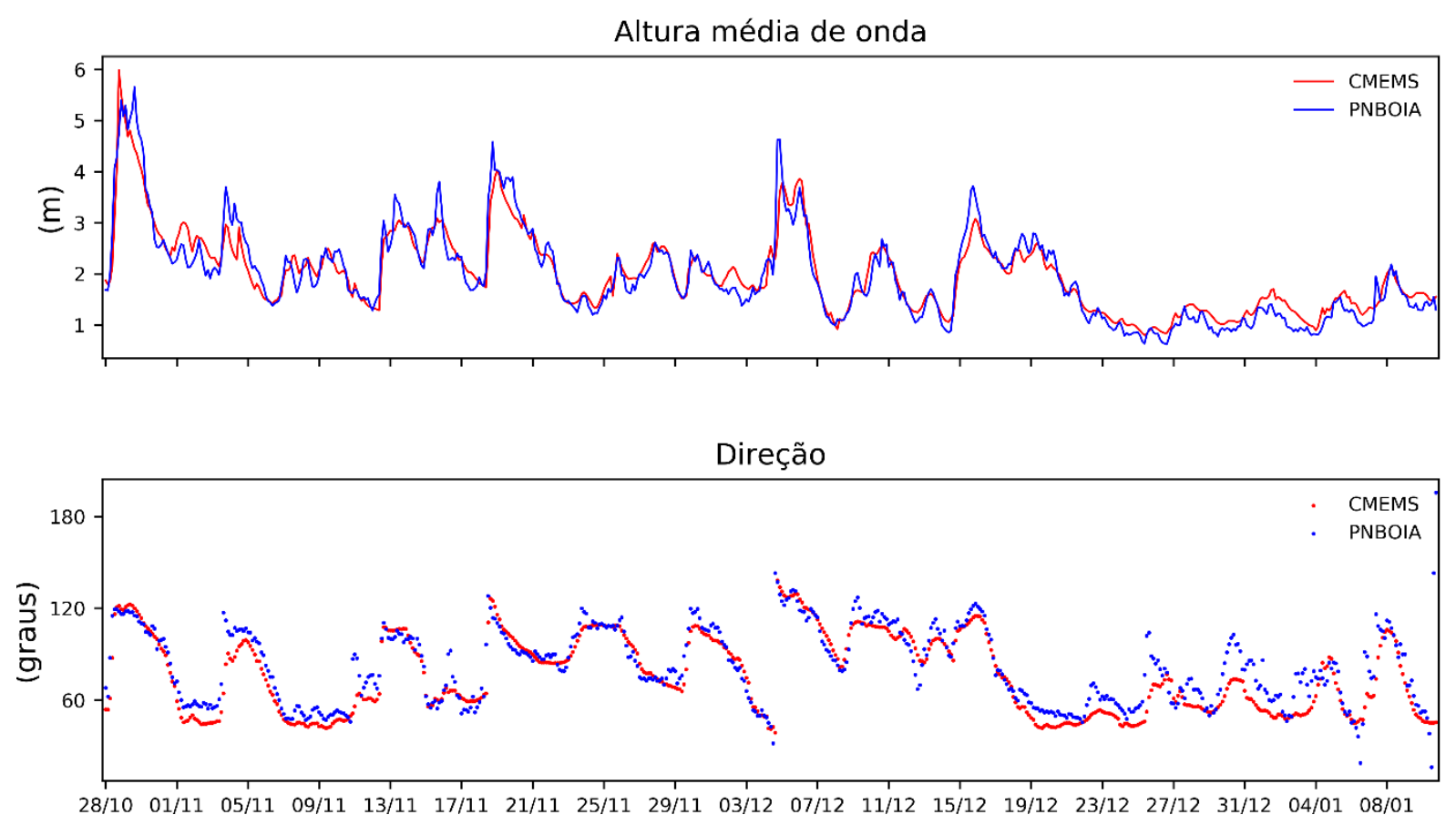

Figura 19 Dados de ondas do CMEMS comparados aos medidos in situ pela boia metaoceanográfica do programa PNBOIA localizada na latitude: $26^{\circ} 10^{\prime}$ 59,4" S longitude: $45^{\circ} 5$ 8.16" O.

Pegorelli et al. (2018) avaliou os dados do modelo operacional WAVEWATCH III (Tolman,2009), no período de abril de 2011 a junho de 2015, com os dados da mesma boia de Santos, encontrado o valor de RMSE de 0,51 para a altura de onda médio. Assim, os dados de altura de onda médio do CMEMS apresentaram uma média de erro $45 \%$ menor em relação ao modelo WAVEWATCH III.

Tabela 10 - Validação dos dados de ondas (CMEMS)

\begin{tabular}{llll}
\hline $\mathrm{n}=599$ & RMSE & Skill Refinado & Skill \\
\hline Altura de onda média & $0,28 \mathrm{~m}$ & 0,85 & 0,97 \\
Direção de onda média & $22,86^{\circ}$ & 0,79 & 0,92 \\
\hline
\end{tabular}

CMEMS, Copernicus Marine Environmental Monitoring Service, CMEMS; n, número amostral.

\subsection{Método de Kwon}

Para avaliar a performance do navio Aframax pelo método de Kwon (2008), foram medidas as reduções de velocidade nas quatros variações da direção aceitas pelo método nas condições de mar na escala de Beaufort de 0 a 7, conforme mostra a Figura 20. 

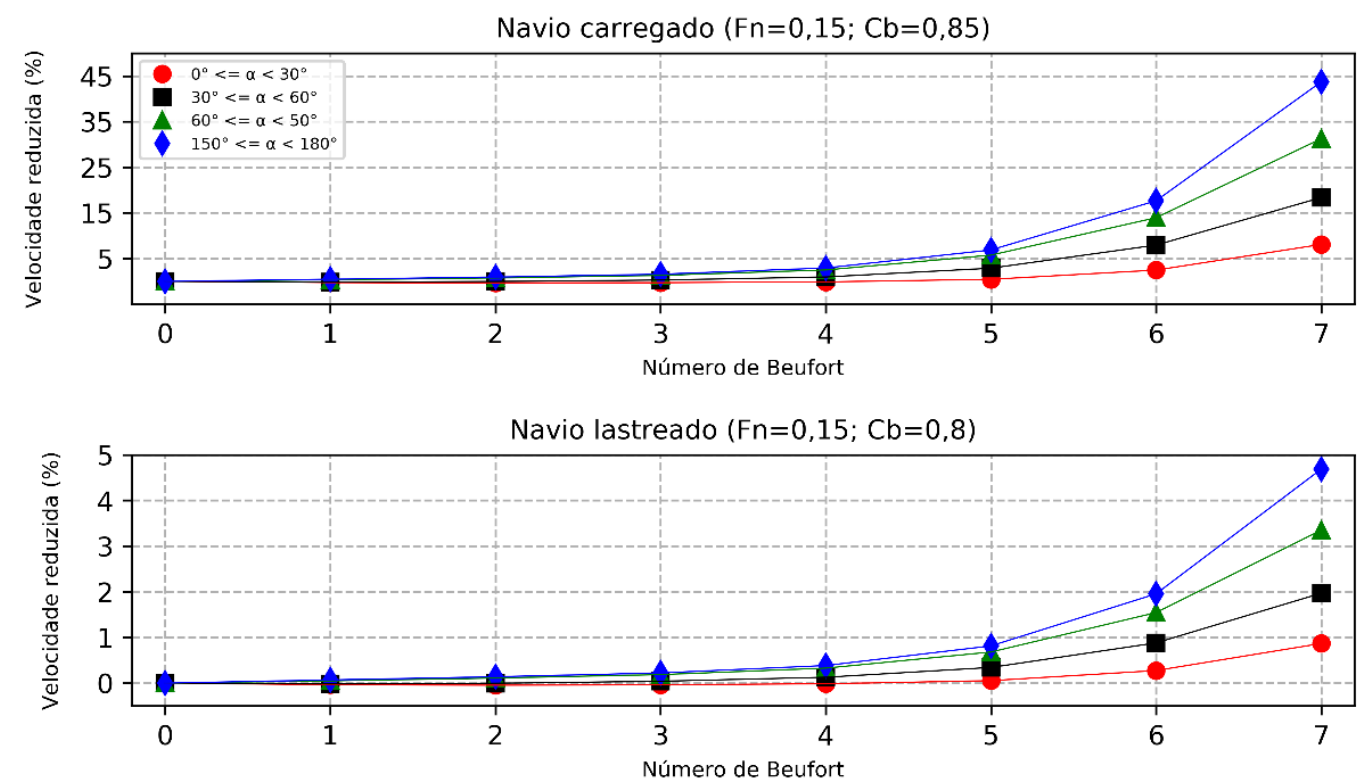

Figura 20. Perda de velocidade do navio devido as condições do tempo e diferentes ângulos de incidência de ondas e ventos.

Em condições de navio lastreado, os resultados mostram uma baixa perda de velocidade, chegando ao máximo em 5\% com vento e ondas frontais para o número de Beaufort 7, o que representa um mar revolto com ondas de até $4,5 \mathrm{~m}$. Já para o navio carregado, em estado de mar 7, há uma enorme perda de velocidade em torno de $45 \%$ para ventos frontais.

\subsection{Variação do tempo de navegação devido as condições do meio}

Para estimar a variação do tempo de navegação na rota TF e FT entre o Terminal de Angra dos Reis (TAR) e o FPSO Cidade de São Paulo (FSP SP), o modelo de navegação descrito pelo item 3.3 foi utilizado no espaço de tempo a cada 60 minutos, o que representa a frequência de partida dos navios. Com isso, é calculado o tempo de navegação de cada viagem, representadas pelo horário de partida do navio. Os resultados de variação do tempo de navegação foram calculados pela seguinte relação:

$$
\operatorname{VTN}_{h} \%=\frac{\Delta t_{h}}{\Delta t_{13,5}}-1
$$

sendo, $\Delta t_{h}$ o tempo de navegação para a partida no horário h, $\Delta t_{13,5}$ o tempo de navegação para a velocidade nominal de 13,5 nós. 


\subsubsection{Variação da velocidade do navio devido somente à deriva por correntes}

A variação do tempo de navegação devido à deriva pelas correntes na rota $\mathrm{TF}$, em um trajeto percorrido do Terminal de Angra dos Reis até o FPSO Cidade de São Paulo, é mostrada pela Figura 21. A maior aumento do tempo de navegação foi de $7,4 \%$ no dia 18 de novembro, e a maior diminuição foi de $5,4 \%$ no dia 2 de novembro. A média do tempo de navegação foi de $-0.2 \%$ e desvio padrão de $1.8 \%$.

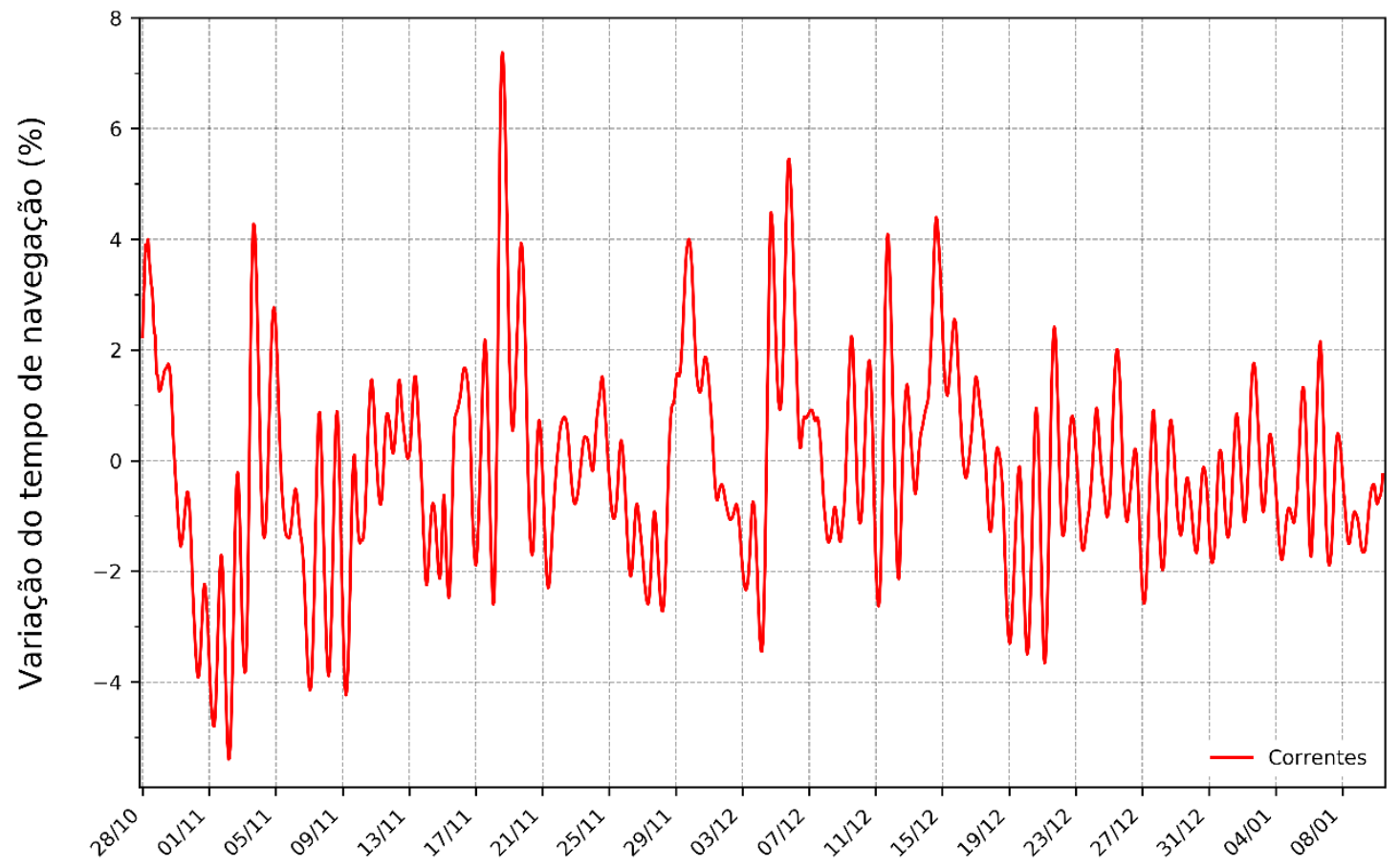

Figura 21 Variação do tempo de navegação na rota Terminal de Angra dos Reis - FPSO Cidade de São Paulo. A variação é determinada somente pela deriva por correntes. 
Na Figura 22, no trajeto oposto (FT) ao da Figura 21, ocorre o efeito oposto das correntes, com pequenas variações nos resultados causadas pela diferença do momento em que o navio passa em um mesmo local. O maior aumento do tempo de navegação foi de $6,3 \%$ na partida do dia 18 de novembro, e a maior diminuição foi de 6,1\% na partida das do dia 18 de novembro. A média do tempo de navegação foi de $0,5 \%$ e desvio padrão de $1,8 \%$

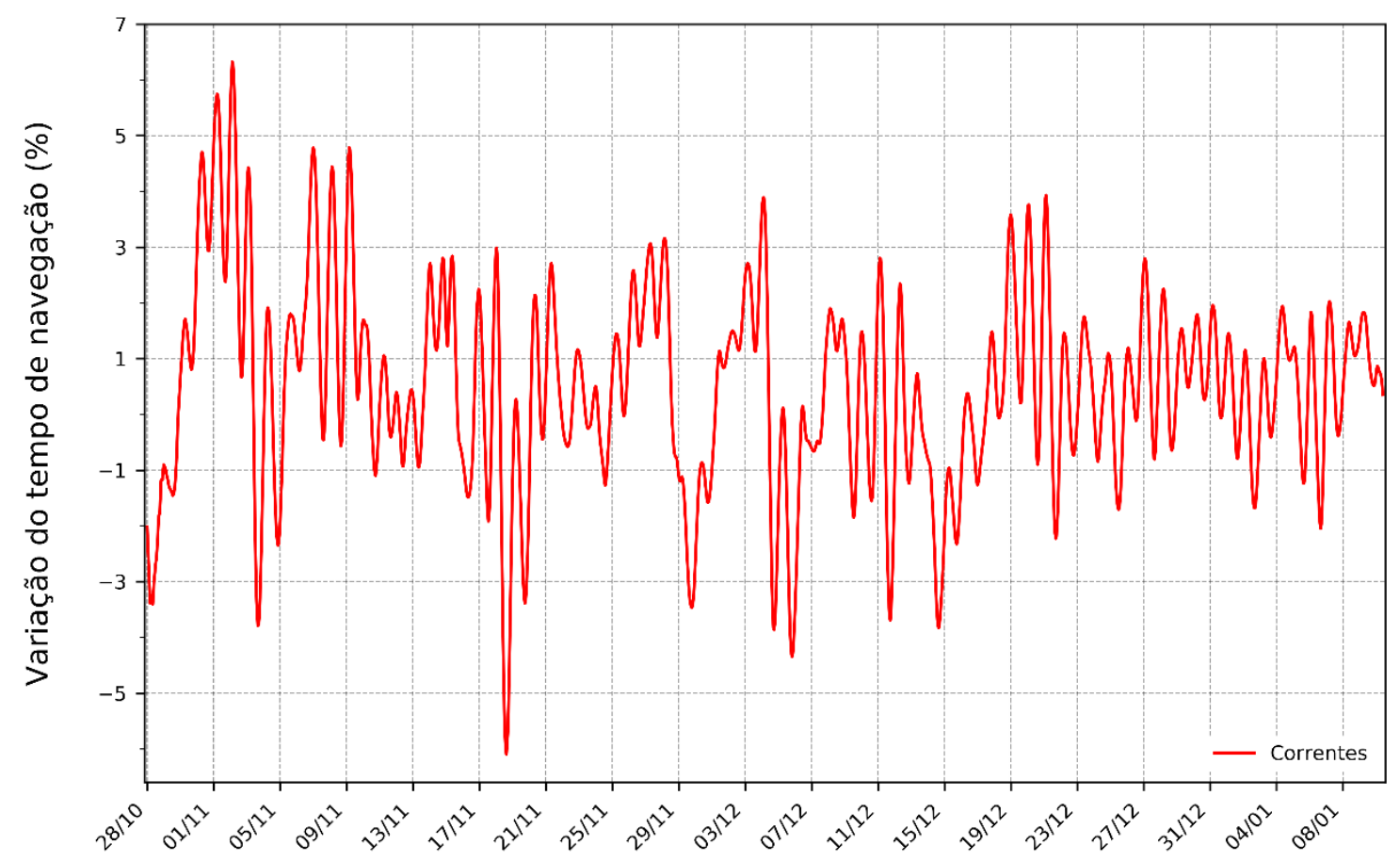

Figura 22 Variação do tempo de navegação na rota FPSO Cidade de São Paulo - Terminal de Angra dos Reis. A variação é determinada somente pela deriva por correntes. 
$\mathrm{Na}$ rota $\mathrm{TF}$, com o navio lastreado, o aumento máximo do tempo de navegação foi de 9,1\% para um estado de mar 7, com ondas de 4 a 5,5 metros, ocorrido na partida do dia 28 de novembro. A média do tempo de navegação foi de 1,2\% e desvio padrão de 1,4\%.

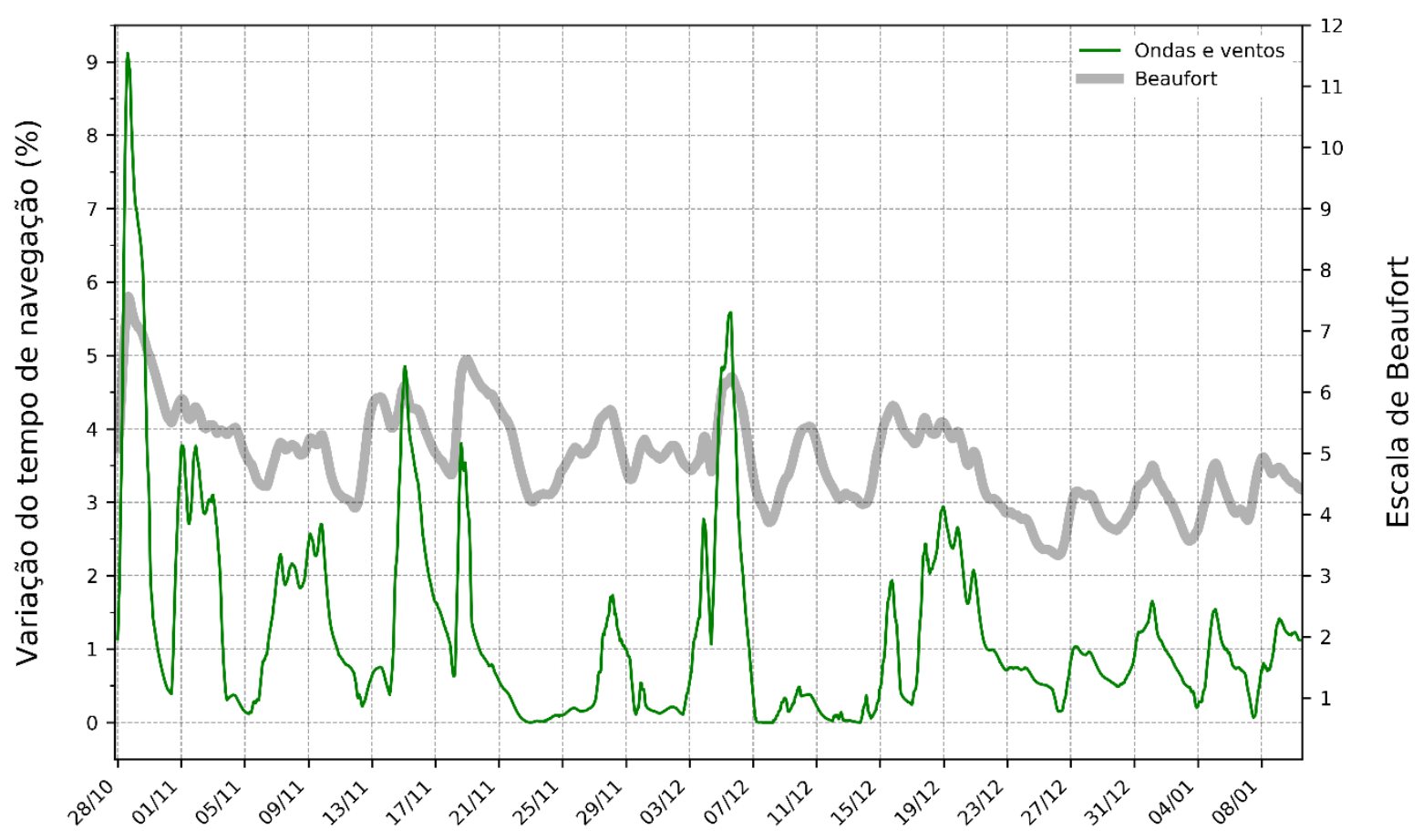

Figura 23 Variação do tempo de navegação na rota Terminal de Angra dos Reis- FPSO Cidade de São Paulo com o navio lastreado, e número de Beaufort. A variação é determinada somente pela resistência adicionada por ondas e ventos. 
Já para o navio carregado, o aumento do tempo de navegação é bem significante sendo de $76 \%$ na partida do dia 28 de novembro para um mar em torno de 8 . Segundo Prpic-Orsic e Faltisen (2012), em condições de mar a partir de 6 ou 7, a redução de velocidade devida às condições do tempo já não são tão importantes, pois ela começa a ser voluntária, ou seja, é dada por comandos do oficial do navio para dar conforto as pessoas a bordo, ou para mitigar danos ao navio. A média foi de $9,2 \%$ e o desvio padrão de $9,6 \%$

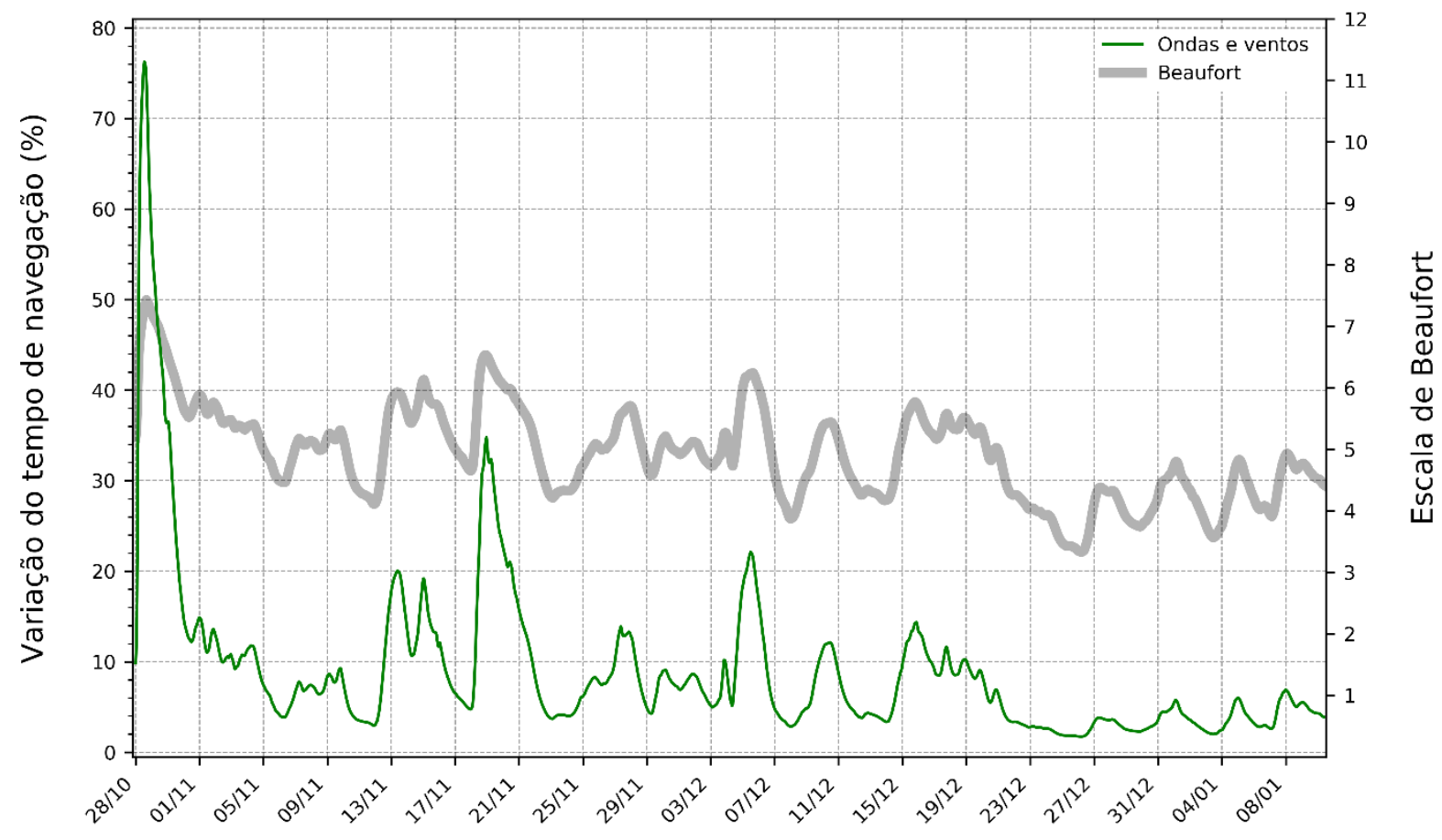

Figura 24 Variação do tempo de navegação na rota FPSO Cidade de São Paulo - Terminal de Angra dos Reis- com o navio totalmente carregado, e número de Beaufort. A variação é determinada somente pela resistência adicionada por ondas e ventos. 
6.3.3 Variação do tempo de navegação do navio devido à resistência adicionada por ondas $e$ ventos e deriva por correntes

Lembramos que, como ilustrado na Figura 7, a velocidade de navegação é primeiramente estimada pelo pela redução de velocidade devido as ondas e ventos, e a partir desta, é estimada à deriva por correntes. Assim, os tempos de navegação foram calculados separadamente para cada fator, e o total sendo a soma dos fatores.

Na rota TF (Figura 25), o maior aumento do tempo de navegação foi em 28 de outubro no valor de $12,3 \%$. Desse valor, $9,0 \%$ foi devido redução da velocidade por ondas e ventos e $3,3 \%$ pela deriva por correntes. O tempo de navegação mínimo dos fatores totais foi de $-3,5 \%$, no qual, as correntes foram responsáveis por uma redução de $4 \%$, e as ondas e ventos por um acréscimo de $0,5 \%$. O tempo de navegação médio teve um aumento de $0,98 \%$, sendo $-1,19 \%$ devido as ondas e ventos, e $0,22 \%$ devido as correntes. O desvio padrão foi de 2,23\%.

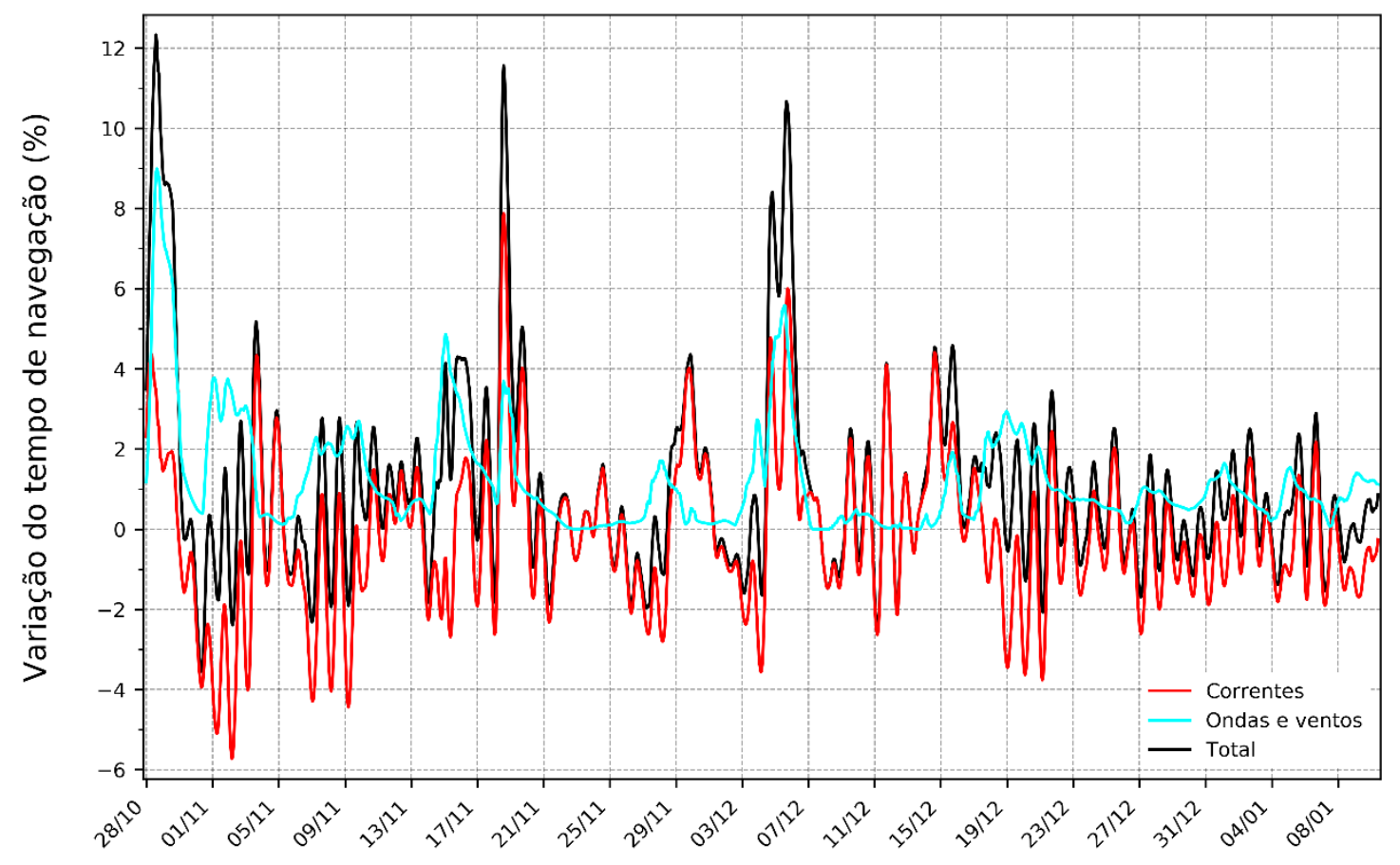

Figura 25 Variação do tempo de navegação na rota FPSO Cidade de São Paulo - Terminal Angra dos Reis com o navio lastreado. A variação do tempo de navegação é determinada resistência adicionada por ondas e ventos e deriva por correntes. $O$ valor total é determinado pela soma dos fatores corrente, ondas e ventos. 
Na rota FT (Figura 26), com o navio carregado, o aumento do tempo de navegação máximo foi de $77,5 \%$ no estado de mar em torno de 8 . Como dito anteriormente, neste caso a redução de velocidade é voluntária, então, mesmo com um tempo de navegação aumentado significantemente a estimativa deixa de ser precisa.

A média do tempo de navegação teve uma redução de 8,34 , sendo que $7,85 \%$ (94,12\% do total) de redução foi causado por ondas e ventos, e apenas $0,52 \%$ (5,88\% do total) pelas correntes. O desvio padrão foi de $6,32 \%$.

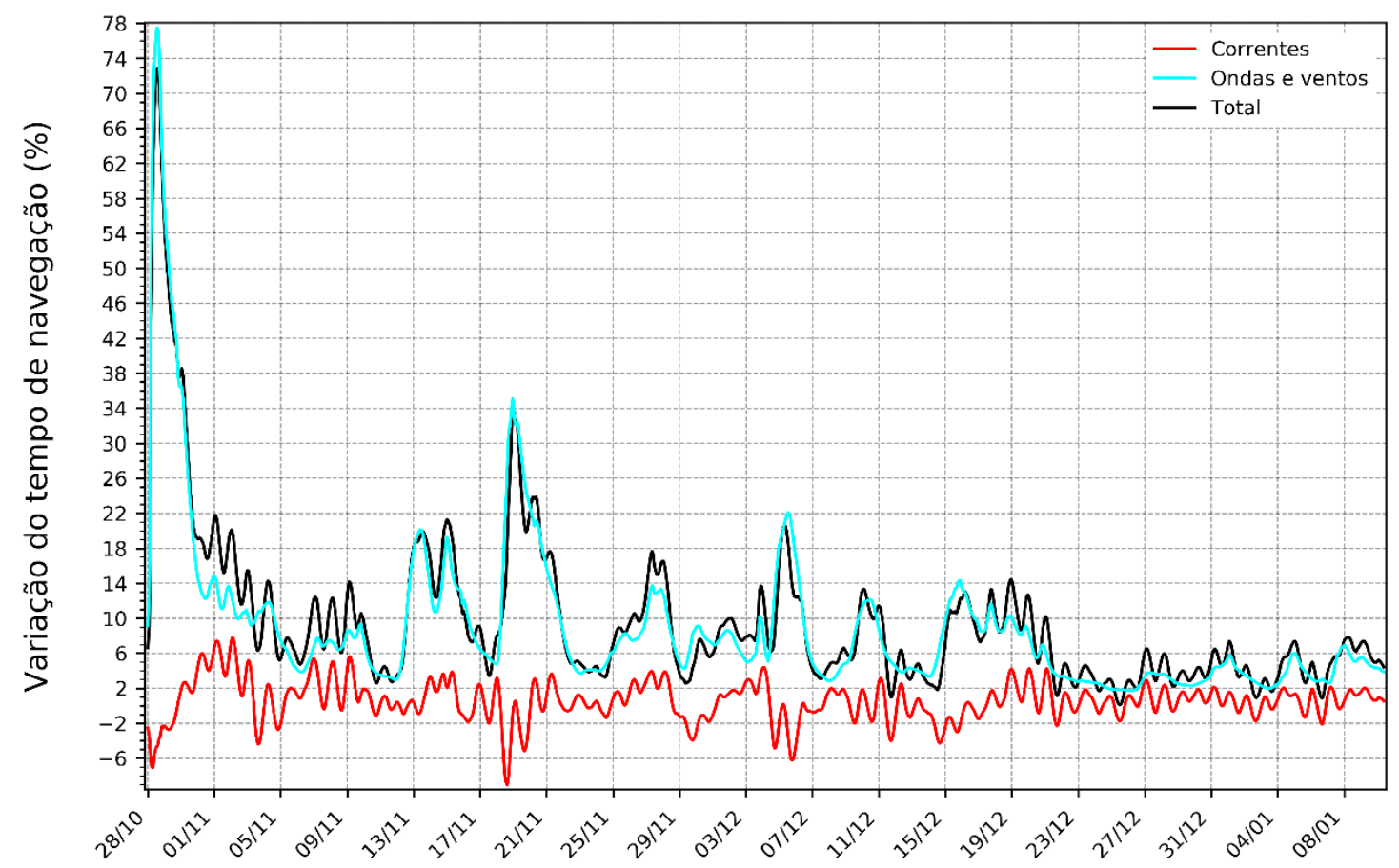

Figura 26 Variação do tempo de navegação na rota Terminal Angra dos Reis - FPSO Cidade de São Paulo com o navio carregado. A variação é determinada pela resistência adicionada por ondas e ventos e deriva por correntes. O valor total é determinado pela soma dos fatores corrente, ondas e ventos.

\subsubsection{Resumo dos resultados}

Para resumir, os resultados estão apresentados considerando os fatores de redução de velocidade pela adição de resistência por ondas e ventos e deriva por correntes, para a rota TF(Tabela 11) e FT(Tabela 12), respectivamente. 
Tabela 11 - Rota: Terminal de Angra dos Reis - FPSO Cidade de São Paulo (lastreado)

\begin{tabular}{lllll}
\hline Média $(\%)$ & Desvio padrão (\%) & Máximo $(\%)$ & Mínimo $(\%)$ & Fator influente \\
\hline$-0,19$ & 1,87 & 7,88 & $-5,73$ & Correntes \\
1,22 & 1,36 & 8,99 & 0,00 & Ondas e ventos \\
1,04 & 2,37 & 12,32 & $-5,73$ & Correntes, ondas e ventos
\end{tabular}

Resultados estatísticas da variação do tempo de navegação (\%) correspondente ao fator influente.

Tabela 12 - Rota: FPSO Cidade de São Paulo - Terminal de Angra dos Reis (totalmente carregado)

\begin{tabular}{lllll}
\hline Média (\%) & Desvio padrão (\%) & Máximo (\%) & Mínimo (\%) & Fator influente \\
\hline 0,58 & 2,25 & 7,76 & $-9,03$ & Correntes \\
9,16 & 9,60 & 77,47 & 1,73 & Ondas e ventos \\
9,73 & 9,29 & 72,87 & $-0,11$ & Correntes, ondas e ventos \\
\hline
\end{tabular}

Resultados estatísticas da variação do tempo de navegação (\%) correspondente ao fator influente. 


\section{Discussões}

\subsection{Simulação hidrodinâmica (ECOM)}

No Projeto Azul, Rocha et. al (2016) modelaram a região da Bacia de Santos utilizando o modelo ROMS com aplicação de assimilação de dados 4D-Var (I4D-Var) durante o período de 1 de março de 2013 a 1 de março de 2014. Os dados assimilados na superfície foram de AVHRR (Advanced Very High Resolution Radiometer), com dados de temperatura, salinidade e nível do mar. Abaixo da superfície, foram utilizados dados de temperatura e salinidade medidos por glider, derivadores e perfis de CTD (Conductivity Temperature Depth). Estes autores mediram o RMSE entre as correntes meridionais e zonais do modelo e dos dados de 28 derivadores dispersos na região. Os valores obtidos foram de $0,24 \mathrm{~m} / \mathrm{s}$ para a corrente zonal e $0,23 \mathrm{~m} / \mathrm{s}$ para a corrente meridional, sem a assimilação de dados para o modelo. Aplicando a assimilação de dados 4D-Var, o autor obteve uma melhora nos resultados, encontrando valores de RMSE de $0,21 \mathrm{~m} / \mathrm{s}$ para a corrente zonal e $0,20 \mathrm{~m} / \mathrm{s}$ para a corrente meridional.

Neste trabalho, os valores encontrados de RMSE foram bastantes similares aos destes autores, para as componentes paralela e perpendicular à costa, obtendo-se 0,22 e $0,24 \mathrm{~m} / \mathrm{s}$, respectivamente. Para motivo de comparação, entre as componentes zonais e meridionais, os valores obtidos foram de $0,17 \mathrm{~m} / \mathrm{s}$ e $0,27 \mathrm{~m} / \mathrm{s}$, respectivamente.

Esta boa concordância entre os resultados simulados e observados para o oceano aberto, assim como outras validações obtidas para a plataforma continental (Moraes, 2016), permitiram identificar no modelo 3 padrões distintos de circulação na superfície (Figura 27). O primeiro, sobre a plataforma continental (PC), corrobora o que já foi observado em diversos outros trabalhos (Castro, 1996; Prevelato, 2014; Coelho, 2008), onde, na ausência de sistemas frontais, as correntes médias associadas à Alta Subtropical do Atlântico Sul (ASAS) fluem para sul, e, durante a passagem de frentes frias ocorre a inversão destas corrente para norte, girando anticiclonicamente. Um segundo padrão de circulação, associado à Corrente do Brasil (CB), mostrando fluxos intensos e bem definido fluindo ao largo da margem continental (Silveira et al., 2000), fluindo para sul-sudoeste, com largura entre 100 - $120 \mathrm{~km}$ (Silveira et al., 2008). O terceiro, denominado, aqui, de anticiclone, corrobora com os trabalhos de Mattos (2006), Tsuchiya (1985) e Vianna e Menezes (2005), no qual, na região próxima a $27^{\circ} \mathrm{S}$, o fluxo da CB se separa do contorno oeste e recircula, caracterizando a origem da Contra-corrente Subtropical do Atlântico Sul (CCST-AS), e que apesar da descontinuidade com a CB a célula anticiclônica se mantém em $27^{\circ}$ permanentemente. 

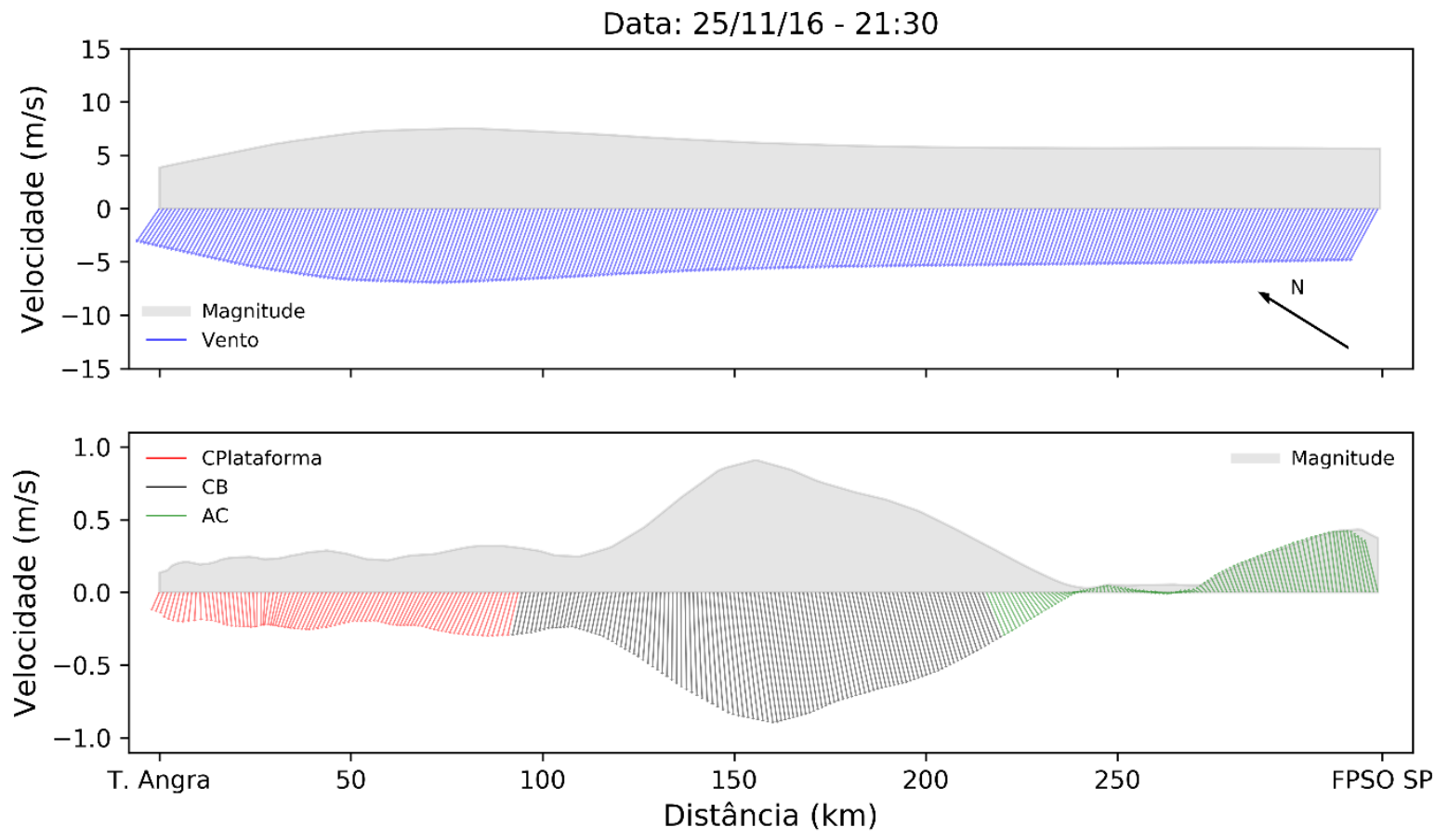

Figura 27 Cenário típico, com ventos de nordeste, na rota Terminal de Angra dos Reis - FPSO Cidade de São Paulo, mostrando os padrões distintos de circulação entre as Correntes da Plataforma Continental (CPlataforma), Corrente do Brasil $(C B)$, e a circulação anticiclônica (AC). Os vetores representam a velocidade e a direção dos ventos (figura superior) e das correntes (figura inferior).

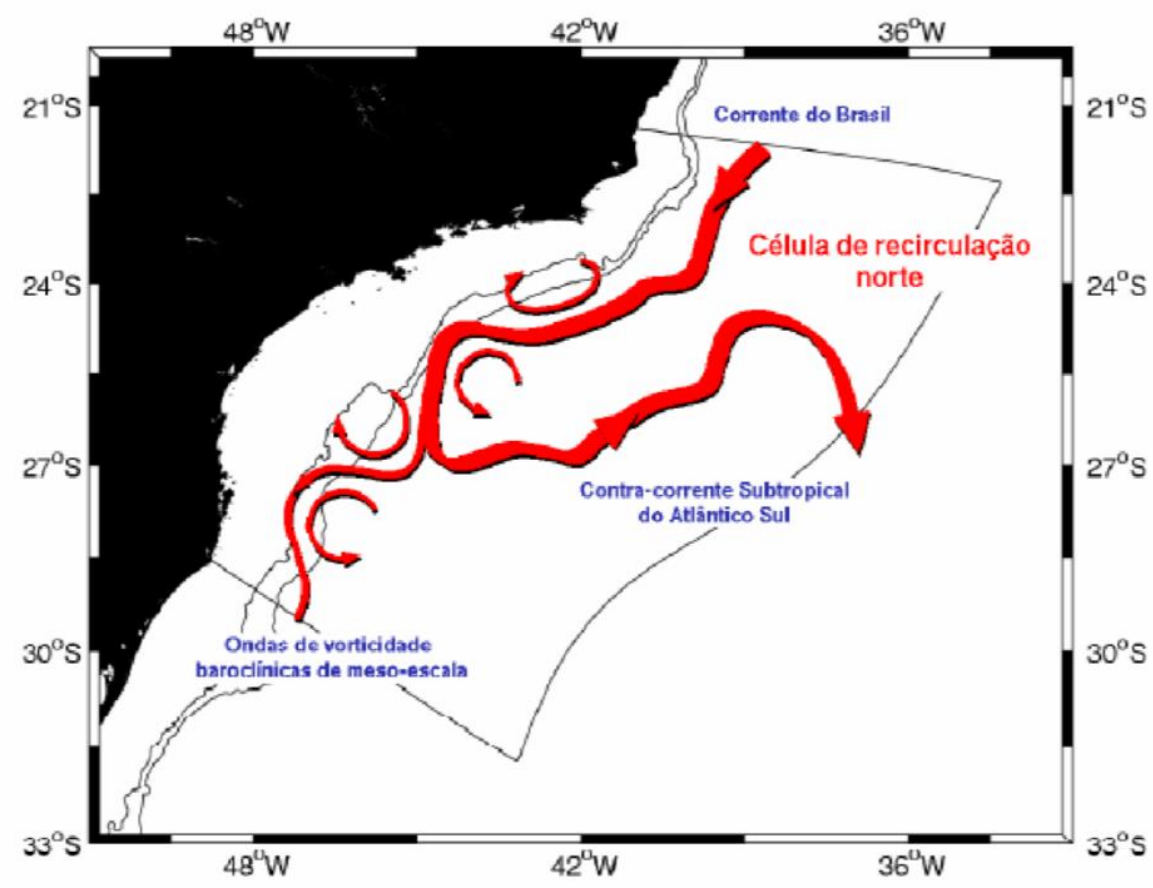

Figura 28 Representação de Mattos (2006) da separação parcial da CB para dar origem à CCST-AS.

Para demonstrar os padrões de corrente de circulação na superfície na rota $\mathrm{TF}$, as correntes e os ventos foram rotacionado em $67^{\circ}$, no sentido anti-horário. Foram, então, observadas duas situações distintas. Na primeira, com ventos predominantes de nordeste, temos 
a Corrente na Plataforma (CP) em direção sul/sudoeste, assim como a CB, e o AC com rotação anti-horária com fluxos para sul/sudoeste do lado esquerdo, e fluxos norte/nordeste do lado direito (Figura 27). Em casos de ventos mais intensos na mesma direção como ventos na ordem de $10 \mathrm{~m} / \mathrm{s}$ ocorre a intensificação das correntes para sudoeste (Figura 29).

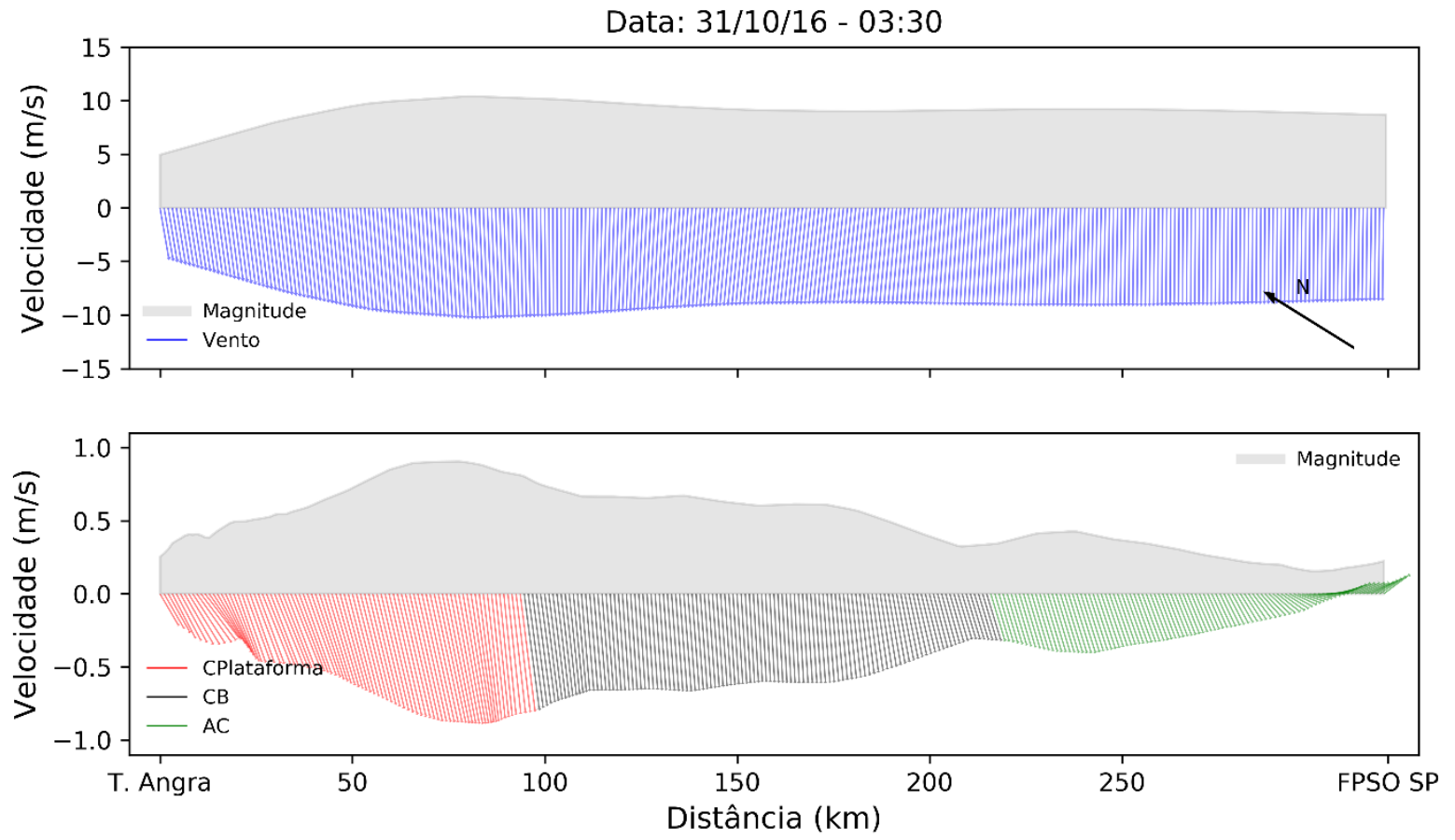

Figura 29 Cenário com ventos de alta intensidade de nordeste na rota Terminal de Angra dos Reis - FPSO Cidade de São Paulo, mostrando os padrões distintos de circulação entre as Correntes da Plataforma Continental (CPlataforma), Corrente do Brasil (CB), e a circulação anticiclônica (AC). Os vetores representam a velocidade e a direção dos ventos (figura superior) e das correntes (figura inferior).

Em um segundo cenário, que ocorre com a inversão dos ventos para sudoeste, durante a ação de frentes frias e, com menor frequência, durante a passagens de ciclones. A Figura 30 mostra o momento da passagem de uma frente fria e inversão das CP. 

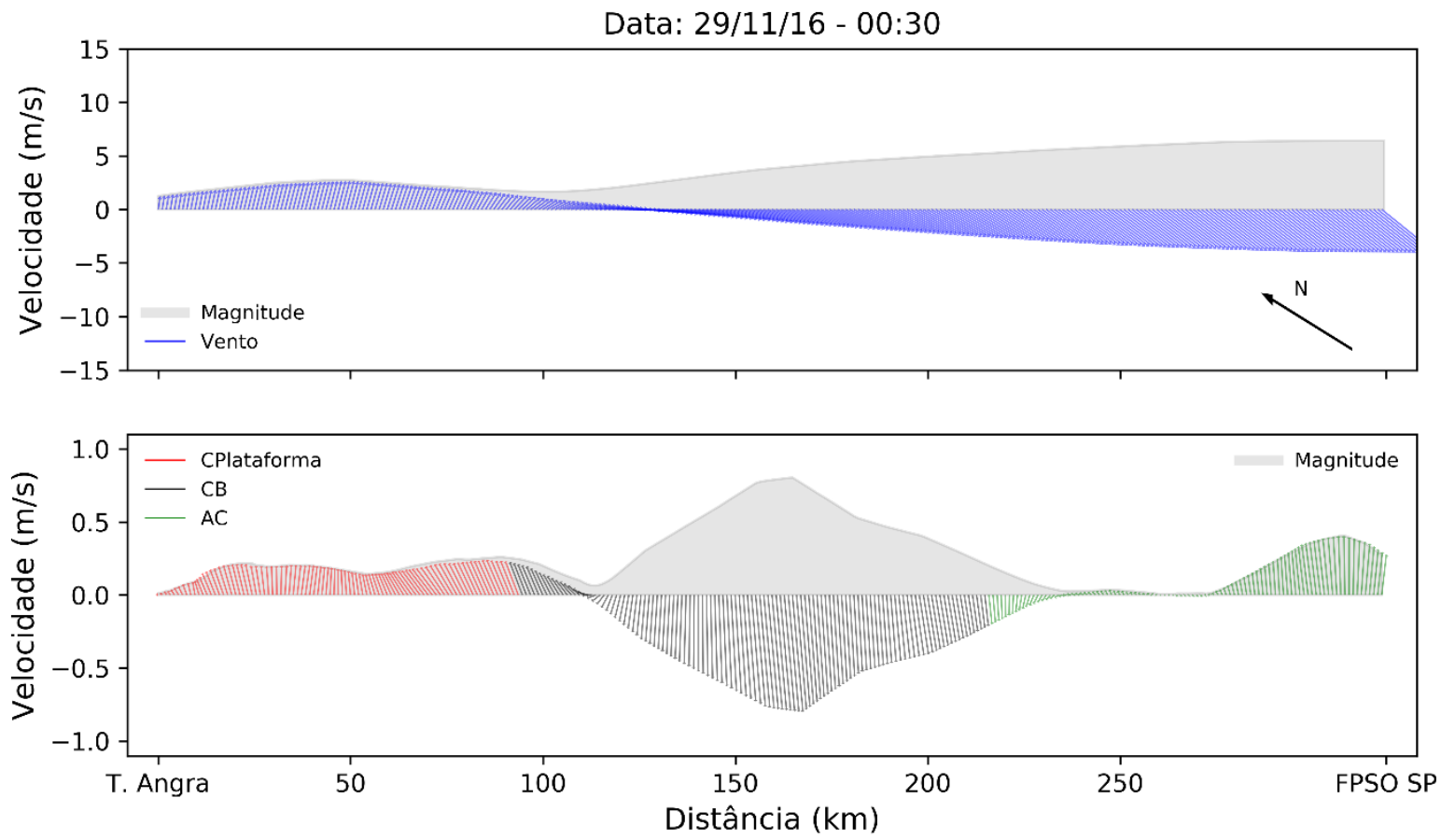

Figura 30 Cenário durante uma passagem de frente fria na rota Terminal de Angra dos Reis - FPSO Cidade de São Paulo, mostrando os padrões distintos de circulação entre as Correntes da Plataforma Continental (CPlataforma), Corrente do Brasil $(C B)$, e a circulação anticiclônica (AC). Os vetores representam a velocidade e a direção dos ventos (figura superior) e das correntes (figura inferior).

Na sequência, cerca de 14 horas após a passagem da frente, ocorreu a intensificação das correntes na PC para nordeste (Figura 31). 

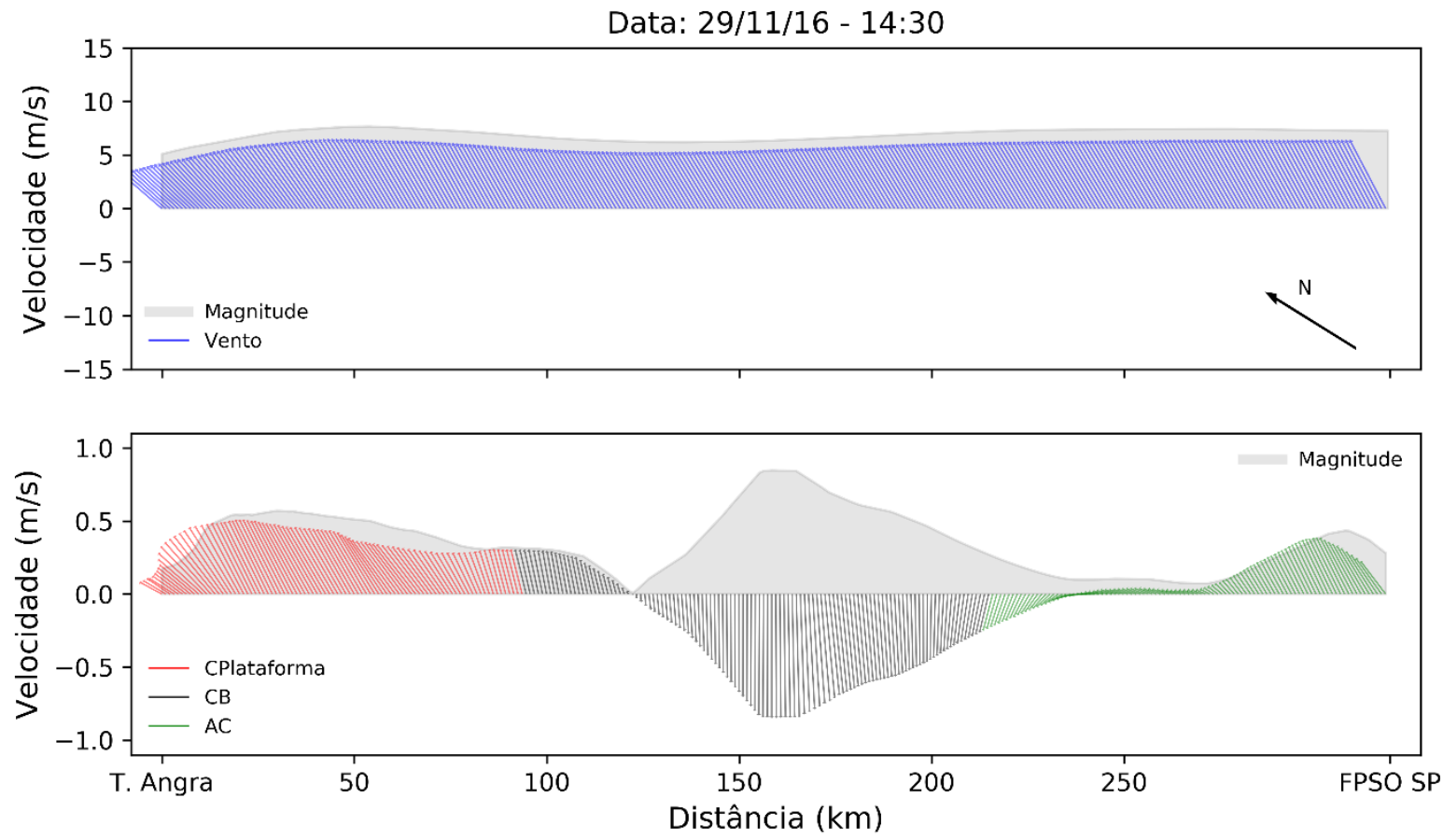

Figura 31 Cenário pós passagem de frente fria na rota Terminal de Angra dos Reis - FPSO Cidade de São Paulo, mostrando os padrões distintos de circulação entre as Correntes da Plataforma Continental (CPlataforma), Corrente do Brasil (CB), e a circulação anticiclônica $(A C)$. Os vetores representam a velocidade e a direção dos ventos (figura superior) e das correntes (figura inferior)

Em casos de ventos muito intensos de sudoeste, de ordem de $10 \mathrm{~m} / \mathrm{s}$, ocorre a intensificação das correntes na PC para nordeste e o enfraquecimento da CB (Figura 32).
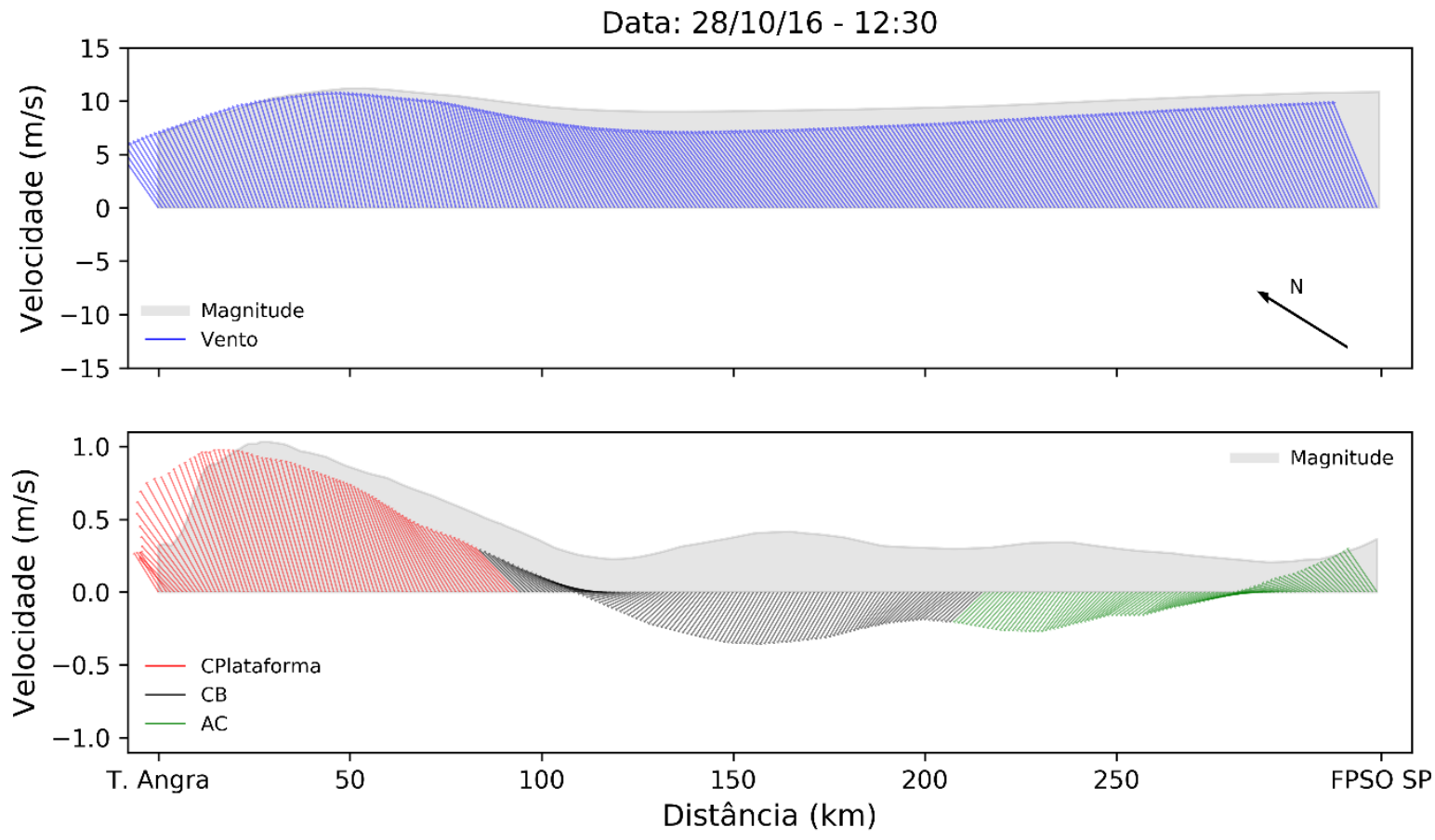

Figura 32 Cenário com ventos intensos de sudoeste na rota Terminal de Angra dos Reis - FPSO Cidade de São Paulo, mostrando os padrões distintos de circulação entre as Correntes da Plataforma Continental (CPlataforma), Corrente do Brasil $(C B)$, e a circulação anticiclônica (AC). Os vetores representam a velocidade e a direção dos ventos (figura superior) e das correntes (figura inferior). 
Para entender que padrão de correntes mais influencia no tempo de navegação, foram plotadas as Figura 33 e 34, com os vetores de velocidade da corrente e vento enfrentados pelo navio no período de maior redução e maior aumento do tempo de navegação com a influência apenas da deriva por correntes, conforme mostra a Figura 21. Ambas as figuras mostram ventos intensos, a primeira de nordeste e a segunda, de sudoeste, com valores que chegam a $15 \mathrm{~m} / \mathrm{s}$. Observa-se que os ventos intensos de nordeste inclinam as correntes das 3 regiões em direção ao FPSO, ocorrendo uma maior inclinação na plataforma mais interna e na AC, mesmo a CB, que possue um comportamente baroclínico, sofre inclinação, fazendo com que a deriva das correntes colabore na navegação em direção ao FPSO. Com ventos intensos de sudoeste conforme mostra a Figura 34, ocorre a inclinação das correntes na direção do Terminal, fazendo com que a deriva das correntes atrapalhem a navegação em direção ao FPSO. Desse modo, há fortes indícios de que o vento é o principal responsável pela variabilidade das correntes superficiais na rota $\mathrm{TF}$.
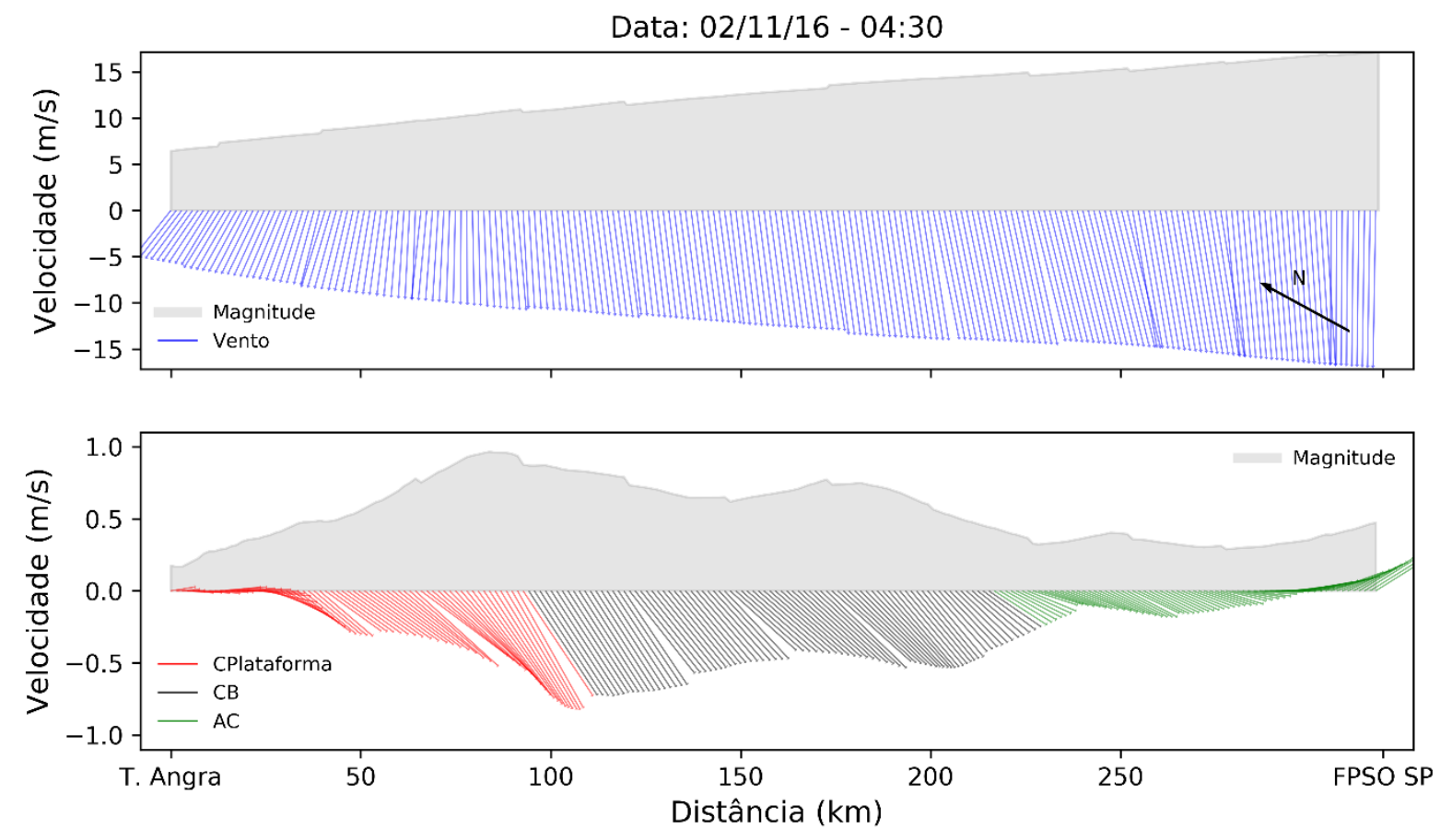

Figura 33 Correntes enfrentadas pelo navio na navegação na rota Terminal de Angra dos Reis - FPSO Cidade de São Paulo, mostrando os padrões distintos de circulação entre as Correntes da Plataforma Continental (CPlataforma), Corrente do Brasil $(C B)$, e a circulação anticiclônica (AC). Os vetores representam a velocidade e a direção dos ventos (figura superior) e das correntes (figura inferior). 
Data: $18 / 11 / 16-14: 30$
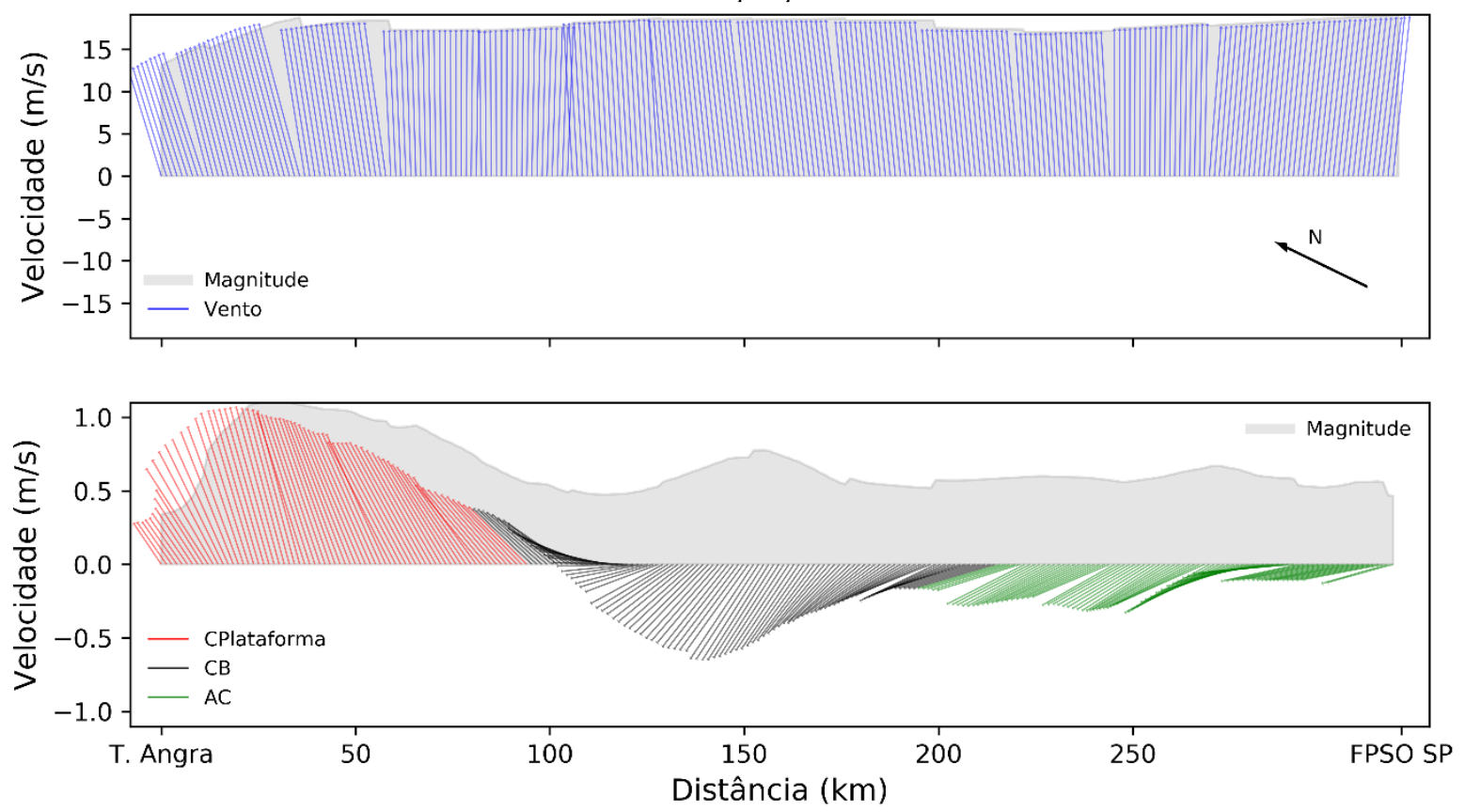

Figura 34 Correntes enfrentadas pelo navio na navegação na rota Terminal de Angra dos Reis - FPSO Cidade de São Paulo, mostrando os padrões distintos de circulação entre as Correntes da Plataforma Continental (CPlataforma), Corrente do Brasil $(C B)$, e a circulação anticiclônica (AC). Os vetores representam a velocidade e a direção dos ventos (figura superior) e das correntes (figura inferior).

Para a avaliar a influência dos ventos sobre as correntes superficiais, foram calculados os coeficientes de correlação na rota TF (Figura 35). As correlações foram calculadas entre as componentes paralela e perpendicular à costa do vento e da corrente. Foram, também, calculadas as correlações corrigidas pelo lag, que correspondem a defasagem entre duas variáveis em relação a correlação máxima. Os valores de lag, para a máxima correlação, foram de duas horas na PC e uma hora na BC, com liderança do vento. 


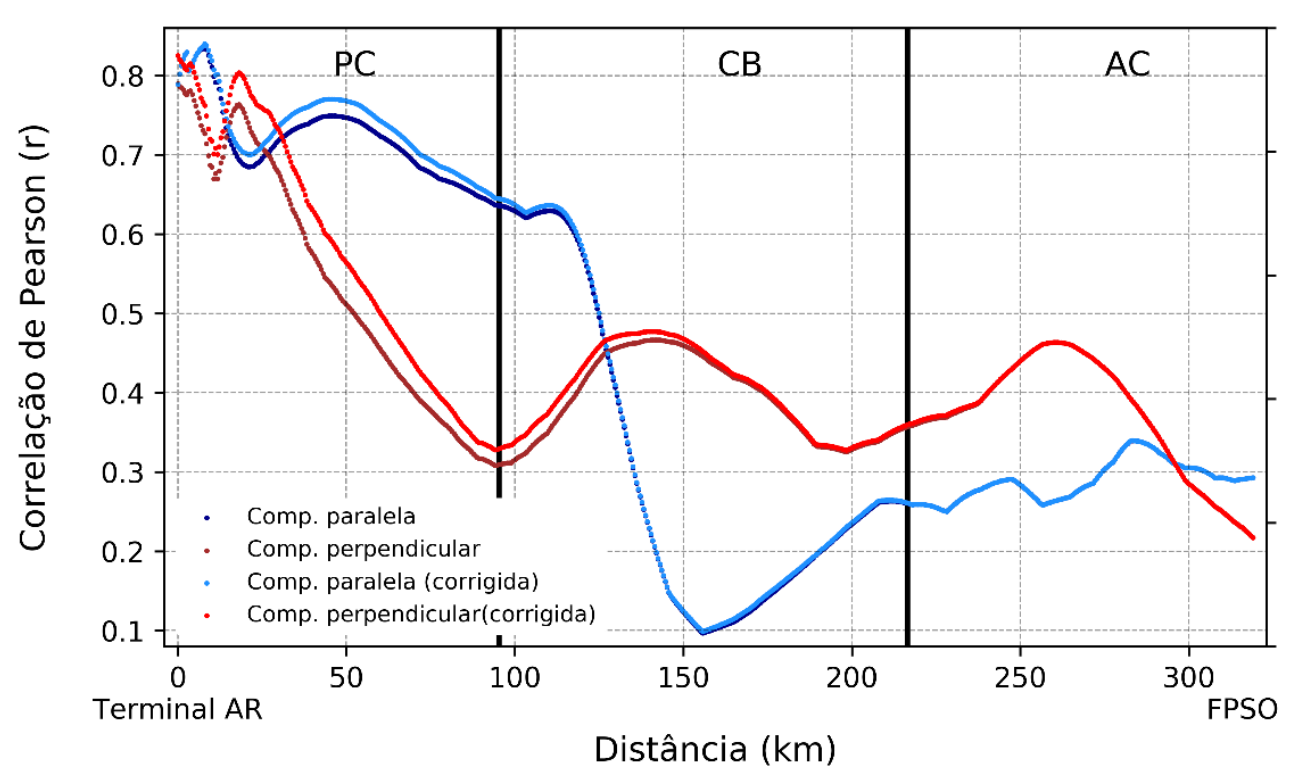

Figura 35 Correlação entre as componentes das correntes e ventos paralelo à costa e perpendiculares à costa. Sendo PC a região da plataforma continental, $C B$ a regição da Corrente do Brasil e AC a regiões do anticiclone.

Como mostra a Figura 35, as correlações estão bem definidas em cada região. Na PC, as correlações corrigidas das componentes paralelas apresentam-se bastante elevada, com valores entre 0,65 e 0,83, ocorrendo um distanciamento dos valores das componentes perpendiculares em torno de $30 \mathrm{~km}$ distante da costa. Este resultado concorda com o trabalho de Dottori e Castro (2009), que encontrou que mais $80 \%$ da variabilidade das correntes na costa é devido a componente barotrópica relacionada ao vento paralelo à costa. A resposta barotrópica ao vento ocorre, tipicamente, em plataformas continentais largas como a Plataforma Continental Sudeste (PCSE). Na CB, após a quebra da PC, em torno de $100 \mathrm{~km}$ da costa, ocorre a diminuição brusca da correlação entre as componentes paralelas do vento e da corrente, chegando ao valor de 0,1 próximo ao centro da $\mathrm{CB}$, e então, um leve aumento até em torno de $210 \mathrm{~km}$. Este resultado corrobora com Silveira (2008), no qual o autor encontrou que a $82 \%$ da variabilidade da CB é explicada pela componente baroclínica da corrente, ou seja, a variabilidade é determinada pelos campos de densidade, e não pelo vento.

Sabe-se então, que a variação da componente do vento paralela à costa está correlacionada com a variabilidade das correntes. No entanto, queremos avaliar o quanto a mudança do sentido dessa componente afeta no tempo de navegação, e o quanto da variação desse tempo é influenciado por ondas e ventos e por correntes. Sendo assim, foi calculada a média dos ventos paralelos à costa para a rota de navegação, e assim foram calculadas a influência de cada fator nos período em que as componentes paralelas são negativas (ventos de 
norte-nordeste) e nos período que as componentes paralelas são positivas (ventos de sul-sud) (Tabela 13).

Tabela 13 - Variação do tempo de navegação conforme o sentido do vento paralelo à costa

\begin{tabular}{llll}
\hline Rota & $\begin{array}{l}\text { Variação do tempo de } \\
\text { navegação }(\%) \text { para a } \\
\text { componente paralela } \\
\text { negativa do vento }\end{array}$ & $\begin{array}{l}\text { Variação do tempo de } \\
\text { navegação }(\%) \text { para a } \\
\text { componente paralela } \\
\text { positiva do vento }\end{array}$ & Fator influente \\
\hline TF & $-0,88$ & 1,57 & Correntes \\
FT & 1,37 & $-1,42$ & Ondas e ventos \\
\hline TF & 1,08 & 1,58 & Ondas, ventos \\
FT & 7,33 & 13,77 & e correntes \\
\hline TF & 0,20 & 3,15 & \\
FT & 8,7 & 12,35 &
\end{tabular}

Rota TF (Terminal de Angra dos Reis - FPSO C. de São Paulo). Rota FT (FPSO C. de São Paulo - Terminal de Angra dos Reis).

O período em que a média das componentes paralelas do vento manteve-se positiva, foi de $28 \%$ do período total, o que corresponde a 20 dias e 17 horas do total de 74 dias. Para a rota $\mathrm{TF}$, neste período, o aumento do tempo de navegação foi de apenas $0,2 \%$, no qual os fatores ondas e ventos corresponderam a 55\% do aumento do tempo de navegação, anulando o efeito das correntes que favoreciam a diminuição do tempo de navegação em 45\%. Já para a rota FT, o aumento do tempo de navegação foi de $8,7 \%$, no qual as correntes colaboraram com apenas $16 \%$ desse valor, sendo o valor restante de $84 \%$ devido as ondas e ventos. Lembrando que o aumento significativo da influência das ondas e ventos nesta rota está relacionado com mudança de condição de carga do navio, de lastreado para totalmente carregado.

No período em que a média das correntes paralelas do vento permaneceram positivas, houve um aumento no tempo de navegação, de $2,9 \%$ na rota $\mathrm{TF}$ e $3,65 \%$ na rota FT. Na rota TF, a influência do vento que colaborava para a diminuição do tempo de navegação em - $0,88 \%$ agora colabora para o aumento no tempo de navegação para 1,57\%, fazendo com que as ondas e ventos e as correntes, influenciem igualmente para o aumento do tempo e navegação, resultando em um aumento de 3,15\%. Já para rota FT, a influência das ondas e ventos, representaram $90 \%$ da variação do tempo de navegação, que sofreu um aumento de $12,35 \%$. 
Assim sendo, a análise dos fatores separados pelos sentidos dos ventos mostrou que, para o navio lastreado, as correntes apresentaram praticamente a mesma influência das ondas, independentemente do sentido da rota. Quando se aplica a média da variação do tempo de navegação, as variações relacionadas com as correntes por variarem positivamente e negativamente se anulam, omitindo então a influência das correntes.

\subsection{Modelo de otimização por janelas}

Para avaliar melhor os efeitos das correntes sob condições mais realísticas, foi elaborado um modelo de otimização por janelas, que se baseia na previsão de ondas, ventos e correntes. selecionando os momentos mais eficientes na redução do tempo de navegação para a partida de um navio. As janelas utilizadas foram de 24, 48 e 72 horas, pois até 72 horas é possível obter dados de vento com precisão através do Centro de Previsão do Tempo e Estudos Climáticos (CPTEC). Com os dados de previsão do vento e dos campos de temperatura e salinidade fornecidos pelo CMEMS, é possível rodar um modelo de previsão utilizando o ECOM. Para a previsão de ondas, os dados também são fornecidos pelo CMEMS. O modelo de otimização calcula uma data de partida com o menor tempo de navegação para cada período de janela. Com esses resultados, foi realizada uma média do tempo de navegação e comparada com o tempo de navegação médio. Os resultados estão apresentados na Tabela 14 (rota TF) e na Tabela 15 (rota FT). 
Tabela 14 - Resultados do modelo de otimização para a rota: Terminal de Angra dos Reis FPSO Cidade de São Paulo (lastreado)

\begin{tabular}{llll}
\hline Janela (horas) & Média (\%) & Média otimizada (\%) & Fator influente \\
\hline 24 & $-1,67$ & \\
48 & $-0,19$ & $-1,52$ & Correntes \\
72 & $-1,87$ & \\
\hline 24 & 1,33 & Ondas e ventos \\
48 & 1,22 & 0,70 & \\
72 & & 0,34 & Ondas, ventos \\
\hline 24 & 1,04 & $-0,33$ & e correntes \\
48 & & $-0,82$ & \\
72 & & $-1,54$ & \\
\hline Para cada período de janela é selecionada a data de partida para o menor tempo de navegação
\end{tabular}

Tabela 15 - Resultados do modelo de otimização para a rota: FPSO Cidade de São Paulo Terminal de Angra dos Reis - (carregado)

\begin{tabular}{llll}
\hline Janela (horas) & Média (\%) & Média otimizada (\%) & Fator influente \\
\hline 24 & 0,58 & Correntes \\
48 & 0,58 & 0,58 & \\
72 & & $-2,12$ & Ondas e ventos \\
\hline 24 & 4,34 & \\
48 & 9,16 & 4,34 & \\
72 & 2,98 & Ondas, ventos \\
\hline 24 & 4,92 & e correntes \\
48 & 9,73 & 4,92 & \\
\hline 72 & & 0,86 & \\
\hline Para cada período de janela é selecionada a data de partida para o menor tempo de navegação
\end{tabular}


Para a rota TF, a diminuição do tempo de navegação foi de $2,4 \%$ em relação ao tempo médio de navegação $(1,04 \%)$, utilizando janelas de 72 horas, desse valor $66 \%$ é responsável pela otimização por correntes. Já para a rota FT, o tempo de viajem foi reduzido em $8,1 \%$ utilizando janelas de 72 horas, no qual a otimização das correntes foi responsável por 30\%, ou seja, 2,4\% do tempo de viajem foi reduzido por correntes. Para as janelas de 24 e 48 horas, a redução do tempo médio de navegação foi de $4,4 \%$, sendo apenas $12 \%$ dessa otimização responsável por correntes.

Contudo, utilizando o modelo de otimização por janelas, as correntes apresentaram um valor pouco significante na redução do tempo de navegação, o vai mais relevante foi na rota FPSO Cidade São Paulo - Terminal de Angra dos Reis, com redução de 2,4\% do tempo de navegação médio. A distância entre o Terminal e o FPSO é de aproximadamente $319 \mathrm{~km}$ e a velocidade de navegação de 13,5 nós, resultando em um tempo de navegação de 12 horas e 45,6 minutos. Então, com a otimização, na rota FT, as correntes representaram uma redução no tempo de navegação de 18,4 minutos, e as ondas e ventos 43,4 minutos, somando no total uma redução de 1 hora e 1,8 minutos.

As velocidades das correntes na Bacia de Santos são mais intensas paralelamente à costa, e como a orientação da rota estudada é quase que perpendicular à costa, os efeitos da deriva não são tão intensos. Estudos sobre a influência das correntes em rotas mais paralelas à costa, principalmente, em rotas em de navegação na região da Corrente do Brasil, supostamente mostrariam resultados mais significativos. 


\section{Conclusão}

A influência da deriva por correntes e da resistência adicionada por ondas e ventos no tempo de navegação de um navio Aframax foi avaliada na rota entre o Terminal de Angra dos Reis- FPSO Cidade de São Paulo. A avaliação foi através de resultados de modelagem numérica (ECOM), em paralelo com o método de Kwon (2008), que estima a redução de velocidade pela adição de resistência por ondas e ventos.

O modelo ECOM mostrou-se preciso na região da Corrente do Brasil (CB), com RMSE de $0,22 \mathrm{~m} / \mathrm{s}$ para as componentes de correntes paralelas à costa e de $0,24 \mathrm{~m} / \mathrm{s}$ para as componentes perpendiculares. Os padrões de circulação na Plataforma Continental corroboraram com trabalhos de diversos autores (Castro, 1996; Prevelato; 2014, Coelho, 2008; Dottori e Castro, 2009), assim como Corrente do Brasil e sua região próxima (Silveira, 2000; Silveira, 2008; Mattos, 2006; Tsuchiya, 1985; Vianna e Menezes, 2005). O método de Kwon (2008) apresentou-se condizente com outros trabalhos (Kim et al., 2017) e preciso nas suas estimativas (Lu et al.,2015). Os dados de ondas (CMEMS) utilizados no método de Kwon (2008) mostraram-se bastante precisos, com valores de RMSE de 0,28 m para a altura de onda média. Desse modo, os valores estimados do tempo de navegação estão alegadamente precisos.

Foi observado que ventos paralelos à costa são bastante influentes na variação do tempo de navegação, devido à alta correlação com as correntes paralelas à costa na região da PC. Assim, em eventos como passagens de frentes frias, que ocasionam a inversão dos ventos paralelos à costa de norte-nordeste para ventos de sul-sudoeste, ocorre uma ampla mudança na influência da deriva por correntes no tempo de navegação. Em um período de ventos intensos de norte-nordeste (na ordem de $10 \mathrm{~m} / \mathrm{s}$ ), foi analisado um aumento máximo de 7,9\% do tempo de navegação devido à deriva por correntes, com velocidade de navegação de 13,5 nós. Para um período com ventos intensos de sul-sudoeste (na ordem de $15 \mathrm{~m} / \mathrm{s}$ ), foi analisado uma redução máxima de $9,03 \%$ do tempo de navegação.

Com o navio lastreado, a média do tempo de navegação na rota Terminal de Angra dos Reis - FPSO Cidade de São Paulo (TF), teve um aumento de apenas 1,04\%, no qual, as correntes tiveram participação de 13,50\% dessa média, e as ondas e ventos, os restantes 86,50\%. No entanto, na navegação na rota oposta (FT), com o navio carregado, ocorreu um aumento de $9,73 \%$ na média do tempo de navegação, deste valor, apenas $6 \%$ foi responsável pela deriva por correntes e $94 \%$ devido à redução da velocidade por ondas e ventos. A condição de carga do navio Aframax mostrou-se bem influente na redução de velocidade do navio, para um mar 
6, a redução foi entre $0,3-2 \%$ na condição de lastreamento conforme a direção de incidência de ondas e ventos, e entre 5-15\% para a condição do navio totalmente carregado.

A análise do tempo médio de navegação separado pelos sentidos opostos da componente paralela dos ventos (positiva/negativa), mostrou-se que, para o navio lastreado, a influência das correntes é bem equivalente a influência das ondas.

Utilizando um modelo de otimização de janelas com base na escolha da melhor condição de navegação, com saídas de navio a cada 72 horas, foi possível reduzir o tempo de navegação em 2,55\% (66\% por influência das correntes) na rota TF e em 8,11\% (30\% por influência das correntes) na rota FT. Esse resultado pode ser convertido diretamente para redução de emissão de gases e diminuição no consumo de combustíveis fosseis, dado que a potência do motor é considerada constante nas simulações realizadas A redução de $8,11 \%$ foi maior do que encontrado nos trabalhos de McCord (1995) que otimizou em 7,5\% a navegação na Corrente do Golfo e Change (2013) que estimou uma redução de 4,5\% na Corrente de Kuroshio.

De maneira geral, a influência das correntes mostrou-se pouco significante na navegação na rota Terminal de Angra dos Reis - FPSO Cidade de São Paulo. Possivelmente devido a orientação da rota estudada ser quase que perpendicular à costa, o que minimiza os efeitos das correntes paralelas à costa que são mais intensas. Procedendo então deste trabalho, o entusiasmo na aplicação dos métodos utilizados, em outras rotas de navegação no Pré-sal que sejam mais paralelas à costa. 


\section{Bibliografia}

AGÊNCIA NACIONAL DO PETRÓLEO (ANP). Disponível em: www.anp.gov.br, acesso em 17 de outubro de 2018.

ANDRIONI, M. et al. Ocean Eddies' Influence on Lula Field, Santos Basin, Brazil. In: Anais...ASME International, 24 ago. 2013.

BELO, Wellington Ceccopieri. A Recirculação Interna do Giro Subtropical do Atlântico Sul e a Circulação Oceânica na Região do Pólo Pré-sal da Bacia de Santos. 2011. Tese (Doutorado em Oceanografia Física) - Instituto Oceanográfico, Université de São Paulo, São Paulo, 2011. doi:10.11606/T.21.2011.tde-20042012-152310. Acesso em: 2019-05-26.

BELO, Wellington Ceccopieri. ; SILVEIRA, I. C. A. . A variabilidade vertical do oceano na Bacia de Santos. Boletim de Geociências da Petrobras (Online) , v. 21, p. 39-62, 2013

BIROCCHI, Paula. Estudo do impacto de efluentes dos emissários submarinos nas áreas adjacentes ao canal de São Sebastião, SP. 2018. Dissertação (Mestrado em Oceanografia Física) - Instituto Oceanográfico, Universidade de São Paulo, São Paulo, 2018. doi:10.11606/D.21.2019.tde-09012019-103948. Acesso em: 2019-05-26.

BLUMBERG, ALAN E MELLOR, GEORGE. (1987). A description of a three-dimensional coastal ocean circulation model, three-dimensional coastal ocean models. Coastal Estuarine Sci.. 4. 10.1029/CO004p0001.

CAMPOS, E. J. D. 1995. Estudos da circulação oceânica no Atlântico tropical e região oeste do Atlântico Subtropical Sul. Tese de livre docência.Universidade de São Paulo, Instituto Oceanográfico. 114p.

CASTRO, B.M., 1996. Correntes e massa de água da plataforma continental norte de São Paulo. Tese livre docência, Instituto Oceanográfico, Universidade de São Paulo, São Paulo. 246p.

CASTRO, B. M.; MIRANDA, L. B.; Physical Oceanography of the western Atlanticcontinental shelf located between $4^{\circ} \mathrm{N}$ and $34^{\circ} \mathrm{S}-$ Coastal segment(4,W). In: ROBINSON, A. R.; BRINK, K. H. The Sea. New York: Jonh Wiley e Sons, Inc., v. 11, 1998, p. 209-251.

CASTRO., B.M.; PEREIRA, A. F. ; CAROLI, A. ; FOLONI NETO, H. ; PASCHOAL, G. C. A. ; SILVEIRA, I. C. A. ; AMOR, C. C. . Correntes e Massas de Água na Plataforma Continental. In: Falcão, A.P.C.; Curbelo-Fernandez, M.P.. (Org.). Série Habitats. 1ed.Rio de Janeiro: Elsevier, 2015, v. 2, p. 189-252.

CASTRO, B. M., PEREIRA, A. F., DOTTORI, M., PASCHOAL, G. C. A., CAROLI, A.D., SILVEIRA, I.C.A. e AMOR, C. C. (2014), 'Correntes e massas de água na plataforma continental da bacia de santos', submetido. 
CENTRO DE HIDROGRAFIA DA MARINHA. PNBOIA -Programa Nacional de Boias. 2013. Disponível em: <http://www.mar.mil.br/dhn/chm/box-goos/pnboia.html>. Acesso em: 03 jun. 2015.

CHANG, Y.-C. et al. Ship Routing Utilizing Strong Ocean Currents. Journal of Navigation, v. 66, n. 6, p. 825-835, 2013.

COELHO, Alexandre Luiz. Resposta da Plataforma Continental Sudeste a ventos sazonais e sinóticos de verão: estudos numéricos. 2008. Tese (Doutorado em Oceanografia Física) - Instituto Oceanográfico, Universidade de São Paulo, São Paulo, 2008. doi:10.11606/T.21.2008.tde-24062008-162856. Acesso em: 2019-05-26.

CLARKE AJ, BRINK K (1985) The response of stratified, frictional flow of shelf and slope waters to fluctuating large-scale, low-frequency wind forcing. J Phys Oceanogr 15:439-454.

DA ROCHA FRAGOSO, M. et al. A 4D-variational ocean data assimilation application for Santos Basin, Brazil. Ocean Dynamics, v. 66, n. 3, p. 419-434, 2016.

DA SILVEIRA, I. C. A. et al. Is the meander growth in the Brazil Current system off Southeast Brazil due to baroclinic instability? Dynamics of Atmospheres and Oceans, [s. 1.], v. 45, n. 3-4, p. 187-207, 2008.

DEFANT A. 1941. Die absolute Topographie des physikalischen Meeres-niveaus un der Druckfl ächen, sowie die Wasserbewegungen im Raum desAtlantischen Ozean.

Wissenschaftliche Ergebnisse Deutschen Atlantis-chen Expedition auf dem Forschungs und Vermessungsschiff. "Meteor”1925-1927, 6(2): 191-260.

DERECZYNSKI et al. (2015). METEOROLOGIA DA BACIA DE CAMPOS. 1-54. 10.1016/B978-85-352-6208-7.50008-8.

DOTTORI, M.; CASTRO, B. M. The response of the São Paulo Continental Shelf, Brazil, to synoptic winds. ocean Dyn., v. 59, n. 4, p. 603-614, 2009.

Diz, G., Scavarda, L. F., Rocha, R., e Hamacher, S. (2014). Decision Support System for PETROBRAS Ship Scheduling. Interfaces, 44(6), 555-566. doi:10.1287/inte.2013.0723

DUCHON, C.E.. (1979). Lanczos Filtering in One and Two Dimensions. Journal of Applied Meteorology - J APPL METEOROL. 18. 1016-1022. 10.1175/15200450(1979)018<1016:LFIOAT >2.0.CO;2.

FROST, R. (1966). The Relation between Beaufort Force Wind Speed and Wave Height, Meteorological Office, Scientific Paper No. 25. 12pp. London: HMSO.

GORDON, ARNOLD e GREENGROVE, C. (1986). Geostrophic circulation of the BrazilFalkland Confluence. Deep Sea Research Part A. Oceanographic Research Papers. 33. 573 585. 10.1016/0198-0149(86)90054-3.

GREGORIO, Helvio Prevelato. Oscilações Subinerciais na Plataforma Continental Sudeste: Estudos Numéricos. 2014. Tese (Doutorado em Oceanografia Física) - Instituto 
Oceanográfico, Universidade de São Paulo, São Paulo, 2014. doi:10.11606/T.21.2014.tde11032015-141317. Acesso em: 2019-05-26.

IMO, 2012. Interim Guidelines for the Calculation of the Coefficient $f_{w}$ for Decrease in Ship Speed in a Representative Sea Condition for Trial Use. International Maritime Organisation (IMO), London.

IMO (2018) INITIAL IMO STRATEGY ON REDUCTION OF GHG EMISSIONS FROM SHIPS. IMO doc. MEPC 72/15/11

ITTC, 2014. The Seakeeping Committee. Technical Report, Copenhagen, Denmank.

KIM, M., HIZIR, O., TURAN, O., DAY, S., e INCECIK, A. (2017) Estimation of added resistance and ship speed loss in a seaway. Ocean Engineering.

10.1016/j.oceaneng.2017.06.051.

KWON YJ, 1981. The effect of weather, particularly short sea waves, on ship speed performance. PhD thesis, University of Newcastle upon Tyne.

KWON, Y.J.. (2008). Speed loss due to added resistance in wind and waves. Naval Architect. 14-16.

LIU et al., 1979: Bulk Parameterizations of Air-Sea Exchanges of Heat and Water Vapor.

LO, H. K. e MCCORD, M. R. (1995). Adaptive ship routing through stochastic ocean currents: Generalformulations and empirical results, Transportation Res., A.,32, 547-561.

LU, R. et al. A semi-empirical ship operational performance prediction model for voyage optimization towards energy efficient shipping. Ocean Engineering, 2015.

MANEEWONGVATANA et al. (1999). Analysis of Approximate Nearest Neighbor Searching with Clustered Point Sets. 59.

MASON, E. et al. Copernicus (CMEMS) operational model intercomparison in the western Mediterranean Sea: Insights from an eddy tracker. Ocean Science Discussions, n. January, p. $1-32,2019$.

MASCARENHAS Jr, A. S. da; MIRANDA, L. B. de \& ROCK, N. J. 1971. A study of the oceanographic conditions in the region of Cabo Frio. In: Costlow Jr, J. D., ed. - Fertility of the sea. New York, Gordon \& Breach, v. 1, p. 285-308.

MOREIRA, J. L. P.; MADEIRA, C. V.; GIL, J. A.; MACHADO, M. A. P. (2007). Bacia de Santos. Boletim de Geociências da Petrobras, v. 15, n. 2, p. 531-549.

PEGORELLI, C.; DOTTORI, M.; FORTES, J. F. Evaluating the gravity wave energy potential off the Brazilian coast. Brazilian Journal of Oceanography, v. 66, n. 2, p. 220 233, 2018. 
PEREIRA, A. F. et al. Numerical simulation of M2 internal tides in the South Brazil Bight and their interaction with the Brazil Current. Journal of Geophysical Research: Oceans, v. 112, n. 4, 2007.

PRPIĆ-ORŠIĆ, J.; FALTINSEN, O. M. Estimation of ship speed loss and associated CO2emissions in a seaway. Ocean Engineering, 2012.

REZENDE, J. H. M. (2003), 'Intrusões da água central do atlântico sul na plataforma continental sudeste durante o verão. Tese de doutorado. Instituto Oceanográfico da Universidade de São Paulo.

SAHA, S., et al. 2012. NCEP Climate Forecast System Version 2 (CFSv2) Monthly Products. Research Data Archive at the National Center for Atmospheric Research, Computational and Information Systems Laboratory. https://doi.org/10.5065/D69021ZF. Acesso em: 2018-10-05.

SIGNORINI, S. (1978). On the circulation and the volume transport of the Brazil Current between the Cape of São Tomé and Guanabara Bay. Deep Sea Research. 25. 481-490. 10.1016/0146-6291(78)90556-8.

SOARES, S. B. C. (Org.). STRAUD 2002: tutoriais de acesso as bases de dados on-line, referências e outros recursos informacionais. São Paulo: UNESP, Coordenadoria Geral de Bibliotecas, 2002. 1 CD-ROM.

SÖDING, HEINRICH E SHIGUNOV, VLADIMIR. (2015). Added resistance of ships in waves. Ship Technology Research. 62. 2-13. 10.1179/0937725515Z.0000000001.

SOUZA, M. C. de ARRUDA. A Corrente do Brasil ao largo de Santos: medições diretas. 2000. MSc. Dissertation (Mestrado em Oceanografia Física) - Instituto Oceanográfico, Universidade de São Paulo, São Paulo, 2000. Available through <doi:10.11606/D.21.2000.tde-10092003-094250> [Accessed 10-14-2016, in Portuguese].

STECH, J. L e LORENZZETTI, J. A. (1992), 'The response of the south brazil bight to the passage of winter time cold fronts', Journal Geophysical Research 97, 9507-9520.

TRANSPETRO. Atividades. Terminais e Oleodutos - Terminais Aquaviários. 2019. Disponível em: <http://www.transpetro.com.br>. Acesso em Março de 2019

SILVEIRA, Ilson Carlos Almeida da et al. A corrente do Brasil ao largo da costa leste brasileira. Rev. Bras. Oceanogr. [online]. 2000, vol.48, n.2, pp.171-183. ISSN 14137739. http://dx.doi.org/10.1590/S1413-77392000000200008.

VLADIMIR S.(2017) Added power in seaway, Ship Technology Research, 64:2, 65-75, DOI: 10.1080/09377255.2017.1331953

WEATHERLY, G. L. 1993. On deep-current and hydrographic observations from a mudwave region and elsewhere in the Argentine basin. Deep-Sea Res. II, 40(4/5):939-961.

Dottori, M., e Castro, B. M. (2009). The response of the Sao Paulo Continental Shelf, Brazil, to synoptic winds. Ocean Dynamics, 59(4), 603-614. doi:10.1007/s10236-009-0209-2 
WEITZ, J. Cataloging electronic resources: OCLC-MARC coding guidelines. Dublin, c2007. Disponível em: <http://www.oclc.org/support/documentation/worldcat/cataloging/ lectronicresources/default.htm >. Acesso em: 12 dez. 2007.

ZEMBRUSKI, S. G. 1979. Geomorfologia da Margem Continental Sul Brasileira e das Bacias Oceânicas Adjacentes. In: CHAVES, H. A. F. (ed).Geomorfologia da Margem Continental Sul Brasileira e das Áreas Oceânicas Adjacentes. Rio de Janeiro: PetrobrasCENPES-DINTEP ,Série Projeto REMAC,n. 7, 1979. p. 129-177. 